\title{
Multiple pathologies in dementia : correlations with clinical diagnoses
}

Citation for published version (APA):

Echávarri Zalba, C. (2012). Multiple pathologies in dementia : correlations with clinical diagnoses.

[Doctoral Thesis, Maastricht University]. Datawyse / Universitaire Pers Maastricht.

https://doi.org/10.26481/dis.20121018ce

Document status and date:

Published: 01/01/2012

DOI:

10.26481/dis.20121018ce

Document Version:

Publisher's PDF, also known as Version of record

\section{Please check the document version of this publication:}

- A submitted manuscript is the version of the article upon submission and before peer-review. There can be important differences between the submitted version and the official published version of record.

People interested in the research are advised to contact the author for the final version of the publication, or visit the DOI to the publisher's website.

- The final author version and the galley proof are versions of the publication after peer review.

- The final published version features the final layout of the paper including the volume, issue and page numbers.

Link to publication

\footnotetext{
General rights rights.

- You may freely distribute the URL identifying the publication in the public portal. please follow below link for the End User Agreement:

www.umlib.nl/taverne-license

Take down policy

If you believe that this document breaches copyright please contact us at:

repository@maastrichtuniversity.nl

providing details and we will investigate your claim.
}

Copyright and moral rights for the publications made accessible in the public portal are retained by the authors and/or other copyright owners and it is a condition of accessing publications that users recognise and abide by the legal requirements associated with these

- Users may download and print one copy of any publication from the public portal for the purpose of private study or research.

- You may not further distribute the material or use it for any profit-making activity or commercial gain

If the publication is distributed under the terms of Article $25 \mathrm{fa}$ of the Dutch Copyright Act, indicated by the "Taverne" license above, 


\section{MULTIPLE PATHOLOGIES IN DEMENTIA: CORRELATIONS WITH CLINICAL DIAGNOSES}


ISBN/EAN 9789075579611

Copyright C. Echávarri Zalba, Maastricht 2012

Cover illustration: Squares with concentric circles, by Wassily Kandinsky 


\title{
MULTIPLE PATHOLOGIES IN DEMENTIA: CORRELATIONS WITH CLINICAL DIAGNOSES
}

\author{
ACADEMIC DISSERTATION \\ to obtain the Degree of Doctor at Maastricht University, \\ on the authority of the Rector Magnificus, \\ Prof. Dr. L.L.G. Soete \\ in accordance with the decision of the Board of Deans, \\ to be defended in public on \\ Thursday 18 October 2012 at $16.00 \mathrm{~h}$
}

by

Carmen Echávarri Zalba

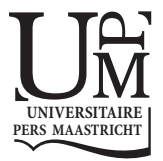




\section{Promotor}

$1^{\text {st }}$ Promotor Prof. F.R.J. Verhey

$2^{\text {nd }}$ Promotor Prof. H. B.M. Uylings, Free University Amsterdam

co-promotor Dr. S. Burgmans

\section{Assessment committee}

Prof. Dr. H. Steinbusch, chairman

Prof. Dr. R.J. van Oostenbrugge

Prof. Dr. J.M. Rozemuller, VU, University Medical Center, Amsterdam

Dr. B. Rutten.

Prof. Dr. T. Tuñón Alvarez, Hospital de Navarra, Pamplona, Spain 


\section{Contents}

Chapter 1

General introduction

Chapter 2

Co-occurrence of different pathologies in dementia: implications for dementia diagnosis

Journal of Alzheimer's Diseas e(2012) 30(4): 909-917

Chapter 3

Correlation between Braak stage and comorbidity in Alzheimer's disease

Submitted

\section{Chapter 4}

Vascular risk factors in neuropathologically confirmed Alzheimer's disease and vascular dementia [and mixed dementia]

Submitted

\section{Chapter 5}

Neuropsychiatric symptoms in Alzheimer's disease and vascular dementia Journal of Alzheimer's Disease (2013) 33 (3)

\section{Chapter 6}

Atrophy in the parahippocampal gyrus as an early biomarker of

Alzheimer's disease

Brain Struct Funct (2011) 215:265-271

\section{Chapter 7}

Concluding remarks

Summary

Acknowledgements

Curriculum vitae

Publications 

CHAPTER 1

General introduction 


\section{Clinical characteristics of dementia}

Dementia is a clinical syndrome characterized by an acquired and persistent impairment in multiple cognitive domains that is severe enough to interfere with everyday functioning (DSM IV) (American Psychiatric Association, 1994). In most patients, it is chronic, progressive, and irreversible. Subtypes of dementia, like Alzheimer's disease ( $A D)$, vascular dementia $(\mathrm{VaD})$, frontotemporal lobar dementia (FTLD), Lewy bodies dementia (LBD) and Creutzfeldt-Jakob disease (CJD), can be defined by progressive cognitive impairment and clinical signs, as well as by their typical pattern of neuropathological changes. Standardized clinical and neuropathological criteria for different subtypes of dementia have been proposed in consensus meetings.

The following are the clinical features of the most common types of dementia:

- $\quad A D$ is a progressive disorder characterized by an impairment of recent memory and of at least one other cognitive domain, such as language, visuospatial function or executive function.

- The clinical characteristics of LBD are dementia associated with any two of the following three core features: fluctuating cognition or level of consciousness, visual hallucinations, and spontaneous parkinsonian motor signs.

- Three different subtypes of FTLD have been described: one behavioural variant of frontotemporal dementia and two language variants, semantic dementia and progressive non-fluent aphasia. These three subtypes overlap clinically with motoneuron disease (FTD-MND), corticobasal degeneration (CBD) and progressive supranuclear palsy (PSP) (Neary et al., 1998; Seelaar et al., 2011). CBD is characterized by rigidity with focal cortical signs, such as apraxia and aphasia, and often by frontal-type dementia. PSP is an atypical parkinsonian disorder associated with progressive axial rigidity, vertical gaze palsy, dysarthria, dysphagia, and often dementia.

- CJD is typically associated with a rapidly progressive course over a period of months from symptom onset to death. CJD patients show global cognitive deterioration, significant psychiatric symptoms and prominent motor symptoms, including signs of pyramidal, cerebellar, and extrapyramidal involvement.

- Vascular dementia (VaD) is the second most frequent cause of dementia after $A D$. These patients most often have a dysexecutive syndrome characterized by reduced mental processing speed, decreased working memory, and impairment of abstract reasoning (Chui et al., 2007).

Although in vivo criteria for types of dementia are based on clinical features, data on abnormal biomarkers, when available, are important to support the early diagnosis. The known biomarkers are based on findings of structural neuroimaging studies with magnetic resonance imaging (MRI) and molecular neuroimaging with positron emission tomography (PET), as well as cerebrospinal fluid analysis of proteins such as amyloid beta or tau proteins (Dubois et al., 2007). 


\section{Neuropathological characteristics of dementia}

The definitive diagnosis of dementia types relies on neuropathological examination of the brain. Dementia syndromes, and neurodegenerative conditions in general, are defined as disorders with progressive loss of neurons showing a distinct anatomical distribution characteristic of the different dementia types. Research has identified a spectrum of proteins that are immunohistochemically detectable in the central nervous system and can serve as a basis for protein-based disease classification. This is the reason why certain dementia types are also described as protein misfolding or conformational diseases.

Types of dementia (or neurodegenerative disorders that may cause dementia), are characterized by the accumulation of certain proteins (Chui et al., 2007; Kovacs et al., 2010).

In $A D$, one of the two key proteins is beta amyloid, which is found in amyloidpositive deposits distributed both diffusely and as dense-core plaques. The other important protein is phosphorylated tau ( $p$-tau), which accumulates within neurons in the form of neurofibrillary tangles (Braak \& Braak, 1991). These two proteins are believed to interact and contribute to cognitive impairment (Desikan et al., 2012).

Phosphorylated tau is also the main protein that accumulates in some forms of FTLD, in CBD and PSP, being found in round tau-positive cytoplasmic inclusions in the behavioural variant of FTLD, in astrocytic plaques in CBD and in tufted astrocytes in PSP. In some forms of FTLD, however, tau negative and TDP 43-positive inclusions are present (Mackenzie et al., 2010). The key protein in LBD is alphasynuclein, which is found in neuronal inclusions, while in CJD, it is the prionic protein $(\operatorname{PrP})$, the disease being characterized by fine and coarse granules, as well as plaques, that stain positive for this protein.

VaD may result from various forms of cerebrovascular injury, including poststroke syndromes (O'Brien et al., 2003). The challenge of identifying the pathological substrates for $\mathrm{VaD}$ is complicated by the heterogeneous nature of cerebrovascular disease and the coexistence of other pathologies, including Alzheimer-type lesions. It has been suggested that subcortical ischemic vascular dementia (SIVD), which is associated with small-vessel disease, lacunar infarcts, and deep white matter changes, is the most important subtype of vascular cognitive impairment (Roman et al., 2002; Kalaria et al., 2004).

\section{Overlap between dementia subtypes}

Thorough analysis of the morphological and biochemical markers of proteins (such as tau, beta amyloid, synuclein and TDP 43) enables classification of the vast majority of cases of dementia. On the other hand, there can be considerable overlap in the patterns of accumulation of different proteins, and this often leads to a diagno- 
sis of co-occurrence of different subtypes of dementia (Kovacs \& Budka, 2010; Kovacs et al., 2010). This raises the question as to whether the mere detection of a particular aggregated protein means that it is really the substrate for the dementia. Several studies comparing clinical and neuropathological diagnoses (Brunnstrom \& Englund, 2009; Jellinger, 2009) have found a relatively low mean rate of agreement for the purely clinical diagnoses, which is mainly attributable to the high degree of comorbidity in neuropathological disorders (Jellinger, 2006; Kovacs et al., 2008;

Richards \& Brayne, 2009; Brunnstrom \& Englund, 2009). Diagnosing dementia types is difficult for clinicians and researchers alike, especially in later stages of the disease, when comorbidity is more likely to occur (Richards \& Brayne, 2009). This implies that the neuropathological diagnosis of "comorbidity of particular types of dementia" may in some cases be a suitable diagnosis in itself. Since medical treatment for patients with dementia is only indicated when the clinical diagnosis is clearly established, cases of comorbidity might be problematic. Besides, the prevalence of cases showing comorbidity is not clear, nor is it clear whether there is a particular clinical cognitive pattern that can be attributed to comorbidity, and what this clinical pattern could be. The present thesis proposes a new way of approaching dementia diagnosis, from a multidimensional point of view.

\section{Aim and outline of the thesis}

This thesis considers dementia as a multifactorial disease and examines the correlations between clinical, neuropathological and neuroimaging changes in demented patients. The main aim of the research underlying this thesis was to correlate clinical and neuropathological findings in dementia. The specific research questions were therefore related to (1) correlations between clinical and neuropathological diagnoses and (2) clinical features of the dementia syndrome.

The questions relating to (1) included "Are dementia types different diseases or should a dementia syndrome be understood as part of a spectrum of diseases?" and "What is the relationship between current clinical and neuropathological diagnoses in dementia?"

The questions relating to (2) included "Are there any clinical features common to all types of dementia or can different profiles be defined?" and "Are there differences in dementia types regarding the presence of vascular risk factors or associated symptoms such as neuropsychiatric symptoms?"

The research was based on three different databases. The first was that of the Maastricht Aging Study (MAAS), carried out at Maastricht University in the Netherlands (Jolles et al., 1995), while the second and third were composed of data from the Netherlands Brain Bank (NBB) (Amsterdam) and the Brain Bank of Navarre (Pamplona, Spain). The present thesis brings together five studies that made use of these three data sources. 
In order to answer the first question, we investigated the rate of agreement between clinical and neuropathological diagnoses of dementia, as is reported in Chapter 2. Chapter 3 focuses on the relationship between the most prevalent pathological changes co-occurring in the same brain, namely Alzheimer disease (AD)-related, Lewy body (LB)-related and vascular pathology.

The second main question, "Are there any clinical features common to all types of dementia or can different profiles be defined?", was addressed by studying cases with confirmed neuropathological diagnoses, as is discussed in Chapters 4 and 5 . In Chapter 4, the role of vascular risk factors in dementia is explored by assessing the prevalence of a range of risk factors in cases of dementia with neuropathologically confirmed $A D$, vascular dementia $(V a D)$, or mixed $A D$ plus vascular pathology. Chapter 5 then reports on an investigation of the prevalence of neuropsychiatric symptoms (NPSs) associated with dementia in cases with neuropathologically confirmed $A D$ and $V a D$.

Results concerning the MRI markers of early stage AD are presented in Chapter 6. Previous neuropathological studies have reported the parahippocampal gyrus to be the first structure to be affected in $A D$, but neuroimaging studies have been focusing on hippocampal volume as a biomarker for the early stages of AD. We assessed the role of changes in the parahippocampal gyrus as a neuroimaging biomarker for early stage $A D$, by measuring the volume of this structure in healthy volunteers as well as in patients with amnestic mild cognitive impairment (aMCl) and mild $A D$. The power of the parahippocampal gyrus volume to discriminate healthy participants from individuals with mild AD was compared with results using hippocampal volume.

The overall conclusions of this thesis are presented in the chapter entitled "Conclusions". 


\section{References}

American Psychiatric Association W, DC (4th ed. 1994) Diagnostic and Statistical

Manual of Mental Disorders.

Braak H and Braak H (1991) Neuropathological stageing of Alzheimer-related changes. Acta Neuropathol. 82(4):239-59

Brunnstrom H, Englund E (2009) Clinicopathological concordance in dementia diagnostics. Am J Geriatr Psychiatry 17:664-670

Chui HC (2007) Subcortical ischemic vascular dementia. Neurol Clin 25:717-740

Desikan RS, McEvoy LK, Thompson WK, Holland D, Brewer JB, Aisen PS, Sperling RA, Dale AM (2012) Amyloid- $\beta$-associated clinical decline occurs only in the presence of elevated p-tau. Arch Neurol April 23.

Dubois B, Feldman HH, Jacova C, Dekosky ST, Barberger-Gateau P, Cummings J, Delacourte A, Galasko D, Gauthier S, Jicha G, Meguro K, O'Brien J, Pasquier F, Robert P, Rossor M, Salloway S, Stern Y, Visser PJ, Scheltens P (2007) Research criteria for the diagnosis of Alzheimer's disease: revising the NINCDS-ADRDA criteria. Lancet Neurol 6:734-746

Jellinger KA (2006) Clinicopathological analysis of dementia disorders in the elderly-an update. J Alzheimers Dis 9:61-70

Jellinger KA (2009) Criteria for the neuropathological diagnosis of dementing disorders: routes out of the swamp? Acta Neuropathol 117:101-110

Jolles J, Houx PJ, Van Boxtel MPJ, Ponds RWHM (1995) Maastricht Aging Study: determinants of cognitive aging. Neuropsych Publishers, Maastricht

Kalaria RN, Kenny RA, Ballard CG, Perry R, Ince P, Polvikoski T (2004) Towards defining the neuropathological substrates of vascular dementia. J Neurol Sci 226:75-80

Kovacs GG, Alafuzoff I, Al-Sarraj S, Arzberger T, Bogdanovic N, Capellari S, Ferrer I, Gelpi E, Kovari V, Kretzschmar H, Nagy Z, Parchi P, Seilhean D, Soininen H, Troakes C, Budka H (2008) Mixed brain pathologies in dementia: the BrainNet Europe consortium experience. Dement Geriatr Cogn Disord 26:343-350

Kovacs GG, Botond G, Budka H (2010) Protein coding of neurodegenerative dementias: the neuropathological basis of biomarker diagnostics. Acta Neuropathol 119:389-408

Kovacs GG, Budka H (2010) Current concepts of neuropathological diagnostics in practice: neurodegenerative diseases. Clin Neuropathol 29:271-288

Mackenzie IR, Neumann M, Bigio EH, Cairns NJ, Alafuzoff I, Kril J, Kovacs GG, Ghetti B, Halliday G, Holm IE, Ince PG, Kamphorst W, Revesz T, Rozemuller AJ, Kumar-Singh S, Akiyama H, Baborie A, Spina S, Dickson DW, Trojanowski JQ, Mann DM (2010) Nomenclature and nosology for neuropathologic subtypes of frontotemporal lobar degeneration: an update. Acta Neuropathol 119:1-4

Neary D, Snowden JS, Gustafson L, Passant U, Stuss D, Black S, Freedman M, Kertesz A, Robert PH, Albert M, Boone K, Miller BL, Cummings J, Benson DF (1998) Frontotemporal lobar degeneration: a consensus on clinical diagnostic criteria. Neurology 51:1546-1554

O'Brien JT, Erkinjuntti T, Reisberg B, Roman G, Sawada T, Pantoni L, Bowler JV, Ballard C, DeCarli C, Gorelick PB, Rockwood K, Burns A, Gauthier S, DeKosky ST (2003) Vascular cognitive impairment. Lancet Neurol 2:89-98

Richards M, Brayne C (2009) What do we mean by Alzheimer's disease?. BMJ 341:865-867

Roman GC, Erkinjuntti T, Wallin A, Pantoni L, Chui HC (2002) Subcortical ischaemic vascular dementia. Lancet Neurol 1:426-436

Seelaar H, Rohrer JD, Pijnenburg YA, Fox NC, van Swieten JC (2011) Clinical, genetic and pathological heterogeneity of frontotemporal dementia: a review. J Neurol Neurosurg Psychiatry 82:476-486 



\section{CHAPTER 2 \\ Co-occurrence of different pathologies in dementia: implications for dementia diagnosis}

Carmen Echávarri, Saartje Burgmans, Maria Cristina Caballero, Federico GarcíaBragado, Frans R.J. Verhey and Harry B.M. Uylings. Co-occurrence of different pathologies in dementia: implications for dementia diagnosis. Journal of Alzheimer's Disease (2012) 30 (4): 909-917. 
The standard for differentiating between dementia subtypes is currently based on neuropathological changes, and follows traditional nosological classifications. However, the high incidence of comorbid neuropathologies complicates the differentiation between dementia diagnoses in the clinic. The aim of this study was to investigate the grades of agreement between clinical and neuropathological diagnoses in neurodegenerative disorders, to compare them with rates found in previous studies, and to propose implications for dementia diagnostics. 200 patients who donated their brains to the Brain Bank of Navarre (Pamplona, Spain). All patients had been diagnosed with a neurodegenerative disorder during life (clinical diagnosis) and post-mortem (neuropathological diagnosis). We studied a sample of patients with a short average time interval between the last clinical assessment and death (4.6 months). Overall, there was a mean grade of agreement of $44.0 \%$ between the clinical diagnosis and the pure neuropathological diagnosis (i.e. without co-morbid neuropathological disorders). This grade of agreement differed between dementia subtypes: e.g. $85 \%$ for prion disease, $49 \%$ for Alzheimer's disease, and $0 \%$ for Lewy body dementia. Our data confirm that co-occurrence of multiple neuropathological disorders is very common in individuals with dementia, and that the underlying neuropathology often differs from the neuropathology implied by the clinical diagnosis. These findings support a multidimensional approach to diagnosing dementia, in which dementia syndromes are not categorized into diagnostic subtypes, but are seen as syndromes characterized by a combination of various neuropathological dimensions. 


\section{Introduction}

Dementia is a syndrome resulting from neuropathological changes in the brain (Kovacs et al., 2012; Uylings et al., 2002), and dementia subtypes are currently classified according to the pattern of these changes. Whereas the pathological diagnoses of neurodegenerative disorders usually follow traditional nosological classifications, previous research suggests that the clinicopathological correlation is weak. Several studies have compared clinical and neuropathological diagnoses (Brunnstrom et al., 2009; Galasko et al., 1994; Gay et al., 2008; Jellinger, 2009; Lim et al., 1999; Massoud et al., 1999; Nelson et al., 2012; Sabbagh et al., 2009; Victoroff et al., 1995) showing a relatively low mean rate of agreement for the pure diagnoses (see Figure 1). This is mainly due to the high degree of comorbidity of neuropathological disorders (Brunnstrom \& Englund, 2009; Gay et al., 2008; Victoroff et al., 1995; Jellinger, 2006). Hence, the traditional nosological classification approach as the gold standard for differentiating between dementia subtypes has been called into question (Richards \&, Brayne, 2009).

Further investigation is necessary for several reasons. First, most previous studies focused mainly on Alzheimer's disease (AD) and vascular dementia (VaD) (Galasko et al., 1994; Gay et al., 2008; Massoud et al., 1999), and failed to take other, less frequent neurodegenerative disorders into account. Second, previous studies reported contradictory results regarding the agreement between clinical and neuropathological diagnoses (Kovacs et al., 2008). Third, the time interval between the clinical and neuropathological diagnoses in reported investigations tended to be rather long. For instance, Brunnstrom et al. (2009) reported that $35 \%$ of the patients had not visited a physician within the last 2 years before death (Brunnstrom \& Englund, 2009). This likely affects the concordance between the clinical and neuropathological diagnoses, since neuropathological findings may change in the course of the illness.

The main aim of the present study was to investigate the rates of agreement between clinical and neuropathological diagnoses in neurodegenerative disorders, to compare them with previous studies, and to propose implications for dementia diagnostics. We investigated a more extensive spectrum of neurodegenerative disorders, and included 200 patients with a short average interval between the clinical and neuropathological diagnoses (an average of 4.6 months). 


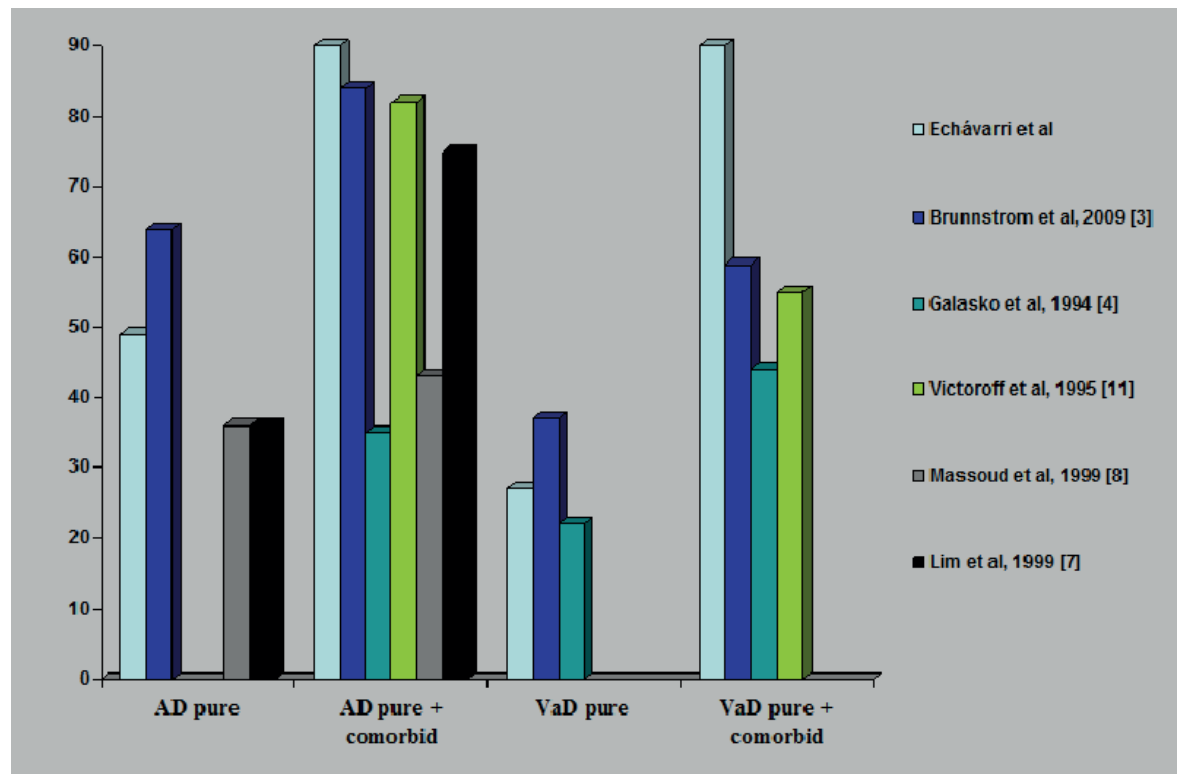

Figure 1.

Note. Rates of agreement (\%) between neuropathological and clinical diagnoses of AD and VaD in different studies. The diagnoses on the $x$-axes represent the neuropathological diagnoses.

\section{Materials and Methods}

\section{Sample}

The study included all the 231 participants who donated their brains to the Brain Bank of Navarre (Pamplona, Spain) between 2004 and 2011. 31 control participants, defined as subjects without clinical symptoms and without neuropathological relevant findings, were excluded from the study. Finally, the sample consisted of 200 patients. All of them had been diagnosed with a neurodegenerative disorder during life (clinical diagnosis) as well as post-mortem (neuropathological diagnosis). The criteria used for the clinical diagnoses were derived from the literature, as follows: Alzheimer's disease (AD) (McKhann et al., 1984), Lewy body dementia (LBD) (McKeith et al., 1996), Mixed Dementia (MD; i.e. Mixed AD and VaD) (Roman et al., 1993), frontotemporal lobar degeneration (FTLD) (Neary et al., 1998), progressive supranuclear palsy (PSP) (Litvan et al., 1996), corticobasal degeneration (CBD) (Boeve et al., 2003), motor neuron disease (MND) (Cairns et al., 2007), prion disease (Budka et al., 1995), Parkinson's disease (PD) (Samii et al., 2004), vascular dementia (VaD) (Roman et al., 1993), Huntington disease (HD) (Vonsattel et al., 1985) and multisystem atrophy (MSA) (Gilman et al., 2008). The criteria used for neuropathological diagnoses were derived from the literature as follows: AD (Braak \& Braak, 1991), LBD (McKeith et al., 1996), MD (Zekry et al., 2003), FTLD (Cairns et 
al., 2007), PSP (Dickson et al., 2007), CBD (Dickson et al., 2002), MND (Cairns et al., 2007), prion disease (Budka et al., 1995), PD (Braak et al., 2003), VaD (Kalaria et al., 2004), HD (Vonsattel et al., 1985), MSA (Trojanowski et al., 2007) and AGD (Saito et al., 2004).

All clinical diagnoses were established by a multidisciplinary team of neurologist and geriatricians at the Navarre Hospitals Complex, who were blinded to the neuropathological data; diagnoses were based on medical history, medical examination of the patient, course of symptoms, and computerized tomography (CT) and/or magnetic resonance imaging (MRI) scans. A neurologist/geriatrician was present at the first clinical interview with the patient, in order to establish the diagnoses, and at most of the follow-up visits. Neuropsychological assessment was additionally performed in a majority of the patients, but not in all. If the dementia diagnosis had been changed during the time the patient was followed, the most recent diagnosis was used for the present clinicopathological comparison. Clinical information was obtained through detailed interviews with the relatives, except for cases in which the clinical diagnoses had been changed; in these cases the patient was re-examined. The interviews were performed during routine visits or when patients were admitted to the hospital for any reason. Only 3 patients couldn't be examined in a follow-up visit. For these 3 patients clinical diagnosis was made then exclusively by interviews with their informants. In our total sample of 200 patients, the average time interval between the last clinical assessment and death was 4.6 (SD 5.7) months. 96\% of our patients had their last clinical assessment within 1 year before death, and only 1 patient had a time interval of over 2 years.

Neuropathological diagnoses were established by one neuropathologist of the Brain Bank of Navarre. A neuropathological diagnosis of mixed dementia (MD) was established when vascular components and Alzheimer-related pathology were both considered to be severe enough to contribute to the dementia symptoms. For vascular pathology, we used the criteria described by Kalaria et al. (2004) (Kalaria et al., 2004): (a) a large infarct or several infarcts (> $50 \mathrm{ml}$ tissue loss) or (b) multiple microinfarcts (more than 3 with a minimum diameter of $5 \mathrm{~mm}$ ) or small vessel disease (hyalinization, amyloid angiopathy, lacunar infarcts, and/or perivascular changes). According to the Kalaria et al. criteria, cases of MD include Alzheimer related pathology at a Braak stage above III (Kalaria et al., 2004).

All patients in the PD group had cognitive impairment, defined as cognitive dysfunction involving memory and/or other domains, but not dementia, which means without evident functional impairment. Demographic data for the patients, by neuropathological diagnosis, are presented in Table 1 . Written informed consent was obtained from all patients or their relatives. The study was approved by the local Medical Ethics Committee of the Tissue Brain Bank of Navarre and Navarre Hospitals Complex (Navarre Health Service). 
Table 1. Demographic data by neuropathological diagnosis

\begin{tabular}{|c|c|c|c|c|c|c|}
\hline & & Age (years) & $\begin{array}{l}\text { Duration of } \\
\text { illness (years) }\end{array}$ & $\begin{array}{l}\text { Last assessment- } \\
\text { death (months) }\end{array}$ & $\begin{array}{l}\text { Weight } \\
\text { (grams) }\end{array}$ & Sex \\
\hline & $\mathrm{n}$ & Mean (range) & Mean (range) & Mean (range) & Mean (range) & $\%$ women \\
\hline All & 200 & $78.7(15-100)$ & $6.9(1-29)$ & $4.6(1-64)$ & $1080.2(575-1800)$ & 55 \\
\hline$A D$ & 52 & $82.1(56-97)$ & $6.5(1-14)$ & $2.4(1-15)$ & $1060.3(850-1800)$ & 69 \\
\hline LBD & 1 & 84.0 & 21.0 & 24.0 & 1150.0 & 0 \\
\hline MD & 31 & $83.4(50-100)$ & $5.9(1-19)$ & $4.5(1-24)$ & $1116.2(725-1400)$ & 52 \\
\hline FTLD & 4 & $69.5(64-73)$ & $10.5(3-15)$ & $4.3(1-37)$ & 882.5 (750-980) & 50 \\
\hline PSP & 11 & $77.5(63-92)$ & $5.5(3-10)$ & $1.1(1-4)$ & $1111.8(800-1400)$ & 54 \\
\hline CBD & 4 & $71.2(56-85)$ & $6.2(5-7)$ & $16.7(1-64)$ & $991.2(840-1200)$ & 25 \\
\hline MND & 5 & $57.5(49-73)$ & $2.7(2-3)$ & $2.6(1-6)$ & $1290.0(950-1500)$ & 60 \\
\hline Prion disease & 12 & $64.0(43-84)$ & $3.5(1-5)$ & $1.4(1-5)$ & $1177.6(850-1700)$ & 27 \\
\hline PD & 2 & 78.5 (78-79) & $12(4-20)$ & $3(1-5)$ & $1212.5(1150-1275)$ & 50 \\
\hline $\mathrm{VaD}$ & 4 & $72.2(51-84)$ & $9.7(4-26)$ & $3.4(1-9)$ & $967.0(918-1100)$ & 50 \\
\hline HD & 4 & $61.7(36-76)$ & $23.0(6-29)$ & $2.6(1-6)$ & $1026.2(700-1255)$ & 25 \\
\hline MSA & 1 & 70.0 & 6.0 & 2.0 & 925.0 & 100 \\
\hline AGD & 4 & $80.7(71-85)$ & $5.0(1-14)$ & $3(1-5)$ & $1199.2(1125-1328)$ & 50 \\
\hline Comorbid diagnoses & $s 56$ & $83.2(65-97)$ & $7.8(1-20)$ & $5.9(1-23)$ & $1053.6(650-1350)$ & 59 \\
\hline Other diagnoses & 9 & $59.3(15-82)$ & $6.5(1-19)$ & $1.5(1-4)$ & $1129.3(575-1390)$ & 44 \\
\hline
\end{tabular}

Note. AD Alzheimer's disease, LBD Lewy body dementia, MD mixed dementia, FTLD frontotemporal lobar degeneration, PSP progressive supranuclear palsy, CBD corticobasal degeneration, MND motor neuron disease, PD Parkinson's disease, VaD vascular dementia, HD Huntington disease, MSA multisystem atrophy, AGD argyrophilic grain disease. Comorbid diagnoses include brains showing more than one neuropathological diagnosis, Other diagnoses include 5 cases with a tumor, 1 case with multiple sclerosis (MS), 1 case with both a brain tumor and MS, 1 case with hereditary spastic paraplegia (suspected diagnosis of FTLD) and 1 case with ceroidolipofuscinosis. Duration of illness = years from onset of symptoms to death; Weight $=$ weight of the whole brain (grams)Histopathological procedure

The histopathological procedures were carried out according to standard practice at the Tissue Brain Bank of Navarre. The left cerebral hemisphere was frozen and the right hemisphere was paraffin-embedded for microscopic examination. Before freezing, all findings of the macroscopic inspection of both hemispheres were carefully recorded (atrophy, vascular lesions, etc.). If any suspected pathology was found in the left hemisphere, the left hemisphere was also paraffin-embedded for microscopic examination. Following fixation in formaldehyde (10\%) for approximately three weeks, the brain was sectioned. The procedure for fixing and sectioning was that recommended by BrainNet Europe. The macroscopic examination of the brains included photographing, weighing, $\mathrm{pH}$ measurement, taking cerebrospinal fluid samples (where possible) and macroscopic description. Twenty-four paraffin blocks were prepared, and at least one slice from each paraffin block was stained with hematoxylin and eosin (H\&E). The immunohistochemical stains used 
for each protein are described in Table 2. The antibody dilutions were: tau (Mouse monoclonal antibody, Novocastra, NCL-Tau-2, clone Tau 2)1:100, $\beta$ amyloid (Mouse monoclonal antibodybody, Novocastra, NCL-B- amyloid, clone 6F-3D 1:200, TDP-43 (Abnova Corporation mouse monoclonal antibody) 1:1500, PrP (Mouse monoclonal antibody, Dako Cytomation, clone 3F4) 1:100, $\alpha$-synuclein (Liquid mouse monoclonal antibody, Novocastra, NCL-L-ASIN, clone KN51) 1:50, ubiquitin (Lyophlized monoclonal antibody, Novocastra, NCL-UBICm, clone FPM1) 1:700, and $\alpha-\beta$ crystallin (Mouse monoclonal antibody, Novocastra, clone ABCrys-512) 1:100.

Table 2. Immunostains used for the neuropathological diagnoses

\begin{tabular}{|c|c|c|c|c|c|c|c|}
\hline REGIONS & $\begin{array}{c}\alpha \\
\text { synuclein }\end{array}$ & ß-Amyloid & Tau & TDP-43 & Ubiquitin & $\begin{array}{c}\alpha-\beta \\
\text { crystalline }\end{array}$ & PrP \\
\hline Cingulate gyrus & $x$ & $x$ & & & & & \\
\hline Motor gyrus & & $x$ & $x$ & & & & \\
\hline Insular cortex & & & $x$ & & & & \\
\hline Frontal gyrus & $x$ & $x$ & $x$ & $x$ & $x$ & $x$ & \\
\hline Anterior thalamus & & $\mathrm{x}$ & $x$ & & & & \\
\hline \multicolumn{8}{|l|}{ Medial thalamus } \\
\hline \multicolumn{8}{|l|}{ Posterior thalamus } \\
\hline Putamen & & & $x$ & & & & \\
\hline Globus pallidus & & & $x$ & & & & \\
\hline Hippocampus & $x$ & $x$ & $x$ & $x$ & $\mathrm{x}$ & & \\
\hline Frontal cortex & $x$ & $x$ & $x$ & $x$ & $\mathrm{x}$ & $\mathrm{x}$ & \\
\hline Temporal cortex & $x$ & $x$ & $x$ & $x$ & $x$ & & \\
\hline Parietal cortex & $x$ & $x$ & $x$ & & & & $x$ \\
\hline Occipital cortex & & $x$ & $x$ & & & & \\
\hline \multicolumn{8}{|l|}{ Frontal white matter } \\
\hline Substantia nigra & $x$ & $x$ & $x$ & & & & \\
\hline Pons & $x$ & $\mathrm{x}$ & $x$ & & & & \\
\hline Medulla oblongata & $x$ & $x$ & $x$ & & & & \\
\hline Amygdala & $x$ & $\mathrm{x}$ & $x$ & & & $\mathrm{x}$ & \\
\hline Caudate-accumbens & & $\mathrm{x}$ & $x$ & $x$ & $x$ & & \\
\hline Olfactory bulb & $x$ & $x$ & $x$ & $x$ & $x$ & & \\
\hline Nucleus basalis of Meynert & $x$ & & $x$ & & & & \\
\hline Cerebellum (vermis) & & $\mathrm{x}$ & & & & & $x$ \\
\hline Cerebellum (dentate nucleus & & & & & & & \\
\hline
\end{tabular}




\section{Statistical analysis}

The rate of agreement between clinical and neuropathological diagnoses was calculated by dividing the number of cases with agreement between the clinical and neuropathological by the total number of clinically diagnosed cases. With Epi Info Statcal program, version 6 (November 1993), we compared these rates of agreement between the diagnostic groups using an exact Fisher test. We performed this comparison only for the most frequent clinical diagnoses ( $A D, L B D, M D, F T L D$, PSP, and Prion disease), since the $n$ of the other diagnoses was not large enough for a reliable statistical comparison.

\section{Results}

\section{Prevalences of clinical and neuropathological diagnoses}

Table 3 shows the frequencies of the clinical diagnoses. The most frequent clinical diagnosis was $A D$, with 80 cases (40\%), followed by MD with 20 cases (10\%) and FTLD with 18 cases ( $9 \%)$. Table 1 shows the frequencies of the neuropathological diagnoses. The most frequent neuropathological diagnosis was $A D$ with 52 cases (26\%), followed by MD with 31 cases (16\%), prion disease with 12 cases (6\%), PSP with 11 cases ( $6 \%$ ) and FTLD with 4 cases ( $2 \%$ ). Comparing Table 1 and 3, it is notable, that the number of cases neuropathologically diagnosed as MD appears to be higher than the number of cases clinically diagnosed as MD. This is in contrast to the other dementias. In addition, fifty-six patients ( $28 \%$ ) had more than one neuropathological diagnosis (see the supplementary table for a detailed overview of the co-occurrence of all neuropathologies). Nine patients had 'other diagnoses', including 5 with a tumor, 1 with multiple sclerosis (MS), 1 with both a brain tumor and MS, 1 with hereditary spastic paraplegia (suspected diagnosis of FTLD) and 1 with ceroidolipofuscinosis.

Dividing the sample into two groups according to age, we found differences between the moderately old (younger than 80 years) and very old ( 80 years or older) patients. Of the 86 patients younger than 80 years, 20 (23\%) had comorbidity, compared to 36 (32\%) of the 114 patients older than 80 (difference nonsignificant).

\section{Agreement between clinical and neuropathological diagnoses}

Table 3 and Figure 2 present the agreement between clinical and neuropathological diagnoses. With respect to the concordance between the clinical diagnosis and the pure neuropathological diagnosis, we found an overall agreement rate of $44 \%$ (Table 3). The agreement was largest in patients with the clinical diagnoses prion disease (85\%), MND (83.3\%) and MD (80\%). The agreement was substantially lower in patients with the clinical diagnoses LBD (0 \%), FTLD (22\%), PD (22\%), VaD (27 $\%)$, and $A D(49 \%)$. When we consider the concordance of the clinical diagnosis with 
both the pure and comorbid neuropathological diagnosis (i.e. two or more neuropathological diagnoses were established, and one of these neuropathological diagnoses is in agreement with the clinical diagnosis), we found an overall agreement rate of $66 \%$. The agreement was substantially larger particularly in patients with the clinical diagnosis MD (100\%), MND (100\%), AD (90\%) and LBD (54\%), see Table 3. In contrast, the agreement in FTLD and PD was still low (28\% and $33 \%$ respectively). Misdiagnoses (i.e. the neuropathological diagnosis is not in agreement with the clinical diagnosis) were most frequent in FTLD (72\%), PD (67\%), and LBD (46 $\%)$.

The exact Fisher tests show that AD diagnoses had a significantly higher rate of agreement compared to LBD and FTLD; MD diagnoses showed a significantly higher rate of agreement compared to LBD and FTLD; and FTLD showed a significantly higher rate of agreement compared to PSP and prion disease (see table 3).

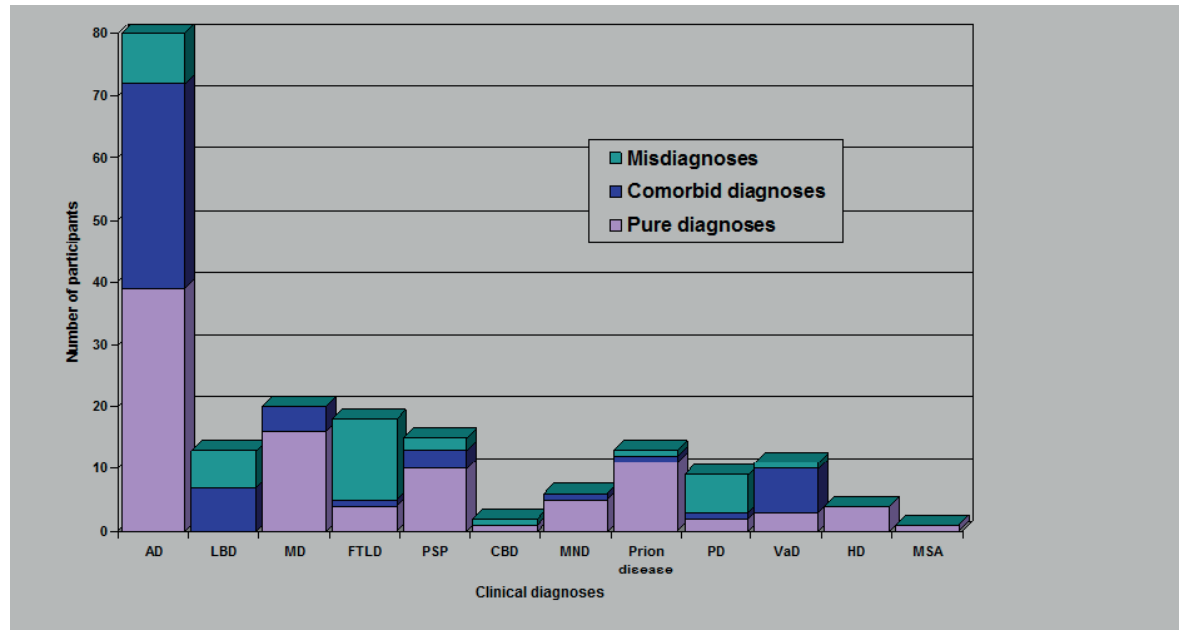

Figure 2. Neuropathological diagnosis for each clinical diagnosis.

Note. AD Alzheimer's disease, LBD Lewy body dementia, MD mixed dementia, FTLD frontotemporal lobar degeneration, PSP progressive supranuclear palsy, CBD corticobasal degeneration, MND motor neuron disease, PD Parkinson's disease, VaD vascular dementia, HD Huntington disease, MSA multisystem atrophy, AGD argyrophilic grain disease; misdiagnosis = the neuropathological diagnosis was not in agreement with the clinical diagnosis; comorbid diagnosis = two or more neuropathological diagnoses were established, and one of these neuropathological diagnoses was in agreement with the clinical diagnosis; pure diagnosis = the neuropathological diagnosis was in complete agreement with the clinical diagnosis. 
Table 3. Agreement between clinical and neuropathological diagnoses.

\begin{tabular}{|c|c|c|c|c|}
\hline \multirow[t]{2}{*}{ Clinical diagnosis } & & \multirow{2}{*}{$\begin{array}{l}\text { Agreement with } \\
\text { pure diagnosis } \\
\mathrm{n}(\%)\end{array}$} & \multirow{2}{*}{$\begin{array}{l}\text { Agreement with } \\
\text { pure and co-morbid } \\
\text { diagnosis }\end{array}$} & \multirow{2}{*}{$\begin{array}{l}\text { Misdiagnosis } \\
\mathrm{n}(\%)\end{array}$} \\
\hline & $\mathrm{N}$ & & & \\
\hline All & 200 & $88(44.0)$ & $132(66.0)$ & $26(13.0)$ \\
\hline$A D$ & 80 & $39\left(48.7^{\mathrm{a}}\right)$ & $72\left(90.0^{1}\right)$ & $8(10.0)$ \\
\hline LBD & 13 & $0(0.0)$ & $7(53.8)$ & $6(46.2)$ \\
\hline $\mathrm{MD}$ & 20 & $16\left(80.0^{b}\right)$ & $20\left(100.0^{2}\right)$ & $0(0.0)$ \\
\hline FTLD & 18 & $4\left(22.2^{c}\right)$ & $5\left(27.7^{3}\right)$ & $13(72.3)$ \\
\hline PSP & 15 & $10\left(66.6^{d}\right)$ & $13(86.6)$ & $2(13.4)$ \\
\hline CBD & 2 & $1(50.0)$ & $1(50.0)$ & $1(50.0)$ \\
\hline MND & 6 & $5(83.3)$ & $6(100.0)$ & $0(0.0)$ \\
\hline Prion disease * & 13 & $11\left(84.6^{e}\right)$ & $12(92.3)$ & $1(7.7)$ \\
\hline PD & 9 & $2(22.2)$ & $3(33.3)$ & $6(66.7)$ \\
\hline $\mathrm{VaD}$ & 11 & $3(27.2)$ & $10(90.9)$ & $1(9.1)$ \\
\hline $\mathrm{HD}$ & 4 & $4(100.0)$ & $4(100.0)$ & $0(0.0)$ \\
\hline MSA & 1 & $1(100.0)$ & $1(100.0)$ & $0(0.0)$ \\
\hline Other ** & 8 & $8(100.0)$ & $8(100.0)$ & $0(0.0)$ \\
\hline
\end{tabular}

Note. For abbreviations see the legend to Table 1. Pure: the neuropathological diagnosis was in complete agreement with the clinical diagnosis; co-morbid = two or more neuropathological diagnoses were established, and one of these neuropathological diagnoses was in agreement with the clinical diagnosis; misdiagnosis = the neuropathological diagnosis was not in agreement with the clinical diagnosis. * Of the 13 cases with a clinical diagnosis of prion disease, 9 had Creutzfeldt-Jakob disease and 4 FFI. ** Including 5 cases with a tumor, 1 with multiple sclerosis (MS), 1 with both a brain tumor and MS and 1 with ceroidolipofuscinosis.

${ }^{1} A D$ diagnoses had a significantly higher rate of agreement compared to LBD and FTLD $(p=0.003$ and 0.000 respectively); ${ }^{2} \mathrm{MD}$ diagnoses showed a significantly higher rate of agreement compared to LBD and FTLD ( $p=0.001$ and 0.000 respectively); ${ }^{3}$ FTLD showed a significantly lower rate of agreement compared to PSP and prion disease ( $p=0.002$ and 0.001 respectively)

${ }^{a} A D$ diagnoses had a significantly higher rate of agreement compared to LBD and FTLD ( $p=0.000$ and 0.000 respectively); ${ }^{b} \mathrm{MD}$ diagnoses showed a significantly higher rate of agreement compared to LBD and FTLD ( $p=0.000$ and 0.000 respectively); ${ }^{c}$ FTLD showed a significantly lower rate of agreement compared to PSP and prion disease ( $p=0.001$ and 0.000 respectively); ${ }^{d}$ PSP showed a significantly higher rate of agreement compared to LBD $(p=0.001) ;{ }^{e}$ Prion disease showed a significantly higher rate of agreement compared to LBD $(p=0.000)$. 
Supplementary table. Most frequent clinical diagnoses (rows) and neuropathological diagnoses (columns).

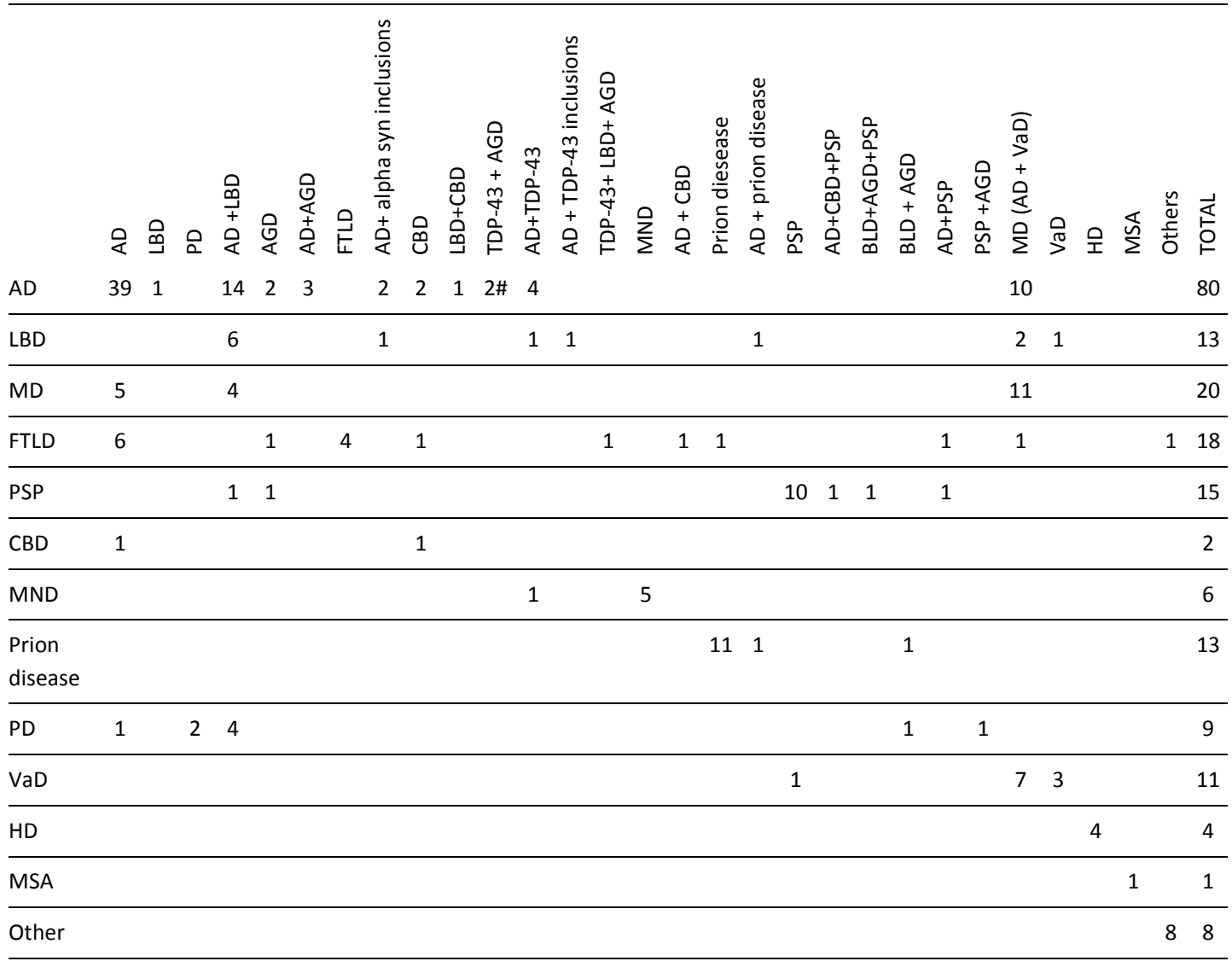

$\begin{array}{llllllllllllllllllllllllllllll}52 & 1 & 2 & 29 & 4 & 3 & 4 & 3 & 4 & 1 & 2 & 6 & 1 & 1 & 5 & 1 & 12 & 2 & 11 & 1 & 1 & 2 & 2 & 1 & 31 & 4 & 4 & 1 & 9 & 200\end{array}$

Note. \# 1 of these 2 patients showed motor neuron involvement. AD Alzheimer's disease, LBD Lewy body dementia, MD mixed dementia, FTLD frontotemporal lobar degeneration, PSP progressive supranuclear palsy, CBD corticobasal degeneration, MND motor neuron disease, PD Parkinson's disease, VaD vascular dementia, HD Huntington disease, MSA multisystem atrophy, AGD argyrophilic grain disease.

\section{Discussion}

Our results confirm that the agreement between clinical and neuropathological diagnoses in neurodegenerative disorders is far from optimal. The majority of the clinical diagnoses did not fully correspond with the neuropathological diagnoses. This was mainly due to the fact that co-occurrence of neuropathological disorders was very common, i.e., a large number of patients had multiple neuropathological diagnoses at the post-mortem examination. A possible explanation for the high frequency of co-morbid depositions in dementia is that certain protein deposits 
may influence the formation of other deposits (Kovacs et al., 2012). For instance, there is evidence that tau and $\alpha$ synuclein can promote each other's fibrillization (Clinton et al., 2010). This is in line with our finding that LB (Lewy body)-related pathology frequently co-occurred with AD pathology, and vice versa (see Table 3).

Compared to previous studies (Kovacs et al., 2012; Brunnstrom \& Englund, 2009; Galasko et al., 1994; Jellinger, 2006; Echávarri et al., 2011), our agreement rates are relatively high. This may be due to the fact that our sample had a relatively short average time interval between the last clinical assessment and death. This relatively high concordance compared to other studies is particularly evident with respect to $A D$ and $\operatorname{VaD}$ (See Figure 1). When we included both the pure and comorbid neuropathological diagnoses in our analysis, our sample had the highest agreement rates for $A D$ as well as for $\mathrm{VaD}$, comparing to other studies. When we included only the pure diagnosis, our sample had the second highest agreement rates for $A D$ and $\operatorname{VaD}$ (Fig.1). Our results also show that the co-occurrence of neuropathologies is likely to increase with advanced age, as the incidence of comorbidity was higher in the patients above the age of 80 . This is in line with other results for communitydwelling older persons and autopsy series (Galasko et al., 1994; Gay et al., 2008; Gilman et al., 2008; Echávarri et al., 2011). Note that the mean age of our sample was similar to those in the studies that we used to compare our concordance rates with.

In our sample, the agreement between clinical and neuropathological diagnoses differed substantially between different neurodegenerative disorders. Patients with a clinical diagnosis of LBD, FTLD, PD, VaD and MD had low agreement rates, while patients with prion disease, HD, MSA or MND had high agreement rates. These data are largely in agreement with previous reports, particularly regarding LBD and VaD (Brunnstrom \& Englund, 2009; Gay et al., 2008; Massoud et al., 1999), supporting the view that both diseases rarely appear as pure pathologies but are very likely to be found in association with other pathologies. Another notable finding is the high prevalence of prion disease. Navarre is a region bordering on the Basque Country, where the rate of prion disease is the highest in Europe (Zarranz et al., 2006). The 4 cases diagnosed in our series with fatal familial insomnia (FFI) were members of the same family. They showed a mutation of the prionic protein gene D178N (Trojanowski et al., 2007), which has been shown to be more frequent in Spain (specifically in Basque Country and Navarre) than in other countries in Europe (Iriarte et al., 2007).

The current results indicate that diagnosing patients with the traditional nosological classification approach is rather artificial, since the underlying neuropathology often differs from the neuropathology implied by the dementia subtype. This underlines the necessity of a multidimensional approach as advocated by Richard and Brayne (Richard \& Brayne, 2009); that is, dementia, especially in older patients, should not be categorized into isolated subtypes, but should be seen as a diffuse clinical syndrome representing the gradual accumulation of multiple pathologies. 
Therefore, a diagnosis of dementia should not be specified by a dementia subtype, but should reflect a spectrum of neuropathological dimensions such as the formation of beta amyloid, phosphorylation of tau, vascular changes and other pathologies. For instance, if a patient is diagnosed with $A D$ in vivo, the likelihood of finding AD-related pathology plus a comorbid pathology - such as Lewy bodies and vascular pathology - in the neuropathological assessment is higher than the likelihood of only finding pure AD.

We think that a multidimensional approach will not only increase the accuracy of dementia diagnoses, but will also lead to a better understanding of neurodegenerative diseases by clinicians, since it stresses that these diseases have a multifactorial nature. An important question is what effect a multidimensional approach has on the diagnosis of dementia. Instead of being diagnosed with a specific dementia subtype, a patient will then receive a less specific diagnosis of 'dementia', including a spectrum of symptoms. This diagnosis is closer to the truth and will probably lead to fewer misdiagnoses. It also takes into account the uncertainties that exist with respect to the role of biomarkers in dementia subtypes. Although many biomarkers, such as white matter lesions and amyloid depositions, are nowadays seen as indicators of specific dementia subtypes, the specificity of these pathological changes is still unclear. Note that we do not want to induce an attitude in clinicians of being oversimplistic by making a generic dementia diagnosis. Instead, we want to encourage clinicians to recognize different neuropathological features and the specific contribution of each of them to the dementing process. We wish they take into account the large spectrum of neuropathological findings and the complexity of neurodegenerative disorders

A few methodological issues need to be mentioned. First, previous studies often used FTLD as an umbrella term to represent a spectrum of pathological entities, including PSP and CBD. In our study we considered FTLD, PSP, and CBD as separate entities, based on the clinical syndromes previously described (Neary et al.,1998; Sha et al., 2006). If we had included CBD and PSP in the FTLD group, the clinicopathological agreement for FTLD would have been higher. Second, the patients in our sample were studied retrospectively and were diagnosed in vivo. Cases of $A D$, $\mathrm{LBD}$, and $\mathrm{VaD}$ met criteria for both possible and probable dementia. It is possible that the use of criteria for probable diagnosis, excluding possible diagnosis according to NINCDS-ADRDA criteria (McKhann et al., 1984), would have resulted in a better concordance. Third, the high prevalence of FTLD and prion disease demonstrates that our sample is not entirely representative of the European population. This is mainly caused by the fact that patients with more exotic neuropathologies are more likely to become Brain Bank donors, and by the high prevalence of prion disease in the region of Navarre and Basque Country (Jicha et al., 2008, Schneider et al., 2009). 
To conclude, we believe that these data support the notion that a multidimensional approach to diagnosing dementia would increase the accuracy of clinical diagnoses as well as understanding the complexity of neurodegenerative diseases. In addition, these data underline the importance of neuropathological confirmation of dementia diagnoses in studies about dementia subtypes. 


\section{References}

Boeve BF, Lang AE, Litvan I (2003) Corticobasal degeneration and its relationship to progressive supranuclear palsy and frontotemporal dementia. Ann Neurol 54 Suppl 5, S15-9.

Braak H, Braak E (1991) Neuropathological stageing of Alzheimer-related changes. Acta Neuropathol 82(4), 239-59.

Braak H, Del Tredici K, Rub U, de Vos RA, Jansen Steur EN, Braak E (2003) Staging of brain pathology related to sporadic Parkinson's disease. Neurobiol Aging 24(2), 197-211.

Brunnstrom H, Englund E (2009) Clinicopathological concordance in dementia diagnostics. Am J Geriatr Psychiatry 17(8), 664-70.

Budka H, Aguzzi A, Brown P, Brucher JM, Bugiani O, Gullotta F, Haltia M, Hauw JJ, Ironside JW, Jellinger K, et al (1995) Neuropathological diagnostic criteria for Creutzfeldt-Jakob disease (CJD) and other human spongiform encephalopathies (prion diseases). Brain Pathol 5(4), 459-66.

Cairns NJ, Bigio EH, Mackenzie IR, Neumann M, Lee VM, Hatanpaa KJ, White CL, 3rd, Schneider JA, Grinberg LT, Halliday G, Duyckaerts C, Lowe JS, Holm IE, Tolnay M, Okamoto K, Yokoo H, Murayama S, Woulfe J, Munoz DG, Dickson DW, Ince PG, Trojanowski JQ, Mann DM (2007) Neuropathologic diagnostic and nosologic criteria for frontotemporal lobar degeneration: consensus of the Consortium for Frontotemporal Lobar Degeneration. Acta Neuropathol 114(1), 5-22.

Clinton LK, Blurton-Jones M, Myczek K, Trojanowski JQ, LaFerla FM (2010) Synergistic Interactions between Abeta, tau, and alpha-synuclein: acceleration of neuropathology and cognitive decline. J Neurosci 30 (21), 7281-9.

Dickson DW, Bergeron C, Chin SS, Duyckaerts C, Horoupian D, Ikeda K, Jellinger K, Lantos PL, Lippa CF, Mirra SS, Tabaton M, Vonsattel JP, Wakabayashi K, Litvan I (2002) Office of Rare Diseases neuropathologic criteria for corticobasal degeneration. J Neuropathol Exp Neurol 61(11), 935-46.

Dickson DW, Rademakers R, Hutton ML (2007) Progressive supranuclear palsy: pathology and genetics. Brain Pathol 17(1), 74-82.

Echávarri C, Caballero MC, Aramendía A, García-Bragado F, Tuñón T (2011) Multi-protein deposits in neurodegenerative disorders. Our experience in the Tissue Brain Bank of Navarra. The Anatomical Record 294, 1191-7.

Galasko D, Hansen LA, Katzman R, Wiederholt W, Masliah E, Terry R, Hill LR, Lessin P, Thal LJ (1994) Clinical-neuropathological correlations in Alzheimer's disease and related dementias. Arch Neurol 51(9), 888-95.

Gay BE, Taylor KI, Hohl U, Tolnay M, Staehelin HB (2008) The validity of clinical diagnoses of dementia in a group of consecutively autopsied memory clinic patients. J Nutr Health Aging 12(2), 132-7.

Gilman S, Wenning GK, Low PA, Brooks DJ, Mathias CJ, Trojanowski JQ, Wood NW, Colosimo C, Durr A, Fowler CJ, Kaufmann H, Klockgether T, Lees A, Poewe W, Quinn N, Revesz T, Robertson D, Sandroni $P$, Seppi K, Vidailhet M (2008) Second consensus statement on the diagnosis of multiple system atrophy. Neurology 71(9), 670-6.

Iriarte J, Ayuso T, Echavarri C, Alegre M, Urrestarazu E, Lacruz F, Gállego J, Artieda J (2007) Agrypnia excitata in fatal familial insomnia. A video-polygraphic study. Neurology Aug 7; 69(6):607-8.

Jellinger KA (2006) Clinicopathological analysis of dementia disorders in the elderly- an update. J Alzheimers Dis 9(3 Suppl), 61-70.

Jellinger KA (2009) Criteria for the neuropathological diagnosis of dementing disorders: routes out of the swamp? Acta Neuropathol 117(2), 101-10.

Jicha GA, Abner E, Schmitt FA, Cooper GE, Stiles N, Hamon R, Carr S, Smith CD, Markesbery WR (2008) Clinical features of mild cognitive impairment differ in the research and tertiary clinic settings. Dement Geriatr Cogn Disord 26(2), 187-92.

Kalaria RN, Kenny RA, Ballard CG, Perry R, Ince P, Polvikoski T (2004) Towards defining the neuropathological substrates of vascular dementia. J Neurol Sci 226(1-2), 75-80. 
Kovacs GG, Botond G, Budka H (2010) Protein coding of neurodegenerative dementias: the neuropathological basis of biomarker diagnostics. Acta Neuropathol 119, 389-408.

Kovacs GG, Alafuzoff I, Al-Sarraj S, Arzberger T, Bogdanovic N, Capellari S, Ferrer I, Gelpi E, Kovari V, Kretzschmar H, Nagy Z, Parchi P, Seilhean D, Soininen H, Troakes C, Budka H (2008) Mixed brain pathologies in dementia: the BrainNet Europe consortium experience. Dement Geriatr Cogn Disord 26(4), 343-50.

Lim A, Tsuang D, Kukull W, Nochlin D, Leverenz J, McCormick W, Bowen J, Teri L, Thompson J, Peskind ER, Raskind M, Larson EB (1999) Clinico- neuropathological correlation of Alzheimer's disease in a community-based case series. J Am Geriatr Soc 47(5), 564-9.

Litvan I, Agid Y, Jankovic J, Goetz C, Brandel JP, Lai EC, Wenning G, D'Olhaberriague L, Verny M, Chaudhuri KR, McKee A, Jellinger K, Bartko JJ, Mangone CA, Pearce RK (1996) Accuracy of clinical criteria for the diagnosis of progressive supranuclear palsy (Steele-Richardson-Olszewski syndrome). Neurology 46(4), 922-30.

Massoud F, Devi G, Stern Y, Lawton A, Goldman JE, Liu Y, Chin SS, Mayeux R (1999) A clinicopathological comparison of community-based and clinic-based cohorts of patients with dementia. Arch Neurol 56(11), 1368-73.

McKeith IG, Galasko D, Kosaka K, Perry EK, Dickson DW, Hansen LA, Salmon DP, Lowe J, Mirra SS, Byrne EJ, Lennox G, Quinn NP, Edwardson JA, Ince PG, Bergeron C, Burns A, Miller BL, Lovestone S, Collerton D, Jansen EN, Ballard C, de Vos RA, Wilcock GK, Jellinger KA, Perry RH (1996) Consensus guidelines for the clinical and pathologic diagnosis of dementia with Lewy bodies (DLB): report of the consortium on DLB international workshop. Neurology 47(5), 1113-24.

McKhann G, Drachman D, Folstein M, Katzman R, Price D, Stadlan EM (1984) Clinical diagnosis of Alzheimer's disease: report of the NINCDS-ADRDA Work Group under the auspices of Department of Health and Human Services Task Force on Alzheimer's Disease. Neurology 34(7), 939-44.

Neary D, Snowden JS, Gustafson L, Passant U, Stuss D, Black S, Freedman M, Kertesz A, Robert PH, Albert M, Boone K, Miller BL, Cummings J, Benson DF (1998) Frontotemporal lobar degeneration: a consensus on clinical diagnostic criteria. Neurology 51(6), 1546-54.

Nelson PT, Abner EL, Schmitt FA, Kryscio RJ, Jicha GA, Smith CD, Davis DG, Poduska JW, Patel E, Mendiondo MS, Markesbery WR (2010) Modeling the association between 43 different clinical and pathological variables and the severity of cognitive impairment in a large autopsy cohort of elderly persons. Brain Pathol 20(1), 66-79.

Richards M, Brayne C (2009) What do we mean by Alzheimer's disease?. BMJ 341, 865-867.

Roman GC, Tatemichi TK, Erkinjuntti T, Cummings JL, Masdeu JC, Garcia JH, Amaducci L, Orgogozo JM, Brun A, Hofman A, et al (1993) Vascular dementia: diagnostic criteria for research studies. Report of the NINDS-AIREN International Workshop. Neurology 43(2), 250-60.

Sabbagh MN, Sandhu SS, Farlow MR, Vedders L, Shill HA, Caviness JN, Connor DJ, Sue L, Adler CH, Beach TG (2009) Correlation of clinical features with argyrophilic grains at autopsy. Alzheimer Dis Assoc Disord 23(3), 229-33.

Saito Y, Ruberu NN, Sawabe M, Arai T, Tanaka N, Kakuta Y, Yamanouchi H, Murayama S (2004) Staging of argyrophilic grains: an age-associated tauopathy. J Neuropathol Exp Neurol 63(9), 911-8.

Samii A, Nutt JG, Ransom BR (2004) Parkinson's disease. Lancet 363(9423), 1783-93.

Schneider JA, Aggarwal NT, Barnes L, Boyle P, Bennett DA (2009) The neuropathology of older persons with and without dementia from community versus clinic cohorts. J Alzheimers Dis 18(3), 691-701.

Sha S, Hou C, Viskontas IV, Miller BL (2006) Are frontotemporal lobar degeneration, progressive supranuclear palsy and corticobasal degeneration distinct diseases? Nat Clin Pract Neurol 2(12), 658-65.

Trojanowski JQ, Revesz T (2007) Proposed neuropathological criteria for the post mortem diagnosis of multiple system atrophy. Neuropathol Appl Neurobiol 33(6), 615-20.

Uylings HBM, de Brabander JM (2002) Neuronal changes in normal human aging and Alzheimer's disease. Brain Cogn 49(3), 268-76. 
Victoroff J, Mack WJ, Lyness SA, Chui HC (1995) Multicenter clinicopathological correlation in dementia. Am J Psychiatry 152(10), 1476-84.

Vonsattel JP, Myers RH, Stevens TJ, Ferrante RJ, Bird ED, Richardson EP, Jr (1985) Neuropathological classification of Huntington's disease. J Neuropathol Exp Neurol 44(6), 559-77.

Zarranz JJ (2006) Prion diseases. Neurologia Oct; 21(8):395-9. [In Spanish].

Zekry D, Duyckaerts C, Belmin J, Geoffre C, Herrmann F, Moulias R, Hauw JJ (2003) The vascular lesions in vascular and mixed dementia: the weight of functional anatomy. Neurobiol Aging 24, 213-219. 



\section{CHAPTER 3}

\section{Associations between Alzheimer pathology, Lewy bodies and cerebrovascular lesions in demented patients}

C. Echávarri, S. Burgmans, T. Tuñón, I. Jáuregui, F.R.J. Verhey and H.B.M. Uylings. Associations between Alzheimer pathology, Lewy bodies and cerebrovascular lesions in demented patients. Submitted. 
In patients with Alzheimer's disease (AD), the typical AD neuropathological features (neurofibrillary tangles and senile plaques) frequently co-occur with other neuropathological findings, particularly cerebrovascular lesions (CVLS) and Lewy bodies (LBs). The relationship between the severity of AD pathology and these comorbid pathologies is unclear. The present neuropathological study investigated the associations between the degree of Alzheimer pathology (i.e., Braak stage), CVLs and LBs in demented patients. The study included 101 patients who donated their brains to the Brain Bank of Navarre between 2004 and 2011. All patients were diagnosed in vivo with dementia, and received a post-mortem neuropathological diagnosis of AD. The mean time interval between the last in vivo clinical assessment and death was 4.2 months. Patients with large-vessel disease were excluded. With respect to the whole-brain analyses, we found a significant positive relationship between AD Braak stage and CVL severity. As for the regional analyses, we only found a significant correlation between AD Braak stage and CVL severity in the frontal cortex. No relationship was found between Braak and LB stage. Our study supports a positive association between AD pathology and CVLs in demented patients with $A D$, suggesting that $A D$ and CVLs may have a common aetiopathogenesis. In contrast, we found no evidence to suggest a direct link between AD and LB pathology in these patients. 


\section{Introduction}

Neurofibrillary tangles (NFTs) and senile plaques, including neuritic plaques (NPs), are considered to be neuropathological hallmarks of Alzheimer's disease (AD) (Braak \& Braak., 1990; Braak et al., 2006; Montine et al., 2012). The severity of AD pathology is generally staged according to Braak and Braak criteria, taking into account the amount and site of the deposition of NFTs and NPs (Braak \& Braak, 1991). Our data at the Navarre Brain Bank show that most donors who meet the clinical criteria for AD have a high Braak and Braak stage, viz. V-VI (Echávarri, 2011). It is well-known that other neuropathological features frequently co-exist in $A D$ brains. Findings that most frequently co-occur with $A D$ are cerebrovascular lesions (CVLs) and Lewy bodies (LB) (Snowdon et al., 1997; de Leeuw et al., 2004; Schneider et al., 2007; Parkkinen et al., 2008; Foster et al., 2010; Nelson et al., 2010). Furthermore, AD-related pathology can be found together with tauopathies such as corticobasal degeneration (CBD), progressive supranuclear palsy (PSP), or TDP-43 inclusions (Tomlinson et al., 1970; Jellinger, 2006; Nelson et al., 2007; Kovacs et al., 2008; Brunnstrom \& Englund, 2009; Echávarri et al., 2011). Comorbid neuropathological processes are thus very common in Alzheimer patients. It is, however, unclear whether there is a relationship between the severity of $A D$ and these comorbid neuropathological features.

To date, studies investigating the relationship between CVLS and Braak stage have produced inconsistent results. Some research has shown a positive relationship, with higher neuritic Braak stages co-occurring with an increased incidence and severity of vascular pathology (Jellinger, 2003; Jellinger, 2008; Jellinger, 2010), while other studies have found an inverse relationship (Goulding et al., 1999; Jellinger, 2000; Sonnen et al., 2011), with more AD pathology correlating with fewer CVLs. Contradictory results were also found when studying the relationship between the severity of AD- and LB-related pathologies. While Oinas et al. (2009) (Oinas et al., 2009) found a positive correlation between Braak stage for AD and the extent of LB-related pathology (Oinas et al., 2009), other researchers have reported the opposite (Selikhova et al., 2009; Compta et al., 2011; Sonnen et al., 2011). All the aforementioned studies were performed post-mortem. Regarding the relationship between $A D$ and CVL severity, the contradictory findings may be explained by the lack of consensus in defining the severity of CVLs. On the other hand, with respect to the association between $A D$ and LB severity, there is a lack of consensus in the classification of the stages of the pathologies, and again this may explain the inconsistent results.

The main aim of the present study was to investigate whether or not there is a correlation between the degree of Alzheimer pathology (i.e., Braak stage) and vascular lesions and LBs. We investigated 101 brains of demented individuals who had donated their brains to the Brain Bank of Navarre (Pamplona, Spain). The patients were diagnosed in vivo with dementia, and post-mortem neuropathological diag- 
noses confirmed $A D$. The sample consisted of 62 cases with pure $A D$ and 39 cases with $A D$ with comorbidity. Comorbidity was defined as a degenerative neuropathological process (sufficiently severe to warrant a separate diagnosis) other than AD. The secondary aim of the study was to add to previous data concerning an important issue namely the distinction between pure $A D$ and $A D$ with comorbidity. These data enabled us to investigate whether the relationship between AD pathology and CVLs is modified by a comorbid degenerative neuropathological process. We hypothesized that, if the severity of AD-related pathology and CVLS were related in patients with $A D$, the relationship might be mediated by the existence of a comorbid degenerative neuropathological process.

\section{Materials and Methods}

\section{Sample}

This study included 101 patients who donated their brains to the Brain Bank of Navarre between 2004 and 2011. They were diagnosed with dementia during life (clinical diagnosis) and a neuropathological diagnosis of $A D$ was made at postmortem. Specifically, of the 296 donors to the Brain Bank, 113 demented patients were found to have AD pathology on post-mortem analysis. Since the present study focused on small-vessel disease, twelve patients with large-vessel lesions (territorial infarcts or lobar bleedings) were excluded. The 101 subjects studied included cases with pure $A D$ and cases with $A D$ plus a comorbid neuropathological process. Comorbid diagnoses included degenerative pathologies other than AD. Neuropathological diagnoses of the 101 patients were as follows: 62 pure $A D ; 33 A D+L B$ dementia (LBD); 2 AD + frontotemporal lobe degeneration (FTLD) with TDP-43positive inclusions; $2 A D+P S P ; 1 A D+C B D ; 1 A D+L B$ in the amygdala. Patients with LBs only in the amygdala were given the diagnosis of LBD.

In the last clinical assessment before death, all subjects scored 2 or 3 on the Clinical Dementia Rating (CDR) scale, indicating moderate to severe dementia (Morris et al., 1993). The mean time interval between this clinical assessment and death was 4.2 months. Neuropathological diagnoses were made by the same experienced neuropathologist of the Brain Bank of Navarre (MCC) according to the standard criteria for AD (Braak \& Braak, 1991), LBD (McKeith et al., 1996), PSP (Dickson et al., 2007), CBD (Dickson et al., 2002), and frontotemporal lobar degeneration (FTLD) with TDP-43 positive inclusions (Cairns et al., 2007). The severity of small-vessel CVLs (from 0 to 2 ) was assessed for each case in a semi-quantitative way (see Table 1 ). In the group of pure $A D, 17$ cases (22.6\%) were found to have at least one non-strategic lacunar infarct, 15 (24\%) one strategic infarct (8 in caudate nucleus, 5 in thalamus and 2 in parietal cortex), 28 (45.2\%) cortical amyloid angiopathy and 36 (58.1\%) diffuse white matter changes. In the group of AD with comorbidity, 7 cases (17.9\%) had at least one non-strategic lacunar infarct, 2 (5.1\%) one 
strategic infarct (both in caudate nucleus), 11 (28.2\%) cortical amyloid angiopathy and 22 (56.4\%) diffuse white matter changes.

Regional analyses of AD-related tissue were performed, in particular classifying the amount of NFTs semi-quantitatively according to the following criteria (lesions counted within the microscopic field with a diameter of $0.79 \mathrm{~mm}^{2}$ at $\times 200$ magnification): NFT: none $=0 ; 1=+($ sparse $) ; 2=++\left(\right.$ moderate, more than 6 NFT per $\left.\mathrm{mm}^{2}\right)$; $3=+++\left(\right.$ frequent, more than 20 NFT per $\mathrm{mm}^{2}$ )

An average score (between 0 and 3) was calculated, representing the density of NFTs in each region studied (hippocampus, amygdala, temporal and frontal cortex).

The LBD cases were classified into three types as in Mc Keith et al. (McKeith et al., 2005) on the basis of the amount of LB and their distribution across brain regions (i.e., into brainstem, limbic and neocortical types). The Braak and Braak stage for $A D$ ranged from III to VI.

Demographic data for the patients are presented in Table 2. Written informed consent was obtained from all patients or their close relatives.

Table 1. Classification of cerebrovascular lesions (CVLs)

\begin{tabular}{ll}
\hline 0 & No concomitant CVLs \\
\hline 1 & $\begin{array}{l}\text { Minimal CVLs: 1-2 small lacunes, mild-moderate cerebral amyloid angiopathy (CAA), } \\
\text { mild CVLs, mild leukoencephalopathy }\end{array}$ \\
\hline 2 & $\begin{array}{l}\text { Moderate CVLs: >2 lacunes, severe subcortical lacunar state, severe CAA with mod- } \\
\text { erate CVLs, diffuse white matter lesions }\end{array}$ \\
\hline
\end{tabular}

Table 2. Demographical data

\begin{tabular}{lcccc}
\hline & $\begin{array}{c}\text { Age (years) } \\
\text { Mean (SD) }\end{array}$ & $\begin{array}{c}\text { Gender } \\
\text { (\% female) }\end{array}$ & $\begin{array}{c}\text { Time from diagnosis } \\
\text { to death (years) } \\
\text { Mean (SD) }\end{array}$ & $\begin{array}{c}\text { Braak stage (AD) } \\
\text { Mean (SD) }\end{array}$ \\
\hline $\begin{array}{l}\text { AD } \\
(n=62)\end{array}$ & $82.5(8.0)$ & 65.0 & $6.5(3.3)$ & $5.5(0.7)$ \\
$\begin{array}{l}A D+\text { comorbidity } \\
(n=39)\end{array}$ & $84.0(7.4)$ & 56.0 & $8.5(4.4)$ & $4.5(1.0)$ \\
$P$ & 0.342 & 0.224 & 0.014 & 0.000 \\
\hline
\end{tabular}

The whole-group analyses revealed a significant positive relationship between $A D$ Braak stage and CVL severity $(r=0.19, p=0.048)$. That is, higher Braak stages were associated with more CVLs. The post-hoc analyses, in which we performed separate calculations for patients with pure $A D$ and patients with $A D$ plus a comorbid neuropathological process, differences did not reach significance. See Figure 1 . When LBD stage was included as a covariate in the partial correlation for the whole group of $A D$ participants, the relationship was no longer significant $(r=0.18, p=0.07)$. Figure 2 shows the prevalence of the CVL categories per Braak stage, with the 
number of subjects for each Braak stage set to $100 \%$. This demonstrates that the relative number of patients with vascular lesions (CVL score $=1$ or 2 ) increases with higher Braak stages.

With respect to regional analyses, considering the hippocampus, amygdala, temporal cortex and frontal cortex separately, the only significant correlation was found ( $r=0.21 ; p=0.034$ ) between the amount of NFTs and severity of CVLs in the frontal cortex and for the two groups together ('AD pure' and 'AD with comorbidity').

No significant association was found between AD Braak stage and LBD stage, either in the whole-brain analysis or in the regional analyses.

Figure 1. Cerebrovascular lesion (CVL) severity per Braak stage

(see Table 1 for the classification of CVLs)

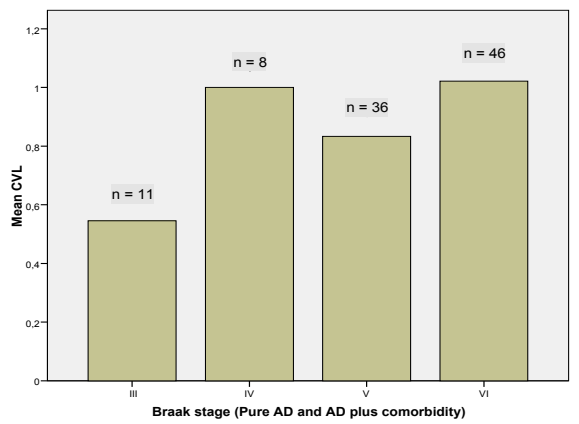

a) Whole group analysis
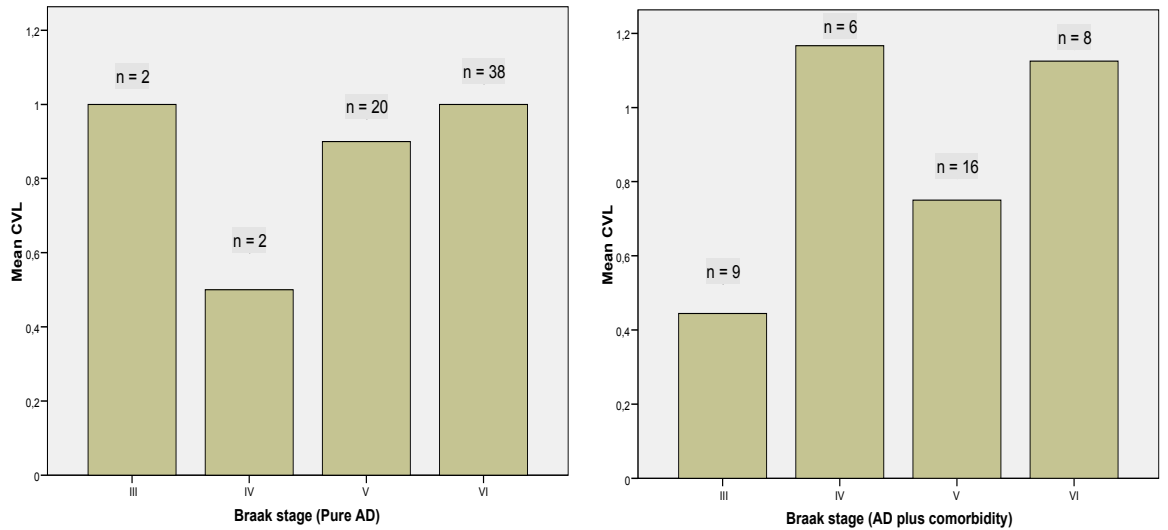

b) Post-hoc analysis in which we analysed the pure AD group (left) and AD with comorbidity group (right) separately 
Figure 2. Prevalence of the CVL categories per Braak stage.

In this figure, the number of subjects for each Braak stage was set at $100 \%$. This demonstrates that the relative number of patients with vascular lesions ( $C V L=1$ or 2$)$ increases with higher Braak stages

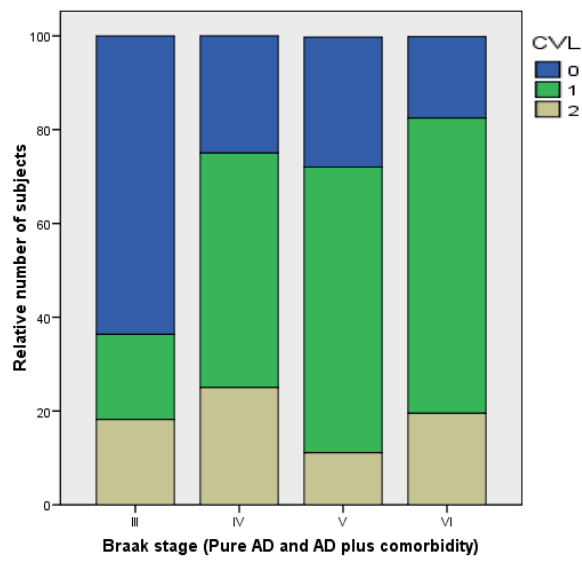

a) Whole group analysis
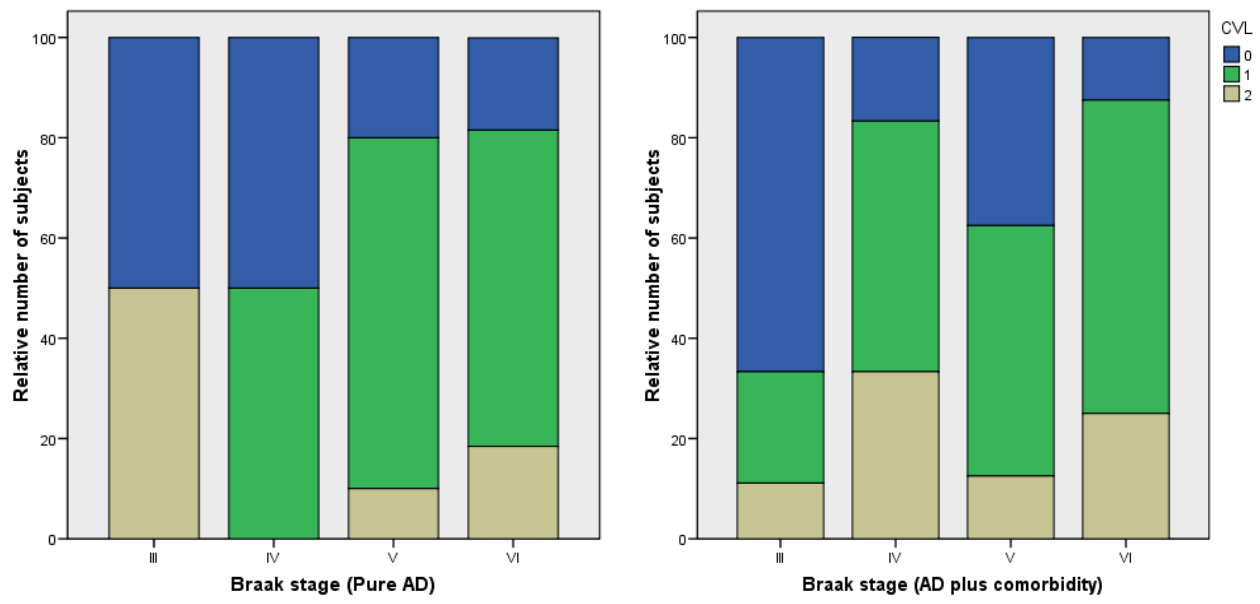

b) Post-hoc analysis in which we analysed the pure $A D$ group (left) and $A D$ with comorbidity group (right) separately

\section{Discussion}

We studied a sample of 101 participants with a diagnosis of dementia during life and AD-related pathology in the neuropathological assessment at post-mortem. We found that higher Braak and Braak stages are associated with more severe vascular lesions, in particular in the frontal cortex. This is in line with the report of Jellinger et al. (2008) (Jellinger et al., 2008), who studied a sample of 100 patients 
with Parkinson's disease and 20 patients with LBD and AD-related pathology and found a positive relationship between CVL severity and AD Braak stage. Previous in vivo studies have also shown a positive correlation between AD and CVLs (Kim et al., 2001; Yoshita et al., 2006). Our results are, however, not consistent with two previous neuropathological studies that found a negative relationship between Braak stage and vascular lesions: Goulding et al. in 1999 (Goulding et al., 1999) and Jellinger et al. in 2000 (Jellinger et al., 2000). Both studies were based on very small samples ( 25 and 27 cases respectively), and although all cases had predominantly AD-type dementia, no other details were provided regarding their diagnoses. This could explain the contradictory results. Indeed, when Jellinger et al. studied a much larger sample in 2008 (120 cases) all cases showed co-occurrence of AD and LB related pathologies, and in this more recent study they found a positive correlation. We therefore conclude that, overall, our positive relationship between AD Braak stages and CVL severity are in line with the other available evidence. This suggests that $A D$ pathology and CVLs have a common aetiopathogenesis in demented patients.

In order to investigate whether this relationship between AD pathology and CVLS is modified by the presence of a comorbid degenerative neuropathological process, we divided our sample into two groups: cases with pure $A D$ and cases with $A D$ plus a comorbid neuropathological process (note that these comorbid diagnoses included other degenerative conditions, but not vascular dementia). Although we did not find any significant associations, this may be due to the small number of subjects in each subgroup, and accordingly we are unable to rule out that the positive association between AD Braak stage and CVLs is mediated by a comorbid degenerative neuropathological process. In fact, since the results were not significant when LBD stage was included as a covariate, we can state that LB pathology is a mediating factor in the positive relationship between severity of CVL and $A D$ related pathology.

In the present study, we found no correlation between AD Braak stage and Lewy body stage. No prior studies have been performed in samples with comparable characteristics to ours, and research that has been conducted has produced contradictory results (Sonnen et al., 2011; Compta et al., 2011). Sonnen et al. (Sonnen et al., 2011) studied a sample of 336 cognitively normal adults and found an inverse relationship, while Compta et al. (Compta et al., 2011) found a positive relationship in a sample of 56 participants with a diagnosis of Parkinson's disease, who in most cases had an AD-related tauopathy at a Braak stage of III-IV. We believe that the lack of homogeneity in the clinical characteristics of the participants and the severity of the degenerative pathology may have led to these contradictory results. In any case, we underline that the present data do not support the idea of a direct relationship between $A D$ pathology and LB in demented patients with AD.

With regard to the regional analysis, the only significant correlation was found in the frontal cortex. We hypothesize that AD-related pathology in the frontal cor- 
tex may lead to disruption of the fronto-subcortical pathway and make it more susceptible to vascular damage due to small-vessel disease or demyelination of the white matter at the frontal area.

Finally, we address the limitations of our study. First, the small number of participants in each subgroup of $A D$ patients may be responsible for the lack of significant results in the post-hoc analyses. Second, most of our patients were at Braak stages $\mathrm{V}$ or $\mathrm{VI}$. This narrow range of Braak stages may have hampered our ability to find robust correlations. Both limitations are not uncommon in post-mortem studies and are a result of the fact that we studied tissue from deceased patients.

In conclusion, our study provides new evidence for a link between AD pathology and CVLs in demented patients with $A D$, suggesting that $A D$ and CVLs may have a common aetiopathogenesis. Our data do not, however, support the theory of a direct relationship between AD pathology and LB in these patients.

\section{References}

Braak H, Alafuzoff I, Arzberger T, Kretzschmar H, Del Tredici K. Staging of Alzheimer disease-associated neurofibrillary pathology using paraffin sections and immunocytochemistry. Acta Neuropathol 2006;112(4):389-404.

Braak H, Braak E. Neurofibrillary changes confined to the entorhinal region and an abundance of cortical amyloid in cases of presenile and senile dementia. Acta Neuropathol 1990;80(5):479-86.

Braak H, Braak E. Neuropathological stageing of Alzheimer-related changes. Acta Neuropathol 1991;82(4):239-59.

Brunnstrom H, Englund E. Clinicopathological concordance in dementia diagnostics. Am J Geriatr Psychiatry 2009;17(8):664-70.

Cairns NJ, Bigio EH, Mackenzie IR, Neumann M, Lee VM, Hatanpaa KJ, White CL, 3rd, Schneider JA, Grinberg LT, Halliday G, Duyckaerts C, Lowe JS, Holm IE, Tolnay M, Okamoto K, Yokoo H, Murayama S, Woulfe J, Munoz DG, Dickson DW, Ince PG, Trojanowski JQ, Mann DM. Neuropathologic diagnostic and nosologic criteria for frontotemporal lobar degeneration: consensus of the Consortium for Frontotemporal Lobar Degeneration. Acta Neuropathol 2007;114(1):5-22.

Compta Y, Parkkinen L, O'Sullivan SS, Vandrovcova J, Holton JL, Collins C, Lashley T, Kallis C, Williams DR, de Silva R, Lees AJ, Revesz T. Lewy- and Alzheimer-type pathologies in Parkinson's disease dementia: which is more important? Brain 2011;134(Pt 5):1493-505.

de Leeuw FE, Barkhof F, Scheltens P. White matter lesions and hippocampal atrophy in Alzheimer's disease. Neurology 2004;62(2):310-2.

Dickson DW, Bergeron C, Chin SS, Duyckaerts C, Horoupian D, Ikeda K, Jellinger K, Lantos PL, Lippa CF, Mirra SS, Tabaton M, Vonsattel JP, Wakabayashi K, Litvan I. Office of Rare Diseases neuropathologic criteria for corticobasal degeneration. J Neuropathol Exp Neurol 2002;61(11):935-46.

Dickson DW, Rademakers R, Hutton ML. Progressive supranuclear palsy: pathology and genetics. Brain Pathol 2007;17(1):74-82.

Echávarri C CM, Aramendía A, García-Bragado F, Tuñón T. Multi-protein deposits in neurodegenerative disorders. Our experience in the Tissue Brain Bank of Navarra. The Anatomical Record 2011;294:1191-7.

Foster ER, Campbell MC, Burack MA, Hartlein J, Flores HP, Cairns NJ, Hershey T, Perlmutter JS. Amyloid imaging of Lewy body-associated disorders. Mov Disord 2010;25(15):2516-23. 
Goulding JM, Signorini DF, Chatterjee S, Nicoll JA, Stewart J, Morris R, Lammie GA. Inverse relation between Braak stage and cerebrovascular pathology in Alzheimer predominant dementia. J Neurol Neurosurg Psychiatry 1999;67(5):654-7.

Jellinger K. Inverse relation between Braak stage and cerebrovascular pathology in Alzheimer predominant dementia. J Neurol Neurosurg Psychiatry 2000;68(6):799-800.

Jellinger KA. Clinicopathological analysis of dementia disorders in the elderly--an update. J Alzheimers Dis 2006;9(3 Suppl):61-70.

Jellinger KA. Prevalence and impact of cerebrovascular lesions in Alzheimer and lewy body diseases. Neurodegener Dis 2010;7(1-3):112-5.

Jellinger KA, Attems J. Incidence of cerebrovascular lesions in Alzheimer's disease: a postmortem study. Acta Neuropathol 2003;105(1):14-7.

Jellinger KA, Attems J. Prevalence and impact of vascular and Alzheimer pathologies in Lewy body disease. Acta Neuropathol 2008;115(4):427-36.

Jellinger KA, Mitter-Ferstl E. The impact of cerebrovascular lesions in Alzheimer disease--a comparative autopsy study. J Neurol 2003;250(9):1050-5.

Kim JH, Hwang KJ, Lee YH, Rhee HY, Park KC. Regional white matter hyperintensities in normal aging, single domain amnestic mild cognitive impairment, and mild Alzheimer's disease. J Clin Neurosci 2011;18(8):1101-6.

Kovacs GG, Alafuzoff I, Al-Sarraj S, Arzberger T, Bogdanovic N, Capellari S, Ferrer I, Gelpi E, Kovari V, Kretzschmar H, Nagy Z, Parchi P, Seilhean D, Soininen H, Troakes C, Budka H. Mixed brain pathologies in dementia: the BrainNet Europe consortium experience. Dement Geriatr Cogn Disord 2008;26(4):343-50.

Mastaglia FL, Johnsen RD, Byrnes ML, Kakulas BA. Prevalence of amyloid-beta deposition in the cerebral cortex in Parkinson's disease. Mov Disord 2003;18(1):81-6.

McKeith IG, Dickson DW, Lowe J, Emre M, O'Brien JT, Feldman H, Cummings J, Duda JE, Lippa C, Perry EK, Aarsland D, Arai H, Ballard CG, Boeve B, Burn DJ, Costa D, Del Ser T, Dubois B, Galasko D, Gauthier S, Goetz CG, Gomez-Tortosa E, Halliday G, Hansen LA, Hardy J, Iwatsubo T, Kalaria RN, Kaufer D, Kenny RA, Korczyn A, Kosaka K, Lee VM, Lees A, Litvan I, Londos E, Lopez OL, Minoshima S, Mizuno Y, Molina JA, Mukaetova-Ladinska EB, Pasquier F, Perry RH, Schulz JB, Trojanowski JQ, Yamada M. Diagnosis and management of dementia with Lewy bodies: third report of the DLB Consortium. Neurology 2005;65(12):1863-72.

McKeith IG, Galasko D, Kosaka K, Perry EK, Dickson DW, Hansen LA, Salmon DP, Lowe J, Mirra SS, Byrne EJ, Lennox G, Quinn NP, Edwardson JA, Ince PG, Bergeron C, Burns A, Miller BL, Lovestone S, Collerton D, Jansen EN, Ballard C, de Vos RA, Wilcock GK, Jellinger KA, Perry RH. Consensus guidelines for the clinical and pathologic diagnosis of dementia with Lewy bodies (DLB): report of the consortium on DLB international workshop. Neurology 1996;47(5):1113-24.

Montine TJ, Phelps CH, Beach TG, Bigio EH, Cairns NJ, Dickson DW, Duyckaerts C, Frosch MP, Masliah E, Mirra SS, Nelson PT, Schneider JA, Thal DR, Trojanowski JQ, Vinters HV, Hyman BT. National Institute on Aging-Alzheimer's Association guidelines for the neuropathologic assessment of Alzheimer's disease: a practical approach. Acta Neuropathol 2012;123(1):1-11.

Morris JC. The Clinical Dementia Rating (CDR): current version and scoring rules. Neurology 1993;43(11):2412-4.

Nelson PT, Jicha GA, Kryscio RJ, Abner EL, Schmitt FA, Cooper G, Xu LO, Smith CD, Markesbery WR. Low sensitivity in clinical diagnoses of dementia with Lewy bodies. J Neurol 2010;257(3):359-66.

Nelson PT, Jicha GA, Schmitt FA, Liu H, Davis DG, Mendiondo MS, Abner EL, Markesbery WR. Clinicopathologic correlations in a large Alzheimer disease center autopsy cohort: neuritic plaques and neurofibrillary tangles "do count" when staging disease severity. J Neuropathol Exp Neurol 2007;66(12):1136-46. 
Oinas M, Polvikoski T, Sulkava R, Myllykangas L, Juva K, Notkola IL, Rastas S, Niinisto L, Kalimo H, Paetau A. Neuropathologic findings of dementia with lewy bodies (DLB) in a population-based Vantaa $85+$ study. J Alzheimers Dis 2009;18(3):677-89.

Parkkinen L, Pirttila T, Alafuzoff I. Applicability of current staging/categorization of alpha-synuclein pathology and their clinical relevance. Acta Neuropathol 2008;115(4):399-407.

Schneider JA, Arvanitakis Z, Bang W, Bennett DA. Mixed brain pathologies account for most dementia cases in community-dwelling older persons. Neurology 2007;69(24):2197-204.

Selikhova M, Williams DR, Kempster PA, Holton JL, Revesz T, Lees AJ. A clinico-pathological study of subtypes in Parkinson's disease. Brain 2009;132(Pt 11):2947-57.

Snowdon DA, Greiner LH, Mortimer JA, Riley KP, Greiner PA, Markesbery WR. Brain infarction and the clinical expression of Alzheimer disease. The Nun Study. JAMA 1997;277(10):813-7.

Sonnen JA, Santa Cruz K, Hemmy LS, Woltjer R, Leverenz JB, Montine KS, Jack CR, Kaye J, Lim K, Larson EB, White L, Montine TJ. Ecology of the aging human brain. Arch Neurol 2011;68(8):1049-56.

Tomlinson BE, Blessed G, Roth M. Observations on the brains of demented old people. J Neurol Sci 1970;11(3):205-42.

Trojanowski JQ, Lee VM. Parkinson's disease and related alpha-synucleinopathies are brain amyloidoses. Ann N Y Acad Sci 2003;991:107-10.

Yoshita M, Fletcher E, Harvey D, Ortega M, Martinez O, Mungas DM, Reed BR, DeCarli CS. Extent and distribution of white matter hyperintensities in normal aging, $\mathrm{MCl}$, and $\mathrm{AD}$. Neurology 2006;67(12):2192-8. 



\section{CHAPTER 4}

Vascular risk factors in neuropathologically confirmed Alzheimer's disease and vascular dementia

C. Echávarri, S. Burgmans, F.R.J. Verhey, H.B.M. Uylings, E. Layana, A.J.M. Rozemuller and W. Kamphorst. Vascular risk factors in neuropathologically confirmed Alzheimer's disease and vascular dementia. Submitted. 
Previous in vivo studies have reported various vascular conditions to be risk factors for dementia. Our main aim was to compare vascular risk factor prevalence in neuropathologically confirmed cases of Alzheimer's disease (AD), vascular dementia $(\mathrm{VaD})$, and mixed $A D$ and $\mathrm{VaD}(\mathrm{MD})$. We compare the results with prevalences in elderly local Dutch control populations. The target population of this retrospective descriptive study comprised 120 brains selected from donations to the Netherlands Brain Bank between 1984 and 2010. Forty VaD patients were matched with $40 \mathrm{AD}$ and $40 \mathrm{MD}$ patients. Data from several control groups representing the elderly Dutch population were also included for comparison.

The only differences found were a greater prevalence of history of stroke in VaD and $\mathrm{MD}$ patients compared to $\mathrm{AD}$ patients and controls, and a greater prevalence of smoking in $A D$. We argue that none of the risk factors we examined may be related to the presence of dementia, except for stroke history in VaD. 


\section{Introduction}

Multiple vascular risk factors, such as hypertension, diabetes, history of stroke, atrial fibrillation, hypercholesterolaemia and smoking have been recognised to be associated with dementia, in particular vascular dementia (VaD) but also Alzheimer's disease (AD) (Cherubini et al., 2007; Henon et al., 2000; Kalaria, 2000; Kivipelto et al., 2001; Skoog et al., 1996). Other studies have failed to distinguish a particular vascular risk factor pattern associated with subtypes of dementia (AD or VaD) (Arvanitakis et al., 2004; Breteler et al., 1994; Luchsinger et al., 2001; Luchsinger et al., 2004; Luchsinger et al., 2005; O’Brien et al., 2003; Ott et al., 1998; Ott et al., 1999; Pohjasvaara et al., 1998; Kivipelto et al., 2001; Knopman et al., 2001; Kuller et al., 2005; Reitz et al., 2008; van Vliet et al., 2010). One possible explanation for this might be the lack of consensus about the clinical diagnoses of $\mathrm{VaD}, \mathrm{AD}$ and mixed $A D$ and $\mathrm{VaD}$ cases (MD). In fact, previous research has shown that clinical diagnoses often have to be revised when neuropathological findings become available (Brunnstrom \& Englund, 2009; Kovacs et al., 2008; Echávarri et al., 2012). In addition, AD-related and vascular pathologies commonly co-occur (Parkkinen et al., 2008; Trojanoswki et al., 2003), which complicates the diagnosis of dementia subtypes. The main aim of our study was to compare the prevalence of vascular risk factors in neuropathologically confirmed $A D, V a D$ and mixed $A D$ and $\operatorname{VaD}(\mathrm{MD})$. We compared the results with prevalences in several elderly local Dutch control populations. To the best of our knowledge, this is the first combined cliniconeuropathological study on this topic.

\section{Material and methods}

\section{Cases}

The target population for this retrospective descriptive study comprised 120 brains selected from donations to the Netherlands Brain Bank (NBB) between 1984 and 2010. Necropsy authorization and informed consent were obtained from each donor, relative or caregiver. We included all 40 cases diagnosed with $\mathrm{VaD}$ during this period (1984 to 2010), as well as 40 cases of AD and another 40 cases of MD. During the period in which the $\mathrm{VaD}$ cases were collected, $660 \mathrm{AD}$ cases were identified at the NBB. Cases of $A D, V a D$, and MD were matched where possible for age and the Braak stage of AD-related neurofibrillary tangle pathology. The stages, as defined in Braak (Braak et al., 2006), were IV or V for AD cases, III or less for VaD, and IV or V for MD. Brains at Braak stage VI were not included, since they were older than the other cases. More details of the diagnostic criteria used are presented in the next subsection, Neuropathological assessment. Brains from the NBB with a mixture of other neurodegenerative disorders or any other structural lesions were also excluded. 
The NBB donors were recruited from nursing homes. All demographic information (age, sex, duration of dementia), clinical data including risk factors (hypertension, history of stroke, diabetes, hypercholesterolaemia, atrial fibrillation, smoking) and neuropathological data were collected from patient medical records and NBB records. These data were provided by the patient's family doctor, the doctor at the nursing home, the patient's neurologist and/or psychiatrist. The patients were considered to have had hypertension if they had one of the following: self-report of physician-diagnosed hypertension, use of antihypertensive medication, or blood pressure $\geq 160 / 95$. They were considered to have had hypercholesterolaemia if their recorded total cholesterol $\geq 6.5 \mathrm{mmol} / \mathrm{L}$. History of stroke included transitory ischemic attack (TIA) as well as actual stroke.

As regards hypertension, $67.5 \%$ of the patients were reported as having had midlife hypertension and $15.5 \%$ as having had late-life hypertension, while no distinction between late-life or mid-life hypertension could be made in $17.5 \%$ of the patients. Neuropathological diagnoses were reviewed by an experienced neuropathologist (WK), while the medical records were examined by an experienced neurologist (CE).

Control group data derived from several epidemiological studies involving elderly Dutch populations were compared with the data from the sample of demented cases from the Brain Bank. These subjects from Dutch populations had been selected at random. Most of them were living at home, and a few of them in nursing homes. Data on hypertension were collected from Van Rossum et al. (2000) (Rossum et al., 2000), data on atrial fibrillation from Heeringe et al. (2006) (Heeringe et al., 2006)), data on history of stroke and diabetes from the Nijmegen Continuous Morbidity Register (Van de Lisdonk E. Personal communication, 2012), data on hypercholesterolaemia from the Measuring the Netherlands study (Verschuuren M. Personal communication, 2012), and data on smoking from the Dutch Continuous Survey of Smoking by STIVORO (2010) (Zeegers T. Personal communication, 2012). All but one of the control groups were chosen so as to comprise individuals aged between 75 and 84 years, in order to ensure that they were as similar as possible to the mean age in the demented groups from the Brain Bank. The exception was the control group for hypercholesterolaemia, which included people aged 61 to 70 years.

\section{Neuropathological assessment}

Macroscopic assessment of the brain included analysis of photographs. The right hemisphere was fixed in $4 \%$ formaldehyde for three weeks, while the left hemisphere was dissected fresh. For diagnostic purposes, the following regions were dissected from the fixed right hemisphere and embedded in paraffin: frontal, cingulate, insular, temporal, parietal and occipital cortices including deep white matter; basal ganglia; thalamus; amygdala; hippocampus and entorhinal areas; mesencephalon including substantia nigra; locus coeruleus and base of pons; medulla 
oblongata; and cerebellum and cervical spinal cord (level C1 or C2). If necessary, selected parts of fixed remnants of the left hemisphere were also analysed. Cortical regions were routinely stained with haematoxylin and eosin, Bodian or Gallyas methods (for neurofibrillary tangles), methenamine-silver (for senile plaques), and Congo red (for congophilic plaques and vessels). Immunohistochemistry was performed for alpha-synuclein (to detect Lewy bodies and Lewy neurites), AT8, beta A4, prion protein, ubiquitin and TDP43.

The neuropathological diagnoses in our study were made on the basis of the following criteria. Vascular dementia was diagnosed if there was clinical dementia and the neuropathology corresponded to the classification by Brun and Gustafson (Brun et al., 1988) and Brun (Brun et al., 1994). . VaD diagnoses could include Alzheimer-related pathology at a Braak and Braak neurofibrillary tangles stage of III or lower, but no other neurodegenerative disorders (especially Lewy body pathologies). Of the 40 cases of $\mathrm{VaD}, 16$ showed small vessel disease with strategic infarcts ( 7 in the caudate, 7 in the thalamus and 2 in the parietal lobe), 19 had territorial infarcts (caused by large vessel disease) and 21 had white matter rarefaction and/or lacunar infarcts.

Alzheimer's Disease was diagnosed according to the criteria described by Braak and Braak, based on the presence, density and distribution of cortical neuritic plaques (Braak and Braak, 1997; Braak and Braak, 1990) and tangle pathology (Braak and Braak, 1991; Braak and Braak, 1990). We included only clinically demented cases with Braak stages IV and V for neurofibrillary tangles, without any Lewy bodies. Seven of the 40 cases with AD showed focally reduced white matter density and/or one lacunar white matter infarct. These white matter lesions coexisting with $A D$ were not considered to be severe enough to contribute to the dementia, and these patients were therefore not included in the mixed dementia group.

Mixed dementia was defined as meeting the criteria for $\mathrm{VaD}$, combined with a Braak stage above III. Of the 40 cases diagnosed with MD, 6 showed territorial infarcts caused by large vessel damage, 22 decreased white matter density and/or lacunar infarcts caused by small vessel damage, and 12 a mixture of both large and small vessel damage. No strategic infarcts were found in the MD group.

\section{Statistical analysis}

Statistical analyses were performed using two different statistical packages. The Statistical Package for the Social Sciences (SPSS, Chicago, IL) version 16.0 for Windows was used to compare the three groups in our own sample in terms of demographic variables. The following statistical tests were performed: ANOVA (with a general linear model) for continuous variables such as mean age and duration of dementia, and chi-square tests for categorical variables such as sex and the presence of each risk factor. The Statcalc module of Epi Info (version 6, November 1993; CDC, Atlanta, GA) was used to compare risk factor percentages between all 
groups (including the control groups) using chi-square tests, and using Fisher's exact test for numerical values. The results were expressed as odds ratios for prevalence, confidence intervals (95\%) and p-values.

\section{Results}

\section{Demographic variables}

The demographic characteristics (age and sex) of the cases and the duration of dementia are summarized in Table 1 . No significant differences between AD and $\mathrm{VaD}$ were found for these variables. However, the mean age of the MD group was significantly higher than that of the $A D$ and $V a D$ groups. The longest mean duration of dementia was found for VaD (8 years), followed by MD (6.5 years) and AD (6 years), but these differences were not statistically significant.

Table 1. Demographic variables in the three groups of demented cases

\begin{tabular}{lcccc}
\hline & $\begin{array}{c}\mathrm{AD} \\
\mathrm{n}=40\end{array}$ & $\begin{array}{c}\mathrm{VaD} \\
\mathrm{n}=40\end{array}$ & $\mathrm{nD}$ & $\mathrm{P}=40$ \\
\hline Age in years; mean (SD) & $79.7(3.7)$ & $77.7(11.1)$ & $82.5(5)$ & 0.017 \\
\hline Female sex; $\mathrm{n}(\%)$ & $27(67.5)$ & $21(52.5)$ & $25(62.5)$ & 0.171 \\
\hline Duration of dementia in years; mean (SD) & $6(3.2)$ & $8(4.8)$ & $6.5(4.6)$ & 0.104 \\
\hline
\end{tabular}

Note. Group differences were assessed with ANOVA (for age and duration of dementia) and chi-square tests (for sex). $A D=$ Alzheimer's disease; $\mathrm{VaD}=$ vascular dementia; $M D=$ mixed dementia; $p=p$ value; $\mathrm{SD}=$ standard deviation.

Distribution of risk factors

Tables 2 and 3 show the number of participants and prevalence of risk factors in all the groups studied. 
Table 2. Number and (\%) of participants and distribution of risk factors in the three groups of demented cases

\begin{tabular}{lccccccccc}
\hline & AD & & & VaD & & & MD & & \\
& Total & Males & Females & Total & Males & Females & Total & Males & Females \\
& $\mathrm{n}=40$ & $\mathrm{n}=13$ & $\mathrm{n}=27$ & $\mathrm{n}=40$ & $\mathrm{n}=19$ & $\mathrm{n}=21$ & $\mathrm{n}=40$ & $\mathrm{n}=15$ & $\mathrm{n}=25$ \\
\hline Hypertension & 24 & 6 & 18 & 21 & 10 & 11 & 22 & 8 & 14 \\
& $(60 \%)$ & $(46.2 \%)$ & $(66.7 \%)$ & $(52.5 \%)$ & $(52.6 \%)$ & $(52.4 \%)$ & $(55 \%)$ & $(53.3 \%)$ & $(56 \%)$ \\
Stroke history & 7 & 3 & 4 & 29 & 16 & 13 & 18 & 7 & 11 \\
& $(17.5 \%)$ & $(23.1 \%)$ & $(14.8 \%)$ & $(72.5 \%)$ & $(84.2 \%)$ & $(61.9 \%)$ & $(45 \%)$ & $(46.7 \%)$ & $(44 \%)$ \\
Diabetes & 9 & 3 & 6 & 4 & 1 & 3 & 9 & 4 & 5 \\
Atrial & $(22.5 \%)$ & $(23.1 \%)$ & $(22.2 \%)$ & $(10 \%)$ & $(5.3 \%)$ & $(14.3 \%)$ & $(22.5 \%)$ & $(26.7 \%)$ & $(20 \%)$ \\
Fibrillation & 8 & 3 & 5 & 9 & 4 & 5 & 4 & 0 & 4 \\
Hypercholester- & 8 & 3 & 5 & 3 & 2 & 1 & 4 & 0 & 4 \\
olaemia & $(20 \%)$ & $(23.1 \%)$ & $(18.5 \%)$ & $(22.2 \%)$ & $(21.1 \%)$ & $(23.8 \%)$ & $(10 \%)$ & $(0 \%)$ & $(16 \%)$ \\
Smoking & 10 & 4 & 6 & 3 & 2 & 1 & 3 & 1 & 2 \\
& $(25 \%)$ & $(30.8 \%)$ & $(22.2 \%)$ & $(7.5 \%)$ & $(10.5 \%)$ & $(4.8 \%)$ & $(7.5 \%$ & $(6.7 \%)$ & $(8 \%)$ \\
\hline
\end{tabular}

Note. $A D=$ Alzheimer's disease $; \mathrm{VaD}=$ vascular dementia; $\mathrm{MD}=$ mixed dementia.

Table 3. Number and (\%) of participants and distribution of risk factors in the control groups

\begin{tabular}{lcccccc}
\hline & \multicolumn{3}{c}{ Number of cases } & \multicolumn{2}{c}{ Prevalence of risk factors } \\
\hline & Total & Males & Females & Total & Males & Females \\
& $\mathrm{N}$ & $\mathrm{n}$ & $\mathrm{N}$ & $\mathrm{n}(\%)$ & $\mathrm{n}(\%)$ & $\mathrm{n}(\%)$ \\
\hline Hypertension $^{26}$ & 1792 & 618 & 1174 & 811 & 225 & 586 \\
& & & & $(45.6 \%)$ & $(36.4 \%)$ & $(50.4 \%)$ \\
Stroke history $^{28}$ & 583 & 238 & 345 & 110 & 51 & 59 \\
& & & & $(18.8 \%)$ & $(21.4 \%)$ & $(17.1 \%)$ \\
Diabetes $^{28}$ & 583 & 238 & 345 & 107 & 42 & 65 \\
& & & & $(18.4 \%)$ & $(17.6 \%)$ & $(18.8 \%)$ \\
Hypercholesterolaemia $^{29}$ & 1167 & 580 & 587 & 288 & 89 & 199 \\
& & & & $(24.7 \%)$ & $(15.5 \%)$ & $(34 \%)$ \\
Atrial fibrillation $^{27}$ & 1392 & 492 & 900 & 149 & 68 & 81 \\
& & & & $(10.7 \%)$ & $(13.8 \%)$ & $(9.2 \%)$ \\
Smoking $^{30}$ & 959 & 603 & 356 & 95 & 61 & 34 \\
& & & & $(9.9 \%)$ & $(10.1 \%)$ & $(9.5 \%)$ \\
\hline
\end{tabular}

Note. Three first columns show total number of cases in each epidemiological group and the three last columns represent number and percentages of cases that had the risk factor. The numbers (26-30) correspond to the references to epidemiological studies from which control group data were obtained.

Figure 1 displays the prevalence of risk factors in each group and the statistical differences between the groups, while Table 4 details differences between the groups, overall and stratified by sex. Hypertension was the most prevalent risk factor in $A D$ and MD groups but not among those diagnosed with $\mathrm{VaD}$. No signifi- 
cant differences in hypertension were detected between the groups, though there was a trend towards a higher prevalence of hypertension in $A D$ compared to controls, especially considering female AD cases and controls (Table 4). Similarly, for diabetes no significant differences or trends were found between groups. History of stroke was the most prevalent risk factor in $\mathrm{VaD}$. For this variable, differences between groups were significant in all cases, except for the control and AD groups in which the prevalence was very similar. Regarding hypercholesterolaemia, there was a significant difference between the controls and both $\mathrm{VaD}$ and MD groups. Notably, this difference was completely attributable to the female control subgroup in which the prevalence of hypercholesterolaemia was notably higher (compare Fig. 1 with Table 4). Atrial fibrillation was significantly more common in the $\mathrm{VaD}$ than the control group and again this was completely attributable to a higher prevalence in the female subgroup (see Fig. 1 and Table 4). A non-significant trend towards a difference was found between female AD cases and controls, with more atrial fibrillation in AD females (Table 4). Finally, the prevalence of smoking was statistically significantly higher in AD cases than controls (Fig 1 and Table 4).

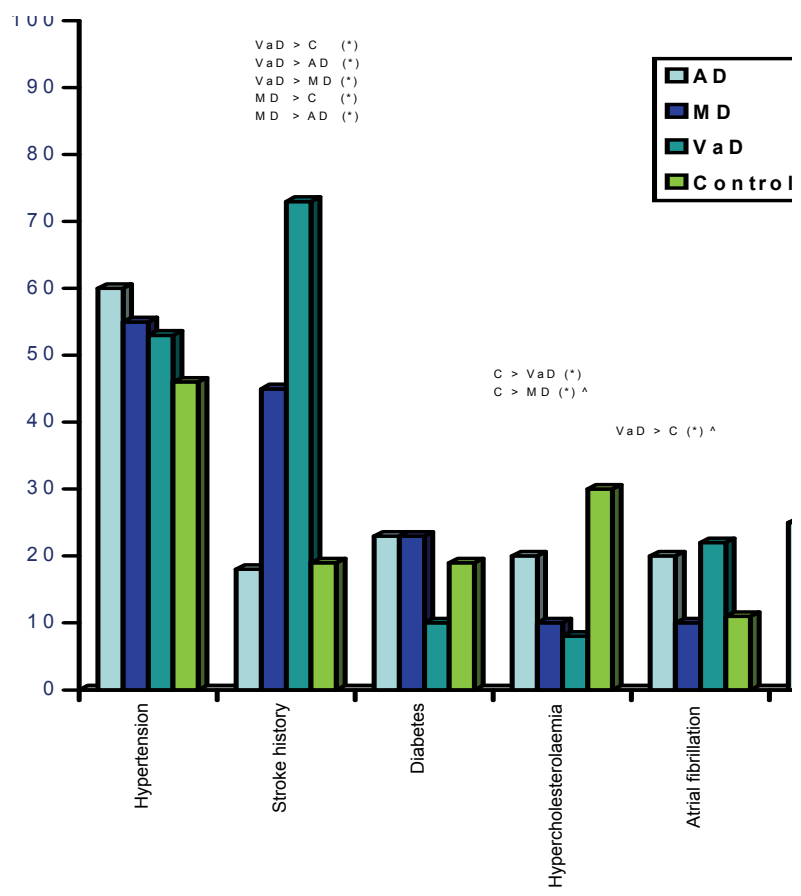

Figure 1. Distribution of vascular risk factors between groups.

Note. The percentage of occurrence of vascular risk factors in the four groups: $A D=$ Alzheimer's disease; $\mathrm{MD}=$ mixed dementia; $\mathrm{VaD}=$ vascular dementia and corresponding controls. Significant differences $\left({ }^{*}\right)$ are shown above the columns. ${ }^{\wedge}=$ the differences in hypercholesterolaemia and atrial fibrillation are solely attributable to the prevalence in the female cases (see Table 4). 


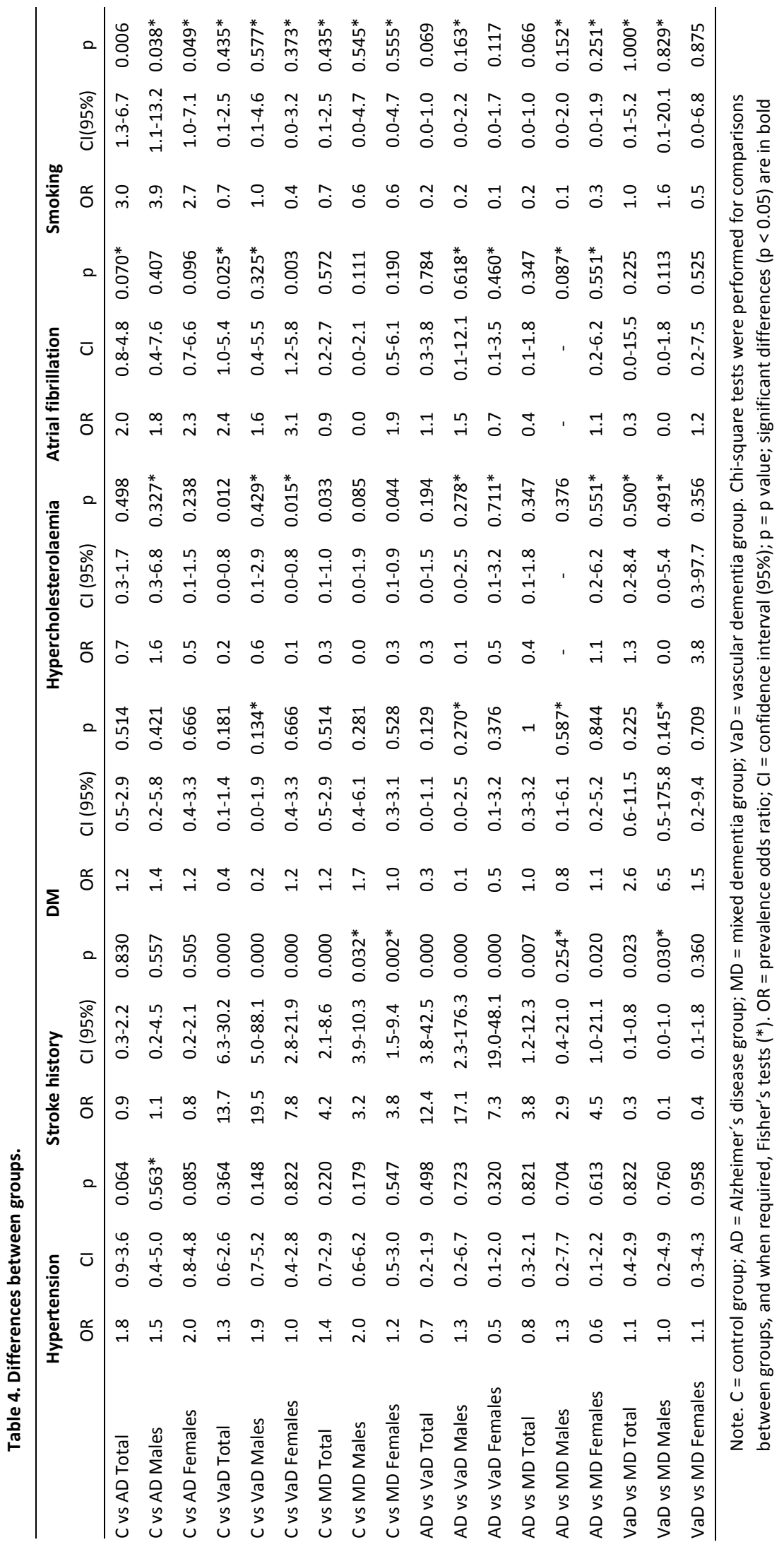




\section{Discussion}

In this clinico-neuropathological study, we compared the presence of vascular risk factors not only between $A D, V a D$ and $M D$ cases (disease groups), but also between the disease groups and elderly Dutch control groups of similar age. The importance of the latter comparison was that it might detect specific causal cofactors (amenable to preventive treatment) for $A D$ and $V a D$. The main results of the pairwise comparisons between groups are discussed below.

$A D$ vs. control group. Our comparison between the $A D$ patients and the control group (Fig.1, Table 4) revealed no significant differences with respect to the presence of hypertension, stroke history, diabetes mellitus, hypercholesterolaemia or atrial fibrillation, with the notable exception of smoking, which was more common in $A D$ patients. This could indicate that smoking is a causal factor for AD, but smoking behaviour might also be disinhibited in $A D$, or caregivers might not discourage it in these patients. We were unable to find data in the patient records on smoking load in terms of pack years for the disease period.

$V a D$ vs. control group. the comparison between the $\mathrm{VaD}$ group and the control groups (Fig.1, Table 4) shows that a history of stroke appears to be more common in VaD. The high significance level evidently depended on the neuropathological (and clinical) definition of VaD. Previous studies have also found this positive relationship between history of stroke and VaD (Chiang et al., 2007; Erkinjuntti et al., 2007). Hypercholesterolaemia was seen to be more common in the control group than in $\mathrm{VaD}$ (and in $\mathrm{MD}$ ), while atrial fibrillation was more common in $\mathrm{VaD}$ cases. The difference in hypercholesterolaemia might be attributable to the female control subgroup, in which the prevalence of hypercholesterolaemia was much higher than in the female VaD and MD groups (compare Fig. 1 with Tables 3 and 4). If this is not a chance observation, we should explore why cholesterol levels are lower in female patients with VaD. Atrial fibrillation was significantly more common in the $\mathrm{VaD}$ group than the control group and this was apparently caused by a higher prevalence in the female VaD subgroup (see Fig. 1 and Tables 3 and 4). It remains unclear why it is especially women with $\mathrm{VaD}$ who have atrial fibrillation.

$M D$ vs. control group. Our comparison of MD with the control groups produced results similar to the comparison of $\mathrm{VaD}$ with its controls, with the exception of the prevalence of atrial fibrillation, which was not significantly different between MD cases and controls.

Comparison of the disease groups with each other did not reveal any significantly different frequencies for any of the risk factors, with the exception, again, as could be expected, for history of stroke. The largest differences in this variable were seen between $\mathrm{VaD}$ and controls, and between $\mathrm{VaD}$ and $\mathrm{AD}$. 
A look at the columns in Table 4 shows that we did not detect any statistically significant differences between the disease groups for the risk factor of hypertension. The prevalence of hypertension was relatively high, between $52.5 \%$ and $60.0 \%$ in the disease groups and $45.6 \%$ in the control group. Although none of the differences reached the significance level, the comparison between $A D$ and control groups showed a trend towards high rates of hypertension in $A D$, once again attributable to the female subgroup.

Notably, although diabetes mellitus is an important co-determinant of vascular disease, rates of diabetes were not significantly different between the disease groups or between the disease groups and controls, and there was not even any detectable trend. This might be due to the relatively small number of patients in the groups with dementia (see Table 2), but another explanation, which we consider highly plausible, is that diabetes is effectively treated in the Netherlands, which may have prevented strokes.

To the best of our knowledge, our study is the first on this topic (prevalence of several vascular risk factors in $A D, V a D$ and $M D$ ) to use a sample of cases with neuropathological confirmation of the diagnoses of dementia. Accordingly, no comparison can be made with previous studies, except with some that were performed in vivo. All in vivo studies that we found were longitudinal epidemiological investigations, and many of them supported the view that there is a relationship between vascular risk factors and dementia (Pohjasvaara et al., 1998; Kivipelto et al., 2001; Kivipelto et al., 2005; Knopman et al., 2001; Kuller et al., 2005; Reitz et al., 2008; Skoog et al., 1996). In particular, some studies examining the implications of hypertension found an association between this risk factor and late-life VaD (Lindsay et al., 1997) and AD (Skoog et al, 1996). Hypertension in midlife has been associated with $\mathrm{VaD}$ and $\mathrm{AD}$ and with the number of neuritic plaques and neurofibrillary tangles (Petrovich et al., 2000). The study by Petrovitch et al. examined the relationship between blood pressure levels and the number of neuropathological lesions of $A D$ using counts of neuritic plaques and neurofibrillary tangles as endpoints, not $A D$, which means that this study is not strictly comparable to ours. Similarly, Launer et al (Launer et al., 2001) found an association between late-life HDL cholesterol levels and the formation of neuropathological lesions of $A D$, irrespective of dementia. On the other hand, other researchers, whose studies focused on the aetiopathogenesis of dementia, found no evidence of a causal relationship between vascular risk factors and dementia (Launer et al., 2008; Purnell et al., 2009; Richard et al., 2009). Frequent clinical dementia ( $A D$, Lewy body dementia and VaD) cases are known to often comprise mixed conditions with Alzheimer's, vascular and Lewy body pathologies (Echávarri et al., 2012; Jellinger et al., 2003; Knopman et al., 2010). This would not only explain the inconsistent results of in vivo studies into the relationship between vascular risk factors and dementia, but also the difficulty of identifying vascular risk factor patterns associated with subtypes of dementia 
$(A D, V a D$ or $M D)$. In this respect, a history of stroke is a risk factor for $\mathrm{VaD}$, as has been assumed by other researchers and is supported by our findings (Erkinjuntti et al., 1988).

Some methodological issues have to be addressed. While clinical studies can be strictly controlled and prospective, neuropathological confirmation is often lacking. On the other hand, a clinico-pathological study like ours is necessarily retrospective, meaning that clinical parameters (like total serum cholesterol) are not always available or compiled consistently, and brain bank donation is not strictly controlled. Nevertheless, the availability of a neuropathological diagnosis is a considerable advantage. While Alzheimer's disease is the most frequent cause of dementia, a clinico-pathological study like ours can distinguish between pure $A D$ and VaD cases. It is important to note that establishing a neuropathological diagnosis of $\mathrm{VaD}$ is a controversial issue, since no clear criteria have so far been established in the literature (Esiri et al., 1997). In fact, prior studies based on neuropathological series of demented patients have reported low prevalence of pure $\mathrm{VaD}$, between 2 and $10 \%$. The NBB database for 1984 to 2010 includes 660 AD cases but only 40 "pure" $\mathrm{VaD}$ cases. This underlines the value of the fact that our study comprised a sample of 40 cases with pure $\mathrm{VaD}$ (Jellinger et al., 2007).

A major weakness of our study is, however, the relatively small number of cases (three times $n=40$ ), which was determined by the lack of $\mathrm{VaD}$ cases. We recognise that these small numbers may explain why we found so few statistically significant differences between groups for the vascular risk factors considered, and many relationships remained unclear, except for some indications from the nonsignificant trends we detected (see Fig. 1 and Table 4). We could not prove that there are causal relations between risk factors and $A D, V a D$ and $M D$, but, on the other hand, neither could we disprove them. Therefore, future meta-analytical studies are needed for further statistical testing.

Another weakness of our study is the partial lack of homogeneity in both of the samples (demented and control) we compared. Despite differences in the selection processes of the patients included in the study sample and the lack of neuropathological assessment among the controls, we still consider that our comparison of these two samples has yielded results that are worthy of serious consideration. On the one hand, we assume that the control groups include two different subgroups: a subgroup that will never become demented and a non-demented subgroup that will become demented in the future. On the other hand, all subjects in the disease groups were demented. Thus, we consider that if risk factors play a role in dementia, they would be more concentrated in the disease groups, as the control groups included subgroups of people who would never become demented. Moreover, we used controls of ages similar to those of the disease groups and have also examined men and women separately, making both samples more homogeneous.

We conclude that our clinico-neuropathological study was unable to detect increased prevalences of vascular risk factors in $A D$ except for a higher proportion of 
smokers. Among VaD patients, we observed that a history of stroke was more common in the total group (men and women).The rates of hypercholesterolaemia were higher in the female controls than in the female VaD patients, and the rates of atrial fibrillation were higher in the female $\mathrm{VaD}$ patients than in the female controls. Overall, however, our approach using neuropathological confirmation of dementia diagnoses seemed to make most of the previously reported group differences in vascular risk factors disappear. We argue that none of the risk factors we examined may be related to the presence of dementia, except for stroke history in VaD.

\section{References}

Arvanitakis Z, Wilson RS, Bienias JL, Evans DA, Bennett DA. 2004. Diabetes mellitus and risk of Alzheimer disease and decline in cognitive function. Arch Neurol 61(5):661-6.

Braak H, Alafuzoff I, Arzberger T, Kretzschmar H, Del Tredici K. 2006. Staging of Alzheimer diseaseassociated neurofibrillary pathology using paraffin sections and immunocytochemistry. Acta Neuropathol 112(4):389-404.

Braak H, Braak E. 1997. Frequency of stages of Alzheimer-related lesions in different age categories. Neurobiol Aging 18(4):351-7.

Braak H, Braak E. 1990. Neurofibrillary changes confined to the entorhinal region and an abundance of cortical amyloid in cases of presenile and senile dementia. Acta Neuropathol 80(5):479-86.

Braak H, Braak E. 1991. Neuropathological stageing of Alzheimer-related changes. Acta Neuropathol 82(4):239-59.

Breteler MM, Van Swieten JC, Bots ML, Grobbee DE, Claus JJ, Van den Hout JH, Van Harskamp F, Tanghe HL, De Jong PT, Van Gijn J, et al. 1999. Cerebral white matter lesions, vascular risk factors, and cognitive function in a population-based study: the Rotterdam Study. Neurology 44(7):1246-52.

Brun A. 1994. Pathology and pathophysiology of cerebrovascular dementia: pure subgroups of obstructive and hypoperfusive etiology. Dementia 5(3-4):145-7.

Brun A GL. 1988. Zerebrovaskulare Erkrankungen. Kisker KP, Lauter H, Meyer J-E, Muller C, Stromgren E, eds; Psychiatrie der Gegenwart Organische Psychosen (Springer Verlag: Berlin, Heidelberg) 6:25395.

Brunnstrom H, Englund E. 2009. Clinicopathological concordance in dementia diagnostics. Am J Geriatr Psychiatry 17(8):664-70.

Cherubini A, Lowenthal DT, Paran E, Mecocci P, Williams LS, Senin U. 2007. Hypertension and cognitive function in the elderly. Am J Ther 14(6):533-54.

Chiang CJ, Yip PK, Wu SC, Lu CS, Liou CW, Liu HC, Liu CK, Chu CH, Hwang CS, Sung SF, Hsu YD, Chen CC, Liu SI, Yan SH, Fong CS, Chang SF, You SL, Chen CJ. 2007. Midlife risk factors for subtypes of dementia: a nested case-control study in Taiwan. Am J Geriatr Psychiatry 15(9):762-71.

Echávarri C, Burgmans S, Caballero MC, García-Bragado F, Verhey FRJ, Uylings HBM. 2012. Cooccurrence of different pathologies in dementia: implications for dementia diagnosis. Journal of Alzheimer's Disease 30 (4): 909-917.

Erkinjuntti T. 2007. Vascular cognitive deterioration and stroke. Cerebrovasc Dis 24 Suppl 1:189-94.

Erkinjuntti T, Haltia M, Palo J, Sulkava R, Paetau A. 1988. Accuracy of the clinical diagnosis of vascular dementia: a prospective clinical and post-mortem neuropathological study. J Neurol Neurosurg Psychiatry 51(8):1037-44.

Esiri MM, Wilcock GK, Morris JH. 1997. Neuropathological assessment of the lesions of significance in vascular dementia. J Neurol Neurosurg Psychiatry 63(6):749-53. 
Heeringa J, Van der Kuip DA, Hofman A, Kors JA, Van Herpen G, Stricker BH, Stijnen T, Lip GY, Witteman JC. 2006. Prevalence, incidence and lifetime risk of atrial fibrillation: the Rotterdam study. Eur Heart J 27(8):949-53.

Henon H, Durieu I, Guerouaou D, Lebert F, Pasquier F, Leys D. 2001. Poststroke dementia: incidence and relationship to prestroke cognitive decline. Neurology 57(7):1216-22.

Jellinger KA. 2007. The enigma of mixed dementia. Alzheimers Dement 3(1):40-53.

Jellinger KA, Attems J. 2003. Incidence of cerebrovascular lesions in Alzheimer's disease: a postmortem study. Acta Neuropathol 105(1):14-7.

Kalaria RN. 2000. The role of cerebral ischemia in Alzheimer's disease. Neurobiol Aging 21(2):321-30.

Kivipelto M, Helkala EL, Hanninen T, Laakso MP, Hallikainen M, Alhainen K, Soininen H, Tuomilehto J, Nissinen A. 2001. Midlife vascular risk factors and late-life mild cognitive impairment: A populationbased study. Neurology 56(12):1683-9.

Kivipelto M, Ngandu T, Fratiglioni L, Viitanen M, Kareholt I, Winblad B, Helkala EL, Tuomilehto J, Soininen $\mathrm{H}$, Nissinen A. 2005. Obesity and vascular risk factors at midlife and the risk of dementia and Alzheimer disease. Arch Neurol 62(10):1556-60.

Knopman D, Boland LL, Mosley T, Howard G, Liao D, Szklo M, McGovern P, Folsom AR. 2001. Cardiovascular risk factors and cognitive decline in middle-aged adults. Neurology 56(1):42-8.

Knopman DS, Roberts R. 2010. Vascular risk factors: imaging and neuropathologic correlates. J Alzheimers Dis 20(3):699-709.

Kovacs GG, Alafuzoff I, Al-Sarraj S, Arzberger T, Bogdanovic N, Capellari S, Ferrer I, Gelpi E, Kovari V, Kretzschmar H, Nagy Z, Parchi P, Seilhean D, Soininen H, Troakes C, Budka H. 2008. Mixed brain pathologies in dementia: the BrainNet Europe consortium experience. Dement Geriatr Cogn Disord 26(4):343-50.

Kuller LH, Lopez OL, Jagust WJ, Becker JT, DeKosky ST, Lyketsos C, Kawas C, Breitner JC, Fitzpatrick A, Dulberg C. 2005. Determinants of vascular dementia in the Cardiovascular Health Cognition Study. Neurology 64(9):1548-52.

Launer LJ, Masaki K, Petrovitch H, Foley D, Havlik RJ. 1995. The association between midlife blood pressure levels and late-life cognitive function. The Honolulu-Asia Aging Study. JAMA 274(23):1846-51.

Launer LJ, Petrovitch H, Ross GW, Markesbery W, White LR. 2008. AD brain pathology: vascular origins? Results from the HAAS autopsy study. Neurobiol Aging 29(10):1587-90.

Launer LJ, White LR, Petrovitch H, Ross GW, Curb JD. 2001. Cholesterol and neuropathologic markers of AD: a population-based autopsy study. Neurology 57(8):1447-52.

Lindsay J, Hebert R, Rockwood K. 1997. The Canadian Study of Health and Aging: risk factors for vascular dementia. Stroke 28(3):526-30.

Luchsinger JA, Reitz C, Honig LS, Tang MX, Shea S, Mayeux R. 2005. Aggregation of vascular risk factors and risk of incident Alzheimer disease. Neurology 65(4):545-51.

Luchsinger JA, Tang MX, Shea S, Mayeux R. 2004. Hyperinsulinemia and risk of Alzheimer disease. Neurology 63(7):1187-92.

Luchsinger JA, Tang MX, Stern Y, Shea S, Mayeux R. 2001. Diabetes mellitus and risk of Alzheimer's disease and dementia with stroke in a multiethnic cohort. Am J Epidemiol 154(7):635-41.

O'Brien JT, Erkinjuntti T, Reisberg B, Roman G, Sawada T, Pantoni L, Bowler JV, Ballard C, DeCarli C, Gorelick PB, Rockwood K, Burns A, Gauthier S, DeKosky ST. 2003. Vascular cognitive impairment. Lancet Neurol 2(2):89-98.

Ott A, Breteler MM, Van Harskamp F, Stijnen T, Hofman A. 1998. Incidence and risk of dementia. The Rotterdam Study. Am J Epidemiol 147(6):574-80.

Ott A, Stolk RP, Van Harskamp F, Pols HA, Hofman A, Breteler MM. 1999. Diabetes mellitus and the risk of dementia: The Rotterdam Study. Neurology 53(9):1937-42.

Parkkinen L, Pirttila T, Alafuzoff I. 2008. Applicability of current staging/categorization of alpha-synuclein pathology and their clinical relevance. Acta Neuropathol 2008;115(4):399-407. 
Petrovitch H, White LR, Izmirilian G, Ross GW, Havlik RJ, Markesbery W, Nelson J, Davis DG, Hardman J, Foley DJ, Launer LJ. 2000. Midlife blood pressure and neuritic plaques, neurofibrillary tangles, and brain weight at death: the HAAS Honolulu-Asia aging Study. Neurobiol Aging 21(1):57-62.

Pohjasvaara T, Erkinjuntti T, Ylikoski R, Hietanen M, Vataja R, Kaste M. 1998. Clinical determinants of poststroke dementia. Stroke 29(1):75-81.

Purnell C, Gao S, Callahan CM, Hendrie HC. 2009. Cardiovascular risk factors and incident Alzheimer disease: a systematic review of the literature. Alzheimer Dis Assoc Disord 23(1):1-10.

Reitz C, Luchsinger JA, Mayeux R. 2008. Vascular disease and cognitive impairment. Expert Rev Neurother 8(8):1171-4.

Richard E, Kuiper R, Dijkgraaf MG, Van Gool WA. 2009. Vascular care in patients with Alzheimer's disease with cerebrovascular lesions-a randomized clinical trial. J Am Geriatr Soc 57(5):797-805.

Skoog I, Lernfelt B, Landahl S, Palmertz B, Andreasson LA, Nilsson L, Persson G, Oden A, Svanborg A. 1996. 15-year longitudinal study of blood pressure and dementia. Lancet 347(9009):1141-5.

Trojanowski JQ, Lee VM. 2003. Parkinson's disease and related alpha-synucleinopathies are brain amyloidoses. Ann N Y Acad Sci 991:107-10.

Van de Lisdonk E. 2012. Personal communication. Coordinator Continue Morbiditeits Registratie Nijmegen.

Van Rossum CT, Van de Mheen H, Witteman JC, Hofman A, Mackenbach JP, Grobbee DE. 2000. Prevalence, treatment, and control of hypertension by sociodemographic factors among the Dutch elderly. Hypertension 35(3):814-21.

Van Vliet P, Westendorp RG, Van Heemst D, De Craen AJ, Oleksik AM. 2010. Cognitive decline precedes late-life longitudinal changes in vascular risk factors. J Neurol Neurosurg Psychiatry 81(9):1028-32.

Verschuuren M. 2012. Personal communication. Nederland de Maat Genomen RIVM (National Institute for Public Health and the Environment).

Zeegers T. 2012. Personal communication. Dutch continuous survey of smoking habits by STIVORO. 



\section{CHAPTER 5}

\section{Neuropsychiatric symptoms in Alzheimer's disease and vascular dementia}

C. Echávarri, S. Burgmans, H.B.M.Uylings, M. J. Cuesta, V. Peralta, W. Kamphorst, A. J.M. Rozemuller and F. R.J. Verhey. Neuropsychiatric symptoms in Alzheimer's disease and vascular dementia. Journal of Alzheimer's disease (2013) 33(3). 
Neuropsychiatric symptoms (NPSs) have a large impact on the quality of life of patients with dementia. A few studies have compared neuropsychiatric disturbances between dementia subtypes, but the results were conflicting. In the present study, we investigated whether the prevalence of NPSs differs between Alzheimer's disease $(A D)$ and vascular dementia $(V a D)$. The merit of our study is that we used clinical as well as histopathological information to differentiate between dementia subtypes. This retrospective descriptive study comprised 80 brains obtained from donors to the Netherlands Brain Bank (NBB) between 1984 and 2010. These donors were diagnosed post-mortem with $A D(n=40)$ or $\operatorname{VaD}(n=40)$. We assessed the presence of NPSs by reviewing the information found in the patients' medical files. The most prevalent symptom in the sample as a whole was agitation (45 cases, $57.0 \%)$, followed by depression $(33,41.2 \%)$ and anxiety $(28,35.4 \%)$. Our study tried to contribute to the discussion by including, for the first time in the literature, a sample of $A D$ and $V a D$ patients with neuropathologically confirmed diagnoses. Since no significant differences were found between $A D$ and $V a D$ patients, we suggest that the prevalence of NPSs cannot be predicted from the dementia diagnosis of $A D$ or $V a D$. 


\section{Introduction}

Neuropsychiatric symptoms (NPSs) are increasingly recognized as an important and intrinsic aspect of the dementia syndrome $[1,2,3,4,5,6]$. These symptoms have a large impact on the quality of life of patients with dementia, and have been associated with increased caregiver burden, more rapid progression of cognitive and functional decline, earlier institutionalization and even increased mortality [7]. Several studies have found that NPSs are common in patients with Alzheimer's disease $(A D)$ and vascular dementia $(\operatorname{VaD})[8,9,10,11,12,13,14,15]$, with apathy, depression, anxiety and agitation/aggression having been most frequently reported $[16,9,18,4,19,6,20,21,22,23]$.

It is important to know whether different types of dementia present different neuropsychiatric profiles, because these differences could affect caregiver distress [15]. In addition, this knowledge may lead to more effective treatment, and to further insights into brain-behaviour relationships. A few studies have compared neuropsychiatric disturbances between dementia subtypes, and so far, the results have been conflicting. Some studies found higher prevalences of NPSs in VaD, including affective disturbances such as depression, anxiety or agitation $[16,9,24,25,13]$; other studies found higher prevalences in $A D$, including anxiety and agitation $[10,18]$; and still others found no differences between groups $[12,21,14]$. This makes it difficult to establish a pattern of NPSs in different subtypes of dementia.

These contradictory results may be due to a lack of accuracy in diagnosing dementia subtypes $[26,4,27,20,28,22,29]$. Clinical diagnoses made in vivo often differ from the neuropathological diagnoses established post-mortem [30,31]. Hence, comparisons of NPSs between dementia subtypes should preferably include neuropathological information. In the present study, we investigated whether the prevalence of NPSs differs between AD and VaD. We focussed on 12 psychiatric symptoms, which are those assessed by Neuropsychiatric Inventory [32] (delusions, hallucinations, agitation, depression, anxiety, euphoria, apathy, disinhibition, irritability, aberrant motor behaviour, night-time behavioural disturbances and appetite changes). We examined the prevalence of NPSs in 80 patients for whom a neuropathological diagnosis of $A D$ or $\mathrm{VaD}$ had been established. The merit of our study is that we used clinical as well as histopathological information to differentiate between dementia subtypes.

\section{Materials and Methods}

\section{Participants}

This retrospective descriptive study comprised 80 brains obtained from donors of the Netherlands Brain Bank (NBB) between 1984 and 2010. During this period of 
time, 660 cases of $A D$ and 40 cases of $\mathrm{VaD}$ were diagnosed the NBB. All $40 \mathrm{VaD}$ cases were included in this study, while $40 \mathrm{AD}$ cases were matched for age with the VaD cases. Demographic data are presented in Table 1 . The clinical dementia rating (CDR) score was assessed before death; presence of comorbidity included the presence of any vascular risk factor (hypertension, diabetes, hyperlipidaemia or atrial fibrillation) or any systemic disorder.

Table 1. Demographic data

\begin{tabular}{lccc}
\hline & VaD (n=40) & AD (n=40) & $p$ \\
\hline Age (years); mean (SD) & $77.7(11.1)$ & $77.8(2.7)$ & 0.947 \\
Sex (\% women) & 52.5 & 60.0 & 0.254 \\
Duration of illness (years); mean (SD) & $8(4.8)$ & $6(3.2)$ & 0.037 \\
Number of NPSs; mean (SD) & $2.3(1.6)$ & $2.2(1.2)$ & 0.836 \\
CDR score prior to death & $2.8(0.3)$ & $2.9(0.3)$ & 0.251 \\
Prior history of depression $\mathrm{n}(\%)$ & $5(16.6)$ & $3(7.5)$ & 0.456 \\
Comorbidity $\mathrm{n}$ (\%) & $38(95.0)$ & $39(97.5)$ & 0.556 \\
Nursing home $\mathrm{n}$ (\%) & $14(35.0)$ & $21(52.5)$ & 0.114 \\
Medication - sleep disorder $\mathrm{n}(\%)$ & $8(20.0)$ & $13(32.5)$ & 0.598 \\
Medication - antidepressant $\mathrm{n}(\%)$ & $9(22.5)$ & $9(22.5)$ & 1.000 \\
Medication - behavioural disorder $\mathrm{n}(\%)$ & $17(42.5)$ & $13(32.5)$ & 0.355 \\
\hline
\end{tabular}

The group differences (between $\mathrm{VaD}$ and $\mathrm{AD}$ ) were calculated with ANOVA for age and duration of illness, and with Chi-square for sex, previous history of depression, presence of comorbidity, living in a nursing home, antidepressant medication, and medication for sleep disorder or for behavioural disorders. The Mann-Whitney test was used for the CDR score. VaD = vascular dementia; AD = Alzheimer's disease; duration of illness = years from onset of symptoms to death; $p=p$-value; $S D=$ standard deviation.

All clinical data were obtained from the patient's GP, the doctor at the nursing home, neurologists or psychiatrists. All patients were diagnosed with dementia, defined as any irreversible and progressive cognitive impairment affecting at least one cognitive domain and interfering with the patient's daily life. Patients were selected according to the neuropathological diagnoses (VaD and AD); all of them had a clinical diagnosis of dementia, but not all neuropathological diagnoses were in agreement with clinical diagnoses. In fact, the clinical diagnoses of the 40 cases with a neuropathological diagnosis of $\mathrm{VaD}$ were as follows: 25 (62.5\%) $\mathrm{VaD}, 7$ (17.5\%) AD, 6 (15\%) mixed dementia, 1 (2.5\%) frontotemporal lobar dementia and $1(2.5 \%)$ Lewy body dementia, while the clinical diagnoses of the 40 cases with a neuropathological diagnosis of $A D$ were as follows: 28 (70\%) AD, 8 (20\%) VaD, 3 $(7.5 \%)$ Lewy body dementia and 1 (2.5\%) frontotemporal lobar dementia. 
The neuropathological diagnoses were obtained by an experienced neuropathologist. The criteria used for neuropathological diagnoses were as follows: AD was diagnosed according to the criteria described by Braak and Braak, based on the presence, density and distribution of cortical neuritic plaques [33,34] and tangle pathology [35,34]. Braak stages of AD-related neurofibrillary tangle pathology were between IV and VI (8 cases [20\%] at Braak stage IV, 14 [35\%] at stage V, and 18 [45\%] at stage $\mathrm{VI})$. $\mathrm{VaD}$ was diagnosed according to the classification of Brun and Gustafson [17] and Brun [36] with a Braak stage for neurofibrillary tangles $\leq$ III. Of the 40 cases of $\mathrm{VaD}, 16$ showed strategic small vessel infarcts ( 7 in the caudate, 7 in the thalamus and 2 in the parietal lobe), 19 showed territorial infarcts (caused by large vessel pathology) and 21 showed white matter rarefaction and/or lacunar infarcts. The severity of the vascular pathology (i.e. staging of the vascular lesions) was assessed according to the classification used by Jellinger et al. (see Table 2) [37], ranging from 0 to 3 . In our VaD sample, 19 brains had a score of 3, 17 participants a score of 2 and 4 a score of 1 . In the AD sample, 38 participants showed no vascular lesions (VL) (score of 0 ) and 2 a score of 1 , but no strategic infarcts were found, and in these two cases VL was considered not to be severe enough to have contributed to the dementia. In order to obtain a more homogeneous distribution of participants in the $\mathrm{VaD}$ group, two subgroups were distinguished: 19 brains with large vessel vascular disease (LV VaD) (mean age $=81.3$, SD age $=8$, percentage women $=52$ ), and 21 brains with small vessel vascular disease (SV VaD) (mean age $=74.4$, SD age $=12.6$, percentage women $=52.4$ ). LV VaD was diagnosed when the brain showed more than one large vessel infarct; SV VaD was diagnosed when moderate (subjectively assessed) white matter damage and more than one lacunar infarct were present (this group also included vasculitis [ $n=1]$, amyloid angiopathy $[n=1]$ and isolated strategic infarcts).

Exclusion criteria were neuropathological diagnoses of other neurodegenerative diseases than $A D$ or $\mathrm{VaD}$ (other tauopathies, Lewy body pathology), mixed $A D$ and $V a D$, and the presence of any tumoural lesion. Written informed consent was obtained from all patients or their relatives.

\section{Neuropsychiatric assessment}

We assessed the presence of 12 NPSs - delusions, hallucinations, agitation, depression, anxiety, euphoria, apathy, disinhibition, irritability, aberrant motor behaviour, night-time behavioural disturbances and appetite changes - based on the information in the patients' medical files. The clinical information was collected as follows: symptoms were considered to be present when their presence was recorded in the medical files or in case of any treatments (e.g. antidepressants) for such symptoms, and absent when no mention of the symptom was found in the patient's file. In many cases, the patient records did not allow a distinction to be made between depressive symptoms and depressive disorders, nor was sufficient information available on the severity of NPSs. Information was collected regarding the frequency of symptoms, the tendency of symptoms to recur or persist, and the medication 
used to treat the NPS. These medications included three groups. The first consisted of those used in sleep disorders, including short-acting benzodiazepines and trazodone, which is an antidepressant with sedative properties, while the second group comprised antidepressants, including selective serotonin uptake inhibitors (SSRIs) and others, used to treat depression or depressive symptoms, anxiety and irritability. The third group comprised medications for behavioural disorders, which are neuroleptic (typical and atypical), usually used to treat agitation. Atypical antipsychotic agents (risperidone, olanzapine, quetiapine) were generally used more often than the typical ones. In some cases medication for an NPS was used though the presence of the symptom was not reported the medical file, and no information was provided about the symptom or symptoms that this medication was prescribed for. In view of this, we set the following criteria for determining the presence of a symptom, based on the most common use of medications for NPSs: users of antidepressants were regarded as suffering from depressive symptoms, users of benzodiazepines or trazodone at night were regarded as suffering from sleep or night-time behavioural disturbances, users of benzodiazepines were regarded as suffering from anxiety and users of neuroleptics were regarded as suffering from agitation. A symptom was considered to be recurrent when more than one episode was reported, and was considered to be persistent when the symptom was reported to last for more than one week. The average time between the last assessment of NPSs and death was 5.6 months, with a range of 1 month to 2 years.

\section{Histopathological procedure}

Macroscopic assessment of the brain included photographs. The right hemisphere was fixed in $4 \%$ formaldehyde for 3 weeks. The left hemisphere was freshly dissected in particular pieces for the Netherlands Brain Bank applicants. For diagnostic purposes, the following regions were dissected from the fixed right hemisphere and embedded in paraffin: frontal, cingulate, insular, temporal, parietal and occipital cortices, including deep white matter; basal ganglia; thalamus; amygdala; hippocampus and entorhinal areas; mesencephalon including substantia nigra; locus coeruleus; medulla oblongata; cerebellum and cervical spinal cord (level C1 or C2). If necessary, selected parts of the fixed remnants of the left hemisphere were also analysed. Cortical regions were routinely stained with HE, Bodian or Gallyas, methenamine-silver, and Congo. Tau (AT 8) immunohistochemistry was applied routinely in every case. Immunohistochemistry for alpha-synuclein was routinely performed to identify Lewy body pathology, while beta A4, prion protein, ubiquitin and TDP43 immunohistochemistry were used when required.

\section{Statistical analysis}

Statistical analyses were performed using the Statistical Package for the Social Sciences (SPSS Inc, Chicago), version 16.0 for Windows. Demographic data were compared between groups, using ANOVA (General Linear Model; GLM) for continuous variables such as mean age and duration of illness; chi-square for categorical 
variables such as sex, previous history of depression, presence of comorbidity, living in a nursing home, antidepressant medication, medication for sleep disorder or medication for behavioural disorders; and Mann-Whitney for ordinal variables such as CDR score. Logistic regression analysis was used to test the association between each neuropsychiatric symptom (independent variable) and the type of dementia (dependent variable), including duration of illness and age as covariates. Results are presented as odds ratios (OR) with $95 \%$ confidence intervals $(95 \% \mathrm{Cl})$. The significance level was set at $p<0.05$ for all analyses.

\section{Results}

The only statistically significant difference in demographic variables between the two diagnostic groups regarded duration of illness $(p<0.05)$. The most prevalent symptom in the sample as a whole was agitation (45 cases, $57.0 \%$ ), followed by depression $(33,41.2 \%)$ and anxiety $(28,35.4 \%)$. Figure 1 shows the prevalence of each NPS in the two groups, while the tendency to persist and the need for pharmacological treatment are shown in Table 3. No significant differences between the groups were found, although depression was slightly more frequent in the $\mathrm{VaD}$ group (50\%, vs. $32.2 \%$ in the $A D$ group). The values of $\mathrm{OR}, \mathrm{Cl}(95 \%)$ and $\mathrm{p}$ for differences between groups were: delusions (OR 0.4; $\mathrm{Cl}[95 \%] 0.0-1.9 ; \mathrm{p}=0.266$ ); hallucinations (OR 1.1; $\mathrm{Cl}$ [95\%] 0.3-1.9; $\mathrm{p}=0.849$ ); agitation (OR 1.6; $\mathrm{Cl}$ [95\%] 0.6-4.1; $\mathrm{p}$ $=0.290$ ); depression (OR 0.5; $\mathrm{Cl}$ [95\%] 0.2-1.3; $\mathrm{p}=0.202$ ); anxiety (OR 1.5; $\mathrm{Cl}$ [95\%] 0.5-3.8; $\mathrm{p}=0.392$ ); euphoria (OR 0.6; $\mathrm{Cl}$ [95\%] 0.0-7.6; $\mathrm{p}=0.710$ ); apathy (OR 0.4; $\mathrm{Cl}$ [95\%] 0.1-1.3; $\mathrm{p}=0.153$ ); disinhibition (OR 0.1; $\mathrm{Cl}$ [95\%] 0.0-1.0; $\mathrm{p}=0.063$ ); irritability (OR 0.4; Cl [95\%] 0.0-2.3; $\mathrm{p}=0.312$ ); aberrant motor behaviour (OR $1.2 ; \mathrm{Cl}$ [95\%] 0.3-4.3; $\mathrm{p}=0.621$ ); night-time behavioural disturbances (OR 2.7; $\mathrm{Cl}$ [95\%] $0.5-12.7 ; p=0.193$ ) and appetite changes (OR 1.2; $\mathrm{Cl}[95 \%] 0.3-4.3 ; \mathrm{p}=0.601$ ). When we excluded duration of illness as a covariate from the analysis, we still did not find significant differences. Results regarding the subgroups of $\mathrm{VaD}$ showed no differences between the two subgroups (LV VaD and SV VaD) or between each subgroup and AD. 


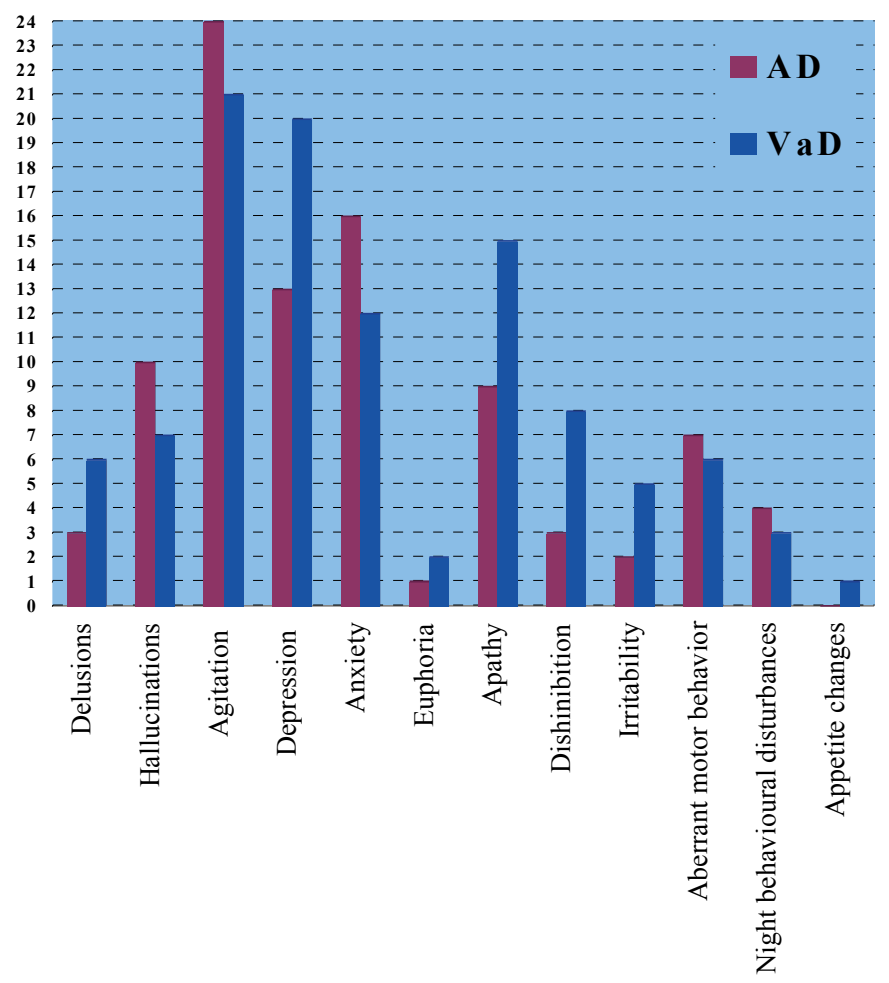

Figure 1. Prevalence of neuropsychiatric symptoms in $A D$ and $V a D$

Distribution, in numbers, of neuropsychiatric disturbances; $A D=$ Alzheimer's disease; $V a D=$ vascular dementia.

Table 2. Classification of vascular lesions (VL)

$0 \quad$ No concomitant VL

1 Minimal VL: 1-2 small lacunae, mild-moderate cerebral amyloid angiopathy (CAA), mild VL, mild leukoencephalopathy

2 Moderate VL: >2 lacunae, severe subcortical lacunar state, severe CAA with moderate VL, diffuse white matter lesions

3 Severe VL: (a) Old infarcts, multiple old microinfarcts or haemorrhages, hippocampal sclerosis; (b) acute ischaemic infarcts, haemorrhages (<1-2 days old) 
Table 3. Numbers of NPSs, tendency to persist and need for medication in each group.

\begin{tabular}{|c|c|c|c|c|c|c|}
\hline \multirow[b]{3}{*}{ Delusions } & \multicolumn{3}{|c|}{$A D(n=40)$} & \multicolumn{3}{|c|}{$\operatorname{VaD}(n=40)$} \\
\hline & $\mathrm{n}$ & $\begin{array}{c}\text { Recurrent } \\
\text { or persistent } \\
\text { cases }\end{array}$ & $\begin{array}{l}\text { Treated with } \\
\text { medication }\end{array}$ & $\mathrm{n}$ & $\begin{array}{c}\text { Recurrent } \\
\text { or persistent } \\
\text { cases }\end{array}$ & $\begin{array}{l}\text { Treated with } \\
\text { medication }\end{array}$ \\
\hline & 3 & 0 & 0 & 6 & 2 & 0 \\
\hline Hallucinations & 10 & 6 & 5 & 7 & 4 & 2 \\
\hline Agitation & 24 & 20 & 12 & 21 & 18 & 17 \\
\hline Depression & 13 & 6 & 9 & 20 & 10 & 9 \\
\hline Anxiety & 16 & 14 & 12 & 12 & 9 & 10 \\
\hline Euphoria & 1 & 1 & 0 & 2 & 0 & 0 \\
\hline Apathy & 9 & 9 & 0 & 15 & 12 & 0 \\
\hline Dishinibition & 3 & 2 & 0 & 8 & 1 & 0 \\
\hline Irritability & 2 & 2 & 2 & 5 & 3 & 3 \\
\hline Aberrant motor behaviour & 7 & 6 & 5 & 6 & 6 & 5 \\
\hline $\begin{array}{l}\text { Night-time behavioural } \\
\text { disturbances }\end{array}$ & 4 & 4 & 2 & 3 & 3 & 3 \\
\hline Appetite changes & 0 & 0 & 0 & 1 & 1 & 0 \\
\hline
\end{tabular}

$\mathrm{AD}=$ Alzheimer's disease; $\mathrm{VaD}=$ Vascular dementia. $\mathrm{A}$ symptom was considered to be recurrent when more than one limited episode was reported, and was considered to be persistent when the symptom was reported to last for more than one week.

\section{Discussion}

Our study did not reveal any significant differences in the prevalence of NPSs between $A D$ and $\mathrm{VaD}$. A few earlier studies have compared NPSs in $A D$ and $V a D$ using the Neuropsychiatric Inventory (NPI). These studies found no consistent differences between dementia subtypes either: Aharon-Peretz et al. [16], Hsieh et al. [25] and Ballard et al. [9] found higher prevalences of apathy, agitation, depression and anxiety in VD; Caputo et al. [18] found a higher prevalence of anxiety in AD; and Fuh et al. [4], Srikanth et al. [21], Johnson et al. [12] and Hargrave et al. [19] found no differences between the two groups. These were all in vivo studies, which did not use neuropathological confirmation of the diagnoses, increasing the risk of misdiagnoses or comorbidity of other pathologies. The added value of the present retrospective study is that, although we could not use standardized tools for assessing the presence and severity of NPSs, we did use neuropathological confirmation of the diagnosis, and can therefore claim to have included "pure" cases of vascular and Alzheimer type dementia. Besides, it is routine clinical practice to ask questions about NPSs in history-taking, which means that the information about the presence or absence of NPSs that we obtained from the patients' files was, from our point of view, accurate and reliable. It is important to take into account that some symp- 
toms are likely to have been gathered with greater reliability than others. In particular, we presume that depression, anxiety and agitation, which are frequent and easily detectable, will have received greater attention from the clinicians in their routine clinical practice than the other symptoms.

Our retrospective study thus had two important limitations, the first one regarding the lack of standardized tools for clinical variables and the second regarding the small number of cases; both could have resulted in a lack of power to observe any differences. Although a trend towards a difference between $A D$ and $V a D$ might be suggested for some symptoms (depression, apathy, disinhibition), Figure 1 shows that the above limitations may explain why we did not find any statistically significant differences. We failed to prove that there are causal relations between NPSs and subtypes of dementia, but neither could we reject them. On the other hand, our study had the advantage of the availability of post-mortem tissue and neuropathological confirmation of the diagnoses.

We would like to draw attention to the higher (though not significantly so) prevalence of depression among the $\mathrm{VaD}$ patients in our study. Depression has been attributed to disruptions of cortico-subcortical circuits, involving basal ganglia, thalamus and frontal lobes. Vascular damage can disturb these corticosubcortical circuits with lacunar lesions and white matter ischaemic injury $[9,38,39]$. Although these pathological processes are also present in $A D$, they are more prominent in $\mathrm{VaD}$ [40], which might explain why the prevalence of depression was slightly higher in our VaD group.

As regards the $\mathrm{VaD}$ group, we had surmised that neuropsychiatric disturbances might depend on the type of $V L$, but we did not find any differences either between the subgroups of $\mathrm{VaD}$ or between these subgroups and the AD group. This lack of significant differences might be due again to the small size of the sample. In view of this, we have to take into account the low prevalence of pure $\mathrm{VaD}$ in the general population. The NBB sample included only 40 cases diagnosed with pure $\mathrm{VaD}$, while 660 AD cases were diagnosed in the same period of time. We also note the considerable heterogeneity of $\mathrm{VL}$ in our $\mathrm{VaD}$ group. Since $\mathrm{VaD}$ is quite a rare diagnosis, it was impossible for us to compose more homogeneous vascular groups that were large enough for proper statistical analyses. Therefore, our conclusions apply to the heterogeneous group which is called $\mathrm{VaD}$ but which is not a pure nosologic entity. In this respect, our approach is similar to that used in previous studies $[40,41]$.

In conclusion, our data suggests that NPSs are related to dementia in a nonspecific way, that is, $A D$ and $V a D$ patients do not differ significantly in terms of the 12 NPSs we included in our analysis. It is therefore important to investigate these NPSs in each demented patient individually, in order to improve the therapeutic approach and decrease caregiver burden as much as possible. We want to stress that previous studies were based on clinical diagnoses, which were probably often not accurate, especially with respect to VaD. Our study is the first one in the litera- 
ture to provide an assessment of NPSs in subtypes of dementia based on clinical as well as neuropathological diagnoses.

\section{References}

1. Borroni B, Costanzi C, Padovani A (2010) Genetic susceptibility to behavioural and psychological symptoms in Alzheimer disease. Curr Alzheimer Res 7(2), 158-64.

2. Cummings JL, Diaz C, Levy M, Binetti G, Litvan II (1996) Neuropsychiatric Syndromes in Neurodegenerative Disease: Frequency and Signficance. Semin Clin Neuropsychiatry 1(4), 241-7.

3. Cummings JL, Miller B, Hill MA, Neshkes R (1987) Neuropsychiatric aspects of multi-infarct dementia and dementia of the Alzheimer type. Arch Neurol 44(4), 389-93.

4. Fuh JL, Wang SJ, Cummings JL (2005) Neuropsychiatric profiles in patients with Alzheimer's disease and vascular dementia. J Neurol Neurosurg Psychiatry 76(10), 1337-41.

5. Kunik ME, Huffman JC, Bharani N, Hillman SL, Molinari VA, Orengo CA (2000). Behavioral disturbances in geropsychiatric inpatients across dementia types. J Geriatr Psychiatry Neurol 13(1), 49-52.

6. Lyketsos CG, Steinberg M, Tschanz JT, Norton MC, Steffens DC, Breitner JC (2000) Mental and behavioral disturbances in dementia: findings from the Cache County Study on Memory in Aging. Am J Psychiatry 157(5), 708-14.

7. Finkel SI (2001) Behavioral and psychological symptoms of dementia: a current focus for clinicians, researchers, and caregivers. J Clin Psychiatry 62 Suppl 21, 3-6.

8. Aalten P, Verhey FR, Boziki M, Brugnolo A, Bullock R, Byrne EJ, Camus V, Caputo M, Collins D, De Deyn PP, Elina K, Frisoni G, Holmes C, Hurt C, Marriott A, Mecocci P, Nobili F, Ousset PJ, Reynish E, Salmon E, Tsolaki M, Vellas B, Robert PH (2008) Consistency of neuropsychiatric syndromes across dementias: results from the European Alzheimer Disease Consortium. Part II. Dement Geriatr Cogn Disord 25(1), 1-8.

9. Ballard C, Neill D, O'Brien J, McKeith IG, Ince P, Perry R (2000) Anxiety, depression and psychosis in vascular dementia: prevalence and associations. J Affect Disord 59(2), 97-106.

10. Bucht G, Adolfsson R (1983) The Comprehensive Psychopathological Rating Scale in patients with dementia of Alzheimer type and multiinfarct dementia. Acta Psychiatr Scand 68(4), 263-70.

11. Groves WC, Brandt J, Steinberg M, Warren A, Rosenblatt A, Baker A, Lyketsos CG (2000) Vascular dementia and Alzheimer's disease: is there a difference? A comparison of symptoms by disease duration. J Neuropsychiatry Clin Neurosci 12(3), 305-15.

12. Johnson DK, Watts AS, Chapin BA, Anderson R, Burns JM (2011) Neuropsychiatric profiles in dementia. Alzheimer Dis Assoc Disord 25(4), 326-32.

13. Sultzer DL, Levin HS, Mahler ME, High WM, Cummings JL (1993) A comparison of psychiatric symptoms in vascular dementia and Alzheimer's disease. Am J Psychiatry 150(12), 1806-12.

14. Swearer JM, Drachman DA, O'Donnell BF, Mitchell AL (1988) Troublesome and disruptive behaviors in dementia. Relationships to diagnosis and disease severity. J Am Geriatr Soc 36(9), 784-90.

15. Vetter PH, Krauss S, Steiner O, Kropp P, Moller WD, Moises HW, Koller O (1999) Vascular dementia versus dementia of Alzheimer's type: do they have differential effects on caregivers' burden? J Gerontol B Psychol Sci Soc Sci 54(2), S93-8.

16. Aharon-Peretz J, Kliot D, Tomer R (2000) Behavioral differences between white matter lacunar dementia and Alzheimer's disease: a comparison on the neuropsychiatric inventory. Dement Geriatr Cogn Disord 11(5), 294-8.

17. Brun A GL (1988) Zerebrovaskulare Erkrankungen in Psychiatrie der Gegenwart Organische Psychosen Kisker KP, Lauter H, Meyer J-E, Muller C, Stromgren E, eds; (Springer Verlag: Berlin, Heidelberg) 6, pp 253-95. 
18. Caputo M, Monastero R, Mariani E, Santucci A, Mangialasche F, Camarda R, Senin U, Mecocci P (2008) Neuropsychiatric symptoms in 921 elderly subjects with dementia: a comparison between vascular and neurodegenerative types. Acta Psychiatr Scand 117(6), 455-64.

19. Hargrave R, Geck LC, Reed B, Mungas D (2000) Affective behavioural disturbances in Alzheimer's disease and ischaemic vascular disease. J Neurol Neurosurg Psychiatry 68(1), 41-6.

20. Moretti R, Torre P, Antonello RM, Cazzato G (2006) Behavioral alterations and vascular dementia. Neurologist 12(1), 43-7.

21. Srikanth S, Nagaraja AV, Ratnavalli E (2005) Neuropsychiatric symptoms in dementia-frequency, relationship to dementia severity and comparison in Alzheimer's disease, vascular dementia and frontotemporal dementia. J Neurol Sci 236(1-2), 43-8.

22. Staekenborg SS, Su T, van Straaten EC, Lane R, Scheltens P, Barkhof F, van der Flier WM (2009) Behavioural and psychological symptoms in vascular dementia; differences between small and large vessel disease. J Neurol Neurosurg Psychiatry 81(5), 547-51.

23. Tschanz JT, Welsh-Bohmer KA, Skoog I, West N, Norton MC, Wyse BW, Nickles R, Breitner JC (2000) Dementia diagnoses from clinical and neuropsychological data compared: the Cache County study. Neurology 54(6), 1290-6.

24. Chui H, Skoog I (2006) Advances in vascular cognitive impairment. Stroke 37(2), 323-5.

25. Hsieh C, Chang CC and Lin CC (2008) Neuropsychiatric profiles of patients with Alzheimer's disease and Vascular Dementia in Taiwan. Int J Geriatr Psychiatry 24(6), 570-5.

26. Chui HC, Mack W, Jackson JE, Mungas D, Reed BR, Tinklenberg J, Chang FL, Skinner K, Tasaki C, Jagust WJ (2000) Clinical criteria for the diagnosis of vascular dementia: a multicenter study of comparability and interrater reliability. Arch Neurol 57(2), 191-6.

27. Gold G, Bouras C, Canuto A, Bergallo MF, Herrmann FR, Hof PR, Mayor PA, Michel JP, Giannakopoulos $P$ (2002) Clinicopathological validation study of four sets of clinical criteria for vascular dementia. Am J Psychiatry 159(1), 82-7.

28. Pohjasvaara T, Mantyla R, Ylikoski R, Kaste M, Erkinjuntti T (2000) Comparison of different clinical criteria (DSM-III, ADDTC, ICD-10, NINDS-AIREN, DSM-IV) for the diagnosis of vascular dementia. National Institute of Neurological Disorders and Stroke-Association Internationale pour la Recherche et I'Enseignement en Neurosciences. Stroke 31(12), 2952-7.

29. Wetterling T, Kanitz RD, Borgis KJ (1996) Comparison of different diagnostic criteria for vascular dementia (ADDTC, DSM-IV, ICD-10, NINDS-AIREN). Stroke 27(1), 30-6.

30. Brunnstrom H, Englund E (2009) Clinicopathological concordance in dementia diagnostics. Am J Geriatr Psychiatry 17(8), 664-70.

31. Echávarri C CM, Aramendía A, García-Bragado F, Tuñón T (2011) Multi-protein deposits in neurodegenerative disorders. Our experience in the Tissue Brain Bank of Navarra. The Anatomical Record 294, 1191-7.

32. Cummings JL, Mega M, Gray K, Rosenberg-Thompson S, Carusi DA, Gornbein J (1994) The Neuropsychiatric Inventory: comprehensive assessment of psychopathology in dementia. Neurology 44(12), 2308-14.

33. Braak H, Braak E (1997) Frequency of stages of Alzheimer-related lesions in different age categories. Neurobiol Aging 18(4), 351-7.

34. Braak H, Braak E. Neuropathological stageing of Alzheimer-related changes. Acta Neuropathol 1991;82(4):239-59.

35. Braak H, Braak E (1990) Neurofibrillary changes confined to the entorhinal region and an abundance of cortical amyloid in cases of presenile and senile dementia. Acta Neuropathol 80(5), 479-86.

36. Brun A (1994) Pathology and pathophysiology of cerebrovascular dementia: pure subgroups of obstructive and hypoperfusive etiology. Dementia 5(3-4),145-7.

37. Jellinger KA (2010) Prevalence and impact of cerebrovascular lesions in Alzheimer and lewy body diseases. Neurodegener Dis 7(1-3), 112-5.

38. Cummings JL (1993) Frontal-subcortical circuits and human behavior. Arch Neurol 50(8), 873-80. 
39. Kuzis G, Sabe L, Tiberti C, Dorrego F, Starkstein SE (1999) Neuropsychological correlates of apathy and depression in patients with dementia. Neurology 52(7), 1403-7.

40. Kalaria RN, Kenny RA, Ballard CG, Perry R, Ince P, Polvikoski T (2004) Towards defining the neuropathological substrates of vascular dementia. J Neurol Sci 226(1-2), 75-80.

41. Pantoni L, Sarti C, Alafuzoff I, Jellinger K, Munoz DG, Ogata J, Palumbo V (2006) Postmortem examination of vascular lesions in cognitive impairment: a survey among neuropathological services. Stroke 37(4), 1005-9. 



\section{CHAPTER 6}

\section{Atrophy in the parahippocampal gyrus as an early biomarker of Alzheimer's disease}

C. Echávarri, P. Aalten, H.B.M. Uylings, H.I.L. Jacobs, P.J. Visser, E.H.B.M. Gronenschild, F.R.J. Verhey and S. Burgmans. Atrophy in the parahippocampal gyrus as an early biomarker of Alzheimer's disease. Brain Struct Funct (2011) 215:265-271. 
The main aim of the present study was to compare volume differences in the hippocampus and parahippocampal gyrus as biomarkers of Alzheimer's disease (AD). Based on previous findings, we hypothesized that there would be significant volume differences between cases of healthy aging, amnestic mild cognitive impairment $(\mathrm{aMCl})$, and $\mathrm{AD}$. Furthermore, we hypothesized that there would be larger volume differences in the parahippocampal gyrus than in the hippocampus. In addition, we investigated differences between the anterior, middle, and posterior parts of both structures.We studied 3 groups of male participants: 18 healthy participants without memory decline; 18 patients with aMCl; and 18 patients with AD. 3T T1-weighted MRI scans were acquired and gray matter volumes of the anterior, middle, and posterior parts of both the hippocampus and parahippocampal gyrus were measured using a manual tracing approach.Volumes of both the hippocampus and parahippocampal gyrus were significantly different between groups in the following order: healthy $>\mathrm{aMCl}>\mathrm{AD}$. Volume differences between the groups were relatively larger in the parahippocampal gyrus than in the hippocampus, in particular when we compared healthy controls with individuals with aMCl. No substantial differences were found between the anterior, middle, and posterior parts of both structures. Our results suggest that parahippocampal volume discriminates better than hippocampal volume between cases of healthy aging, aMCl, and $A D$, in particular in the early phase of the disease. The present results stress the importance of parahippocampal atrophy as an early biomarker of AD. 


\section{Introduction}

Atrophy in the medial temporal lobe has repeatedly been associated with agerelated memory decline, mild cognitive impairment $(\mathrm{MCl})$, and dementia (Burgmans et al., 2009; Hackert et al., 2002; Laakso et al., 2000; Raz et al., 2005; Scher et al., 2007; van de Pol et al., 2006; Visser et al., 2002; Wang et al., 2006). This is particularly true for hippocampal atrophy, which is considered to be one of the best predictors of Alzheimer's disease (AD) (Detoledo-Morrel et al., 1997; Jack et al., 2010; Jack et al.,1997; Pennanen et al., 2004). Recent findings suggest, however, that parahippocampal atrophy might have more potential as a predictor of AD.

Previous histological studies have already shown that the earliest neuropathological changes in AD appear in the entorhinal cortex, which is the anterior part of the parahippocampal gyrus (Braak and Braak 1990; Van Hoesen 1982). At present, several MRI studies suggest that volume measures of the entorhinal cortex provide higher sensitivity than volume measures of the hippocampus when it comes to detecting $A D$ in an early phase of the disease (Detoledo-Morrel et al., 2004; Dickerson et al., 2001; Pennanen et al., 2004). Despite these findings, the parahippocampal gyrus has until now received much less attention than the hippocampus as an early predictor of AD. Moreover, the total parahippocampal volume including posterior parts of the gyrus - has rarely been investigated in clinical populations. There is only scant evidence that this posterior part is involved in agerelated and pathological changes (Burgmans et al., 2009; Insausti et al., 1998; Thangavel et al., 2008; Weniger and Irle 2006).

There is some evidence that the amount of atrophy differs between anterior, middle and posterior areas of the hippocampus and parahippocampal gyrus. One hypothesis is that differences in the amount of atrophy along the longitudinal axis are caused by the way cortical connections are organized. Van Hoesen et al. (1982) and Insausti and Amaral (2008) concluded from nonhuman primate studies that the posterior parahippocampal gyrus plays a key role in the information flow between cortical association areas and the hippocampal formation. There are massive projections from the posterior parahippocampal areas TF and TH to the rostral portion of the entorhinal cortex. Since the entorhinal cortex is reciprocally connected to the anterior hippocampus, we may speculate that damage in the posterior parahippocampal gyrus can lead to tissue changes in the anterior hippocampus. However, more research is needed to reveal the mechanism of differential decline in the medial temporal lobe structures.

In the present study, we compared volume differences in the hippocampus and parahippocampal gyrus in three groups of older individuals: healthy controls, individuals with amnestic $\mathrm{MCl}$, and patients with $A D$. We hypothesized that volume differences between these groups are larger in the parahippocampal gyrus than in the hippocampus. In addition, we investigated differences between the anterior, middle, and posterior parts of both structures. 


\section{Materials and Methods}

\section{Participants}

Three groups of older male participants were included in this study: healthy participants without memory impairment, patients with amnestic $\mathrm{MCl}(\mathrm{aMCl})$ and patients with $A D$. The healthy participants were recruited by means of advertisements in local newspapers. They were administered an extensive neuropsychological test battery and were included if their performance did not deviate from normal on the Verbal Learning Test (Folstein et al., 1975; Van der Elst et al., 2005). The patients with $\mathrm{aMCl}$ or $\mathrm{AD}$ were recruited from the Memory Clinic of the Maastricht University Hospital. All the diagnoses were made by a multidisciplinary team under supervision of an experienced neuropsychiatrist from the Memory Clinic (FRJV) according to the Petersen criteria for aMCl (with at least an impairment in the memory domain)(Petersen et al., 2001; Petersen et al., 1999), and according to the DSM-IV and NINCDS-ADRDA criteria for AD (McKhann et al., 1984). The diagnoses were based on medical history, co-morbidity, course, and MRI scan. The MRI scan was used to exclude vascular pathology; levels of atrophy were not used for the diagnosis of $\mathrm{aMCl}$ and $\mathrm{AD}$.

The exclusion criteria were: use of psychoactive medication; abuse of alcohol and drugs; other past or present psychiatric or neurological diseases or serious system diseases; and structural abnormalities in the brain that could account for the cognitive decline. Two participants in the control group were excluded because a brain infarct was detected on the MRI scans and two patients in the AD group were excluded because their MRI images showed motion artefacts. The remaining number of participants (after excluding these 4 subjects) was 18 per group. Thus the final population consisted of: 18 healthy male participants (mean age $=64.5$ years, SD age $=3.3$ years); 18 male patients with aMCl (mean age $=65.11$ years, SD age $=4.5$ years) and 18 male patients with $A D$ (mean age $=72.2$ years, SD age $=9.7$ years). $A$ standardized eight-point scale was used to indicate educational level (1=primary school, 8=university). Written informed consent was obtained from all participants and from the primary caregiver of the AD patients. The study was approved by the local Medical Ethics Committee of the Maastricht University Medical Center.

\section{Image acquisition and analysis}

MRI scans were acquired with a 3 Tesla Gyroscan NT MRI scanner (Philips, Best, The Netherlands). Structural T1 images were acquired in the sagittal plane using an MPRAGE sequence $(\mathrm{TR}=8, \mathrm{TE}=3,7 \mathrm{msec}, \mathrm{FA}=9, \mathrm{FOV}=240 \times 240$, matrix size $=240 \mathrm{x}$ 240 , number of slices=180; voxel size $=1 \times 1 \times 1 \mathrm{~mm}^{3}$ ). For data analysis, we used a manual tracing approach. The images were viewed using GIANT (General Image Analysis Tools) (Gronenschild et al., 2010), which is a customized software program that allows tracing of regions of interest in a tri-planar and a rotatable 3D surfacerendered view as well as calculation of volumes of interest. The definitions of 
boundaries and divisions of the hippocampus and parahippocampal gyrus were performed according to the criteria described in a previous publication (Burgmans et al., 2009). Volumetric measures were obtained of the anterior, middle, and posterior parts of the hippocampus and parahippocampal gyrus (Figure 1).
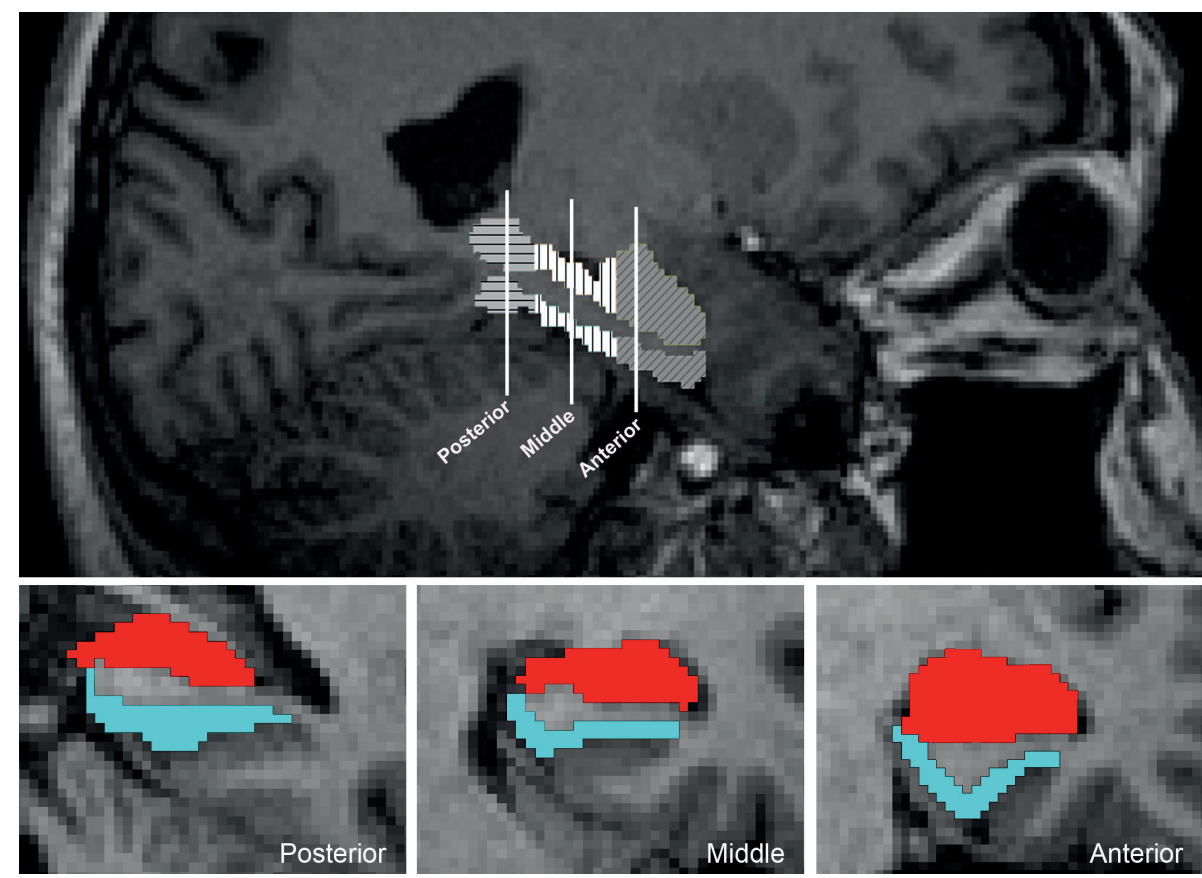

Figure 1.

Note. Patterns in the top panel show the subdivision of the hippocampus and parahippocampal gyrus along the antero-posterior axis. The anterior part included the anterior 35\% of the coronal slices (and any rounded off number of slices closest to this cutoff), the middle part comprised $35 \%$, and the posterior part included the remaining $30 \%$. The bottom panel shows the coronal sections of the hippocampus (red) and parahippocampal gyrus (blue) along the anterior-posterior axis.

A single rater (CEZ), who was blind to the demographic and cognitive characteristics of the participants, traced all structures. Intra-rater reliability was determined by the Intraclass Correlation Coefficient (ICC) (Shrout and Fleiss 1979). Ten randomly selected brains were measured twice, and these yielded high test-retest reliability. The ICC of the total hippocampal volume was 0.97 (95\% confidence interval= $0.91 ; 0.99$ ), and the ICC of the total parahippocampal volume was 0.95 (95\% confidence interval $=0.84 ; 0.98)$. To correct for individual differences in unatrophied brain, intracranial volumes were measured using an automated method (FSL Brain Extraction Tool) developed at the Oxford Centre for Functional MRI of the brain (Smith 2002). 


\section{Statistical analysis}

Statistical analyses were performed using the Statistical Package for the Social Sciences (SPSS Inc, Chicago) version 16.0 for Windows. To compare the mean age, educational level, and MMSE scores between the 3 groups, ANOVA (General Linear Model; GLM) was performed. For the volumetric comparisons between the 3 groups, ANCOVA (GLM) was used, with volume as dependent variable, group as independent variable, and intracranial volume and age as covariates.

Three main things were tested in the ANCOVA analysis. First, the effect of group was calculated to test the overall difference across the three groups. Second, contrasts were calculated by pairwise comparisons among means to test the differences between two groups: i.e. control vs $\mathrm{MCl}$; control vs $A D$; and $\mathrm{aMCl}$ vs $A D$. Third, the hypothesis that group differences are larger in the parahippocampal gyrus than in the hippocampus was tested by adding the hippocampus as covariate in the ANCOVA analysis with the parahippocampal gyrus as dependent variable. If group differences are still significant in this analysis, we can state that the parahippocampal gyrus has added value in discriminating between groups on top of the discriminating ability of the hippocampus. For all tests, Pearson's correlation coefficient was calculated as a measure of effect size.

\section{Results}

The 3 groups differed significantly with respect to age $(p=0.001)$ and MMSE $(p=$ $0.000)$, but did not differ with respect to educational level ( $p>0.697)$. The AD group was older (mean age 72.2, SD 9.7) than the other two groups. Minimental scores differed in the following order: control (mean MMSE score 28.8, range 2730) > $\mathrm{MCl}$ (mean MMSE score 27.6, range 22-30) > AD (mean MMSE score 21.0, range 10-28). 16 of the $18 \mathrm{AD}$ patients were in a mild stage of the disease (mean MMSE score 21.0, range 18-28), and two patients in a moderate-severe stage (MMSE score 10 and 15). The mean educational level in the control group was 4.2 (SD 1.4). The mean educational level in the $\mathrm{MCl}$ and the $A D$ group was 3.8 (SD 1.8).

Volumetric comparisons between the 3 groups are summarized in Tables 1 and 2. Age and intracranial volume were included as covariates to correct for possible age and cohort effects. With regard to the main effect of group on the total volumes of the hippocampus and parahippocampal gyrus: differences between the three groups were significant in both volumes (parahippocampal gyrus: $F(2,46)=$ 24.23, $p<0.001$, hippocampus: $F(2,46)=12.07, p<0.001)$. Volumes were significantly different in the following order: healthy $>\mathrm{aMCl}>\mathrm{AD}$. ANCOVA analyses demonstrated that the parahippocampal gyrus is better in discriminating between groups than the hippocampal gyrus. When we added the hippocampus as covariate in the ANCOVA analysis with the parahippocampal gyrus as dependent variable, we still found robust significant group differences $(F(2,45)=11.07 ; p<0.001)$. In contrast, when we added the parahippocampal gyrus as covariate in the ANCOVA anal- 
ysis with the hippocampus as dependent variable, the significant group differences disappeared $(F(2,45)=2.42 ; p=0.100)$. This indicates that the parahippocampal volume has added value on top of the discriminating ability of the hippocampus. Furthermore, pairwise comparisons between the healthy and $\mathrm{aMCl}$ groups showed a significant difference in the parahippocampal gyrus $(12.4 \%, F(1,29)=10.46, p=$ $0.003)$ but not in the hippocampus $(1.7 \%, F(1,29)=0.85, p=0.362)$. When we compared the control or the aMCl group with the $\mathrm{AD}$ group, significant differences were found in both structures (Figure 2).

With respect to differences along the longitudinal axis in the hippocampus and parahippocampal gyrus, the repeated-measures GLM showed a significant group by structure interaction $(p=0.034)$ in the left parahippocampal gyrus when we compared controls with AD patients. The group difference was larger in the anterior part than in the middle and posterior parts. No other significant differences were found between anterior, middle, and posterior parts. Furthermore, repeatedmeasures analysis showed no significant differences between both hemispheres (i.e., left-right differences).
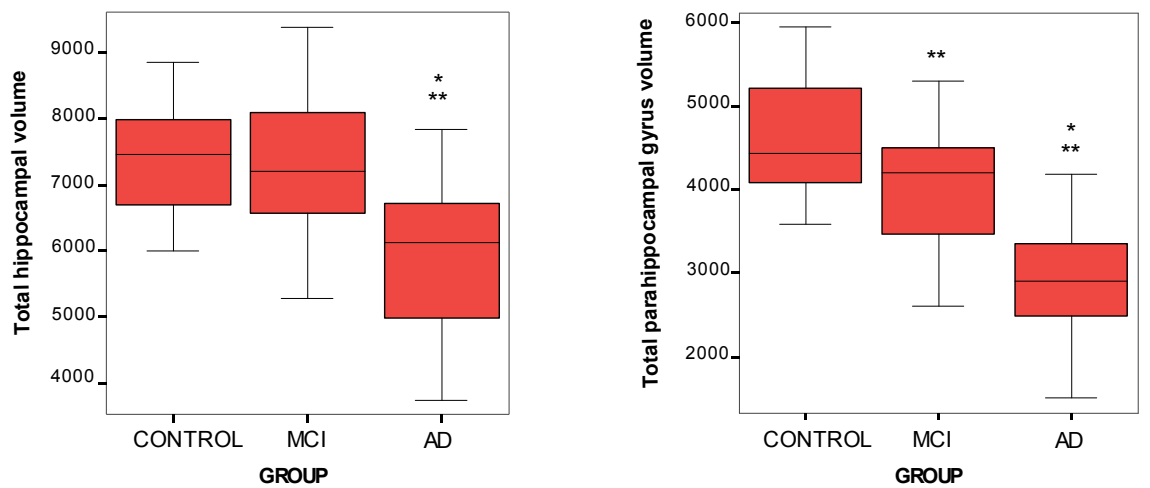

Figure 2. Boxplot of the hippocampal and parahippocampal gyrus volumes in $\mathrm{mm}^{3}$ in controls, $\mathrm{MCl}$ and AD patients.

** = significant difference with control group; * = significant difference with $\mathrm{MCl}$ group. 
Table 1. Volumetric comparisons between the three groups

\begin{tabular}{|c|c|c|c|c|c|c|}
\hline \multirow[t]{2}{*}{ Volume in $\mathrm{mm}^{3}$} & \multirow{2}{*}{$\begin{array}{c}\text { Controls }(n=18) \\
\text { Mean (SD) }\end{array}$} & \multirow{2}{*}{$\begin{array}{l}\text { aMCl }(n=18) \\
\text { Mean (SD) }\end{array}$} & \multirow{2}{*}{$\begin{array}{l}A D(n=18) \\
\text { Mean (SD) }\end{array}$} & \multirow[b]{2}{*}{$F(2,46)$} & \multirow[b]{2}{*}{$r$} & \multirow[b]{2}{*}{$\mathrm{p}$} \\
\hline & & & & & & \\
\hline HCG total & 7464 (794) & 7334 (111) & $5922(122)$ & 12.0 & 0.1 & 0.000 \\
\hline HCG ant & 2959 (375) & 2970 (459) & $2452(500)$ & 8.4 & 0.4 & 0.001 \\
\hline HCG middle & 2434 (269) & 2321 (333) & 1915 (394) & 10.0 & 0.5 & 0.000 \\
\hline HCG post & 2100 (359) & 2045 (434) & 1592 (383) & 7.0 & 0.4 & 0.002 \\
\hline PHG total & $4623(680)$ & 4047 (732) & 3014 (588) & 24.2 & 0.7 & 0.000 \\
\hline PHG ant & 1657 (318) & 1389 (326) & $954(303)$ & 16.6 & 0.6 & 0.000 \\
\hline PHG middle & 1646 (322) & $1482(421)$ & $1074(298)$ & 15.6 & 0.6 & 0.000 \\
\hline PHG post & $1.335(202)$ & 1169 (170) & $881(200)$ & 20.3 & 0.6 & 0.000 \\
\hline HCG total L & 3773 (344) & 3704 (450) & $3050(684)$ & 11.6 & 0.5 & 0.000 \\
\hline HCG ant L & 1503 (210) & $1500(187)$ & $1241(156)$ & 7.4 & 0.4 & 0.002 \\
\hline HCG middle L & 1239 (154) & 1194 (154) & 994 (217) & 11.3 & 0.5 & 0.000 \\
\hline HCG post L & 1031 (207) & 1009 (188) & $813(241)$ & 4.1 & 0.4 & 0.023 \\
\hline HCG total R & 3719 (575) & 3630 (709) & 2872 (620) & 9.4 & 0.4 & 0.000 \\
\hline HCG ant R & 1455 (276) & $1470(272)$ & $1204(287)$ & 5.8 & 0.3 & 0.005 \\
\hline HCG middle R & 1194 (183) & $1123(216)$ & 920 (198) & 11.3 & 0.4 & 0.000 \\
\hline HCG post R & 1069 (159) & $1036(231)$ & 747 (214) & 6.8 & 0.4 & 0.000 \\
\hline PHG total L & $2321(487)$ & 2111 (374) & 1468 (319) & 18.3 & 0.6 & 0.000 \\
\hline PHG ant L & $843(212)$ & 705 (203) & $436(184)$ & 11.7 & 0.6 & 0.000 \\
\hline PHG middle L & 839 (205) & $188(794)$ & 555 (129) & 12.7 & 0.5 & 0.000 \\
\hline PHG post L & 637 (142) & $611(106)$ & 476 (123) & 8.3 & 0.5 & 0.001 \\
\hline PHG total R & 2301 (274) & 1936 (429) & 1546 (329) & 18.9 & 0.6 & 0.000 \\
\hline PHG ant R & 802 (162) & $683(208)$ & 518 (177) & 8.3 & 0.5 & 0.001 \\
\hline PHG middle R & $812(100)$ & 693 (159) & $586(140)$ & 11.1 & 0.6 & 0.000 \\
\hline PHG post R & $687(130)$ & $558(122)$ & 441 (115) & 15.3 & 0.6 & 0.000 \\
\hline
\end{tabular}

Note. The group differences were calculated with ANCOVA (Univariate General Linear Model); HCG = Hippocampus; $\mathrm{PHG}=$ Parahippocampal gyrus; ant = anterior; post = posterior; $\mathrm{L}=$ left; $\mathrm{R}=$ right; $\mathrm{SD}=$ Standard deviation; $r$ = effect size by Pearson's correlation coefficient; $p=p$ value; $F(2,46)=F$-ratio and the degrees of freedom; $p, r$ and $F$ represent group difference. 
Table 2. Volumetric pairwise comparisons

\begin{tabular}{|c|c|c|c|c|c|c|c|c|c|c|c|c|}
\hline \multirow[b]{2}{*}{ Volume in $\mathrm{mm} 3$} & \multicolumn{4}{|c|}{ Control and $\mathrm{aMCl}$} & \multicolumn{4}{|c|}{$\mathrm{aMCl}$ and $\mathrm{AD}$} & \multicolumn{4}{|c|}{ Control and AD } \\
\hline & $\%$ & $F(1,29)$ & $r$ & $\mathrm{P}$ & $\%$ & $F(1,29)$ & $r$ & $\mathrm{p}$ & $\%$ & $F(1,29)$ & $r$ & $\mathrm{p}$ \\
\hline HCG total & 1.7 & 0.8 & 0.0 & 0.362 & 19.2 & 12.2 & 0.5 & 0.002 & 20.6 & 22.7 & 0.6 & 0.000 \\
\hline HCG ant & -0.3 & 0.2 & 0.0 & 0.628 & 17.8 & 9.2 & 0.5 & 0.005 & 17.1 & 14.4 & 0.5 & 0.001 \\
\hline HCG middle & 4.6 & 3.5 & 0.1 & 0.069 & 17.4 & 12.5 & 0.5 & 0.001 & 21.3 & 30.8 & 0.6 & 0.000 \\
\hline HCG post & 2.5 & 0.3 & 0.0 & 0.559 & 22.0 & 8.3 & 0.4 & 0.007 & 24.1 & 15.3 & 0.5 & 0.001 \\
\hline PHG total & 12.4 & 10.4 & 0.3 & 0.003 & 25.5 & 24.5 & 0.6 & 0.000 & 34.8 & 36.8 & 0.7 & 0.000 \\
\hline PHG ant & 16.1 & 9.4 & 0.3 & 0.004 & 31.3 & 12.8 & 0.5 & 0.001 & 42.4 & 25.2 & 0.7 & 0.000 \\
\hline PHG middle & 13.2 & 4.9 & 0.2 & 0.033 & 19.3 & 17.4 & 0.5 & 0.000 & 34.7 & 25.2 & 0.7 & 0.000 \\
\hline PHG post & 12.4 & 9.8 & 0.4 & 0.004 & 24.6 & 21.6 & 0.6 & 0.000 & 34.0 & 27.2 & 0.7 & 0.000 \\
\hline HCG total L & 1,8 & 1.2 & 0.0 & 0.266 & 17.6 & 10.9 & 0.5 & 0.003 & 19.1 & 19.8 & 0.5 & 0.000 \\
\hline HCG ant L & 0.19 & 0.4 & 0.0 & 0.499 & 17.2 & 8.0 & 0.4 & 0.008 & 17.4 & 11.6 & 0.5 & 0.002 \\
\hline HCG middle L & 3.6 & 1.4 & 0.1 & 0.233 & 16.7 & 12.7 & 0.5 & 0.001 & 19.7 & 19.7 & 0.5 & 0.000 \\
\hline HCG post $\mathrm{L}$ & 2.1 & 0.2 & 0.0 & 0.654 & 19.4 & 5.0 & 0.4 & 0.032 & 21.1 & 7.6 & 0.4 & 0.010 \\
\hline HCG total R & 2.3 & 0.7 & 0.0 & 0.379 & 20.8 & 10.0 & 0.4 & 0.004 & 22.7 & 19.7 & 0.5 & 0.000 \\
\hline HCG ant R & -1.0 & 0.0 & 0.0 & 0.844 & 18.9 & 7.7 & 0.4 & 0.009 & 17.2 & 10.4 & 0.4 & 0.003 \\
\hline HCG middle R & 5.9 & 3.7 & 0.1 & 0.063 & 18.0 & 8.1 & 0.4 & 0.008 & 22.9 & 24.4 & 0.5 & 0.000 \\
\hline HCG post $R$ & 3.08 & 0.3 & 0.0 & 0.580 & 27.7 & 8.5 & 0.4 & 0.007 & 30.1 & 14.1 & 0.5 & 0.001 \\
\hline PHG total L & 9.04 & 3.4 & 0.2 & 0.071 & 30.4 & 36.9 & 0.7 & 0.000 & 36.7 & 24.4 & 0.7 & 0.000 \\
\hline PHG ant L & 16.3 & 4.6 & 0.3 & 0.039 & 38.1 & 10.9 & 0.5 & 0.003 & 48.2 & 19.9 & 0.7 & 0.000 \\
\hline PHG middle L & 17.9 & 1.1 & 0.1 & 0.282 & 19.3 & 26.8 & 0.6 & 0.000 & 33.8 & 17.7 & 0.6 & 0.000 \\
\hline PHG post $L$ & 4.08 & 0.8 & 0.1 & 0.368 & 22.0 & 15.6 & 0.5 & 0.000 & 25.3 & 10.4 & 0.5 & 0.003 \\
\hline PHG total R & 15.8 & 18.4 & 0.4 & 0.000 & 20.1 & 8.0 & 0.4 & 0.008 & 32.8 & 35.4 & 0.7 & 0.000 \\
\hline PHG ant R & 20.4 & 6.4 & 0.3 & 0.016 & 18.8 & 4.5 & 0.4 & 0.042 & 35.4 & 13.9 & 0.6 & 0.000 \\
\hline PHG middle $\mathrm{R}$ & 14.6 & 10.2 & 0.4 & 0.003 & 15.4 & 4.1 & 0.4 & 0.050 & 27.8 & 21.1 & 0.7 & 0.000 \\
\hline PHG post $R$ & 19.02 & 11.3 & 0.4 & 0.002 & 20.9 & 7.7 & 0.4 & 0.009 & 35.8 & 23.7 & 0.7 & 0.000 \\
\hline
\end{tabular}

Note. The groups differences were calculated with ANCOVA (Univariate General Linear Model); HCG = Hippocampus; PHG = Parahippocampal gyrus; \% = difference between the two groups (V1-V2 x 100/V1); $r=$ effect size by Pearson's correlation coefficient; $p=p$ value; $F(d f)=$ for the covariate effect we give the F-ratio and the degrees of freedom (df) 


\section{Discussion}

The main aim of the present study was to compare volume differences in the hippocampus and parahippocampal gyrus between healthy controls, individuals with $\mathrm{aMCl}$, and patients with $\mathrm{AD}$. In addition, differences along the longitudinal axis of both structures were investigated. Our results suggest that parahippocampal volume discriminates better than hippocampal volume especially in the early phase of AD. No significant differences were found along the longitudinal axis, except for the left parahippocampal gyrus in which the anterior parts showed significantly larger differences than the posterior parts when controls were compared to AD patients.

Our finding that parahippocampal volume discriminates better than hippocampal volume is in line with the findings of most previous studies on pathological aging in which a comparison was made between healthy and $\mathrm{MCl}$ groups (Detoledo-Morrel et al., 2000; Jack et al., 2000; Jauhiainen et al., 2009; Killiany et al., 2002; Pennanen et al., 2004; Xu et al., 2000), between MCl and AD groups (Du et al., 2001; Jauhiainen et al., 2009; Tapiola et al., 2008; Visser et al., 1999; Xu et al., 2000), or between healthy and AD groups (Detoledo-Morrel et al., 2000; Dickerson et al., 2001; Du et al., 2001; Jauhiainen et al., 2009; Killiany et al., 2002; Pennanen et al.,2004). There have been, however, also a few studies that found larger group differences in the hippocampus (Detoledo-Morrel et al., 1997; Jack et al.,1997; Pennanen et al., 2004; Visser et al., 2002). Nevertheless, in these cases a group of $A D$ patients was always involved. Thus, in those cases where the hippocampus was found to be a better discriminator than the parahippocampal gyrus, the group comparisons were always between $M C l$ and $A D$, or between control and $A D$, but never between control and $\mathrm{MCl}$. This might indicate that the parahippocampal gyrus is a better discriminator particularly in the early (preclinical) phase of AD. The suggestion that the parahippocampal gyrus in particular is a highly sensitive marker with which to detect $A D$ at a very early stage is in line with earlier reports on the entorhinal cortex (Detoledo-Morrel et al., 2004; Dickerson et al., 2001; Pennanen et al., 2004). The present study adds a new finding as it shows that this is not only the case with regard to the anterior part, but also with regard to the posterior part of the parahippocampal gyrus.

The present data are also partly in line with a previous study by our group (Burgmans et al., 2009) in which healthy, aging individuals with and without memory decline were compared. In that study we also reported larger group differences in the parahippocampal gyrus. However, we found the largest group difference in the posterior part of the parahippocampal gyrus. This is in contrast with the present results, since here we found larger differences in the anterior part of the left parahippocampal gyrus than in the posterior parts of the left parahippocampal gyrus between controls and AD patients. A possible explanation for these different findings could be that atrophy in the posterior medial temporal lobe is more strongly related to healthy aging, whereas atrophy in the anterior medial 
temporal lobe is more strongly related to pathological aging. In a recent study, Raji et al., (2009) observed that in normal aging the most affected region was the posterior part of the hippocampus, while in $A D$ patients the most affected regions were the anterior parts of the hippocampus and the parahippocampal gyrus.

There remain a few methodological issues to be addressed. First, our MRI data were acquired at only one time point, which precludes the assessment of actual pathological aging changes in volume, or of causality. Second, we included only male participants in order to decrease interindividual variation. We must therefore be cautious with generalizing our findings to females. Previous studies, however, did not reveal substantial gender-related differences with respect to hippocampal and parahippocampal atrophy in AD. Third, the subdivision applied to the hippocampus and the parahippocampal gyrus was an MRI macroscopical one. We chose to divide both structures into three subregions along the longitudinal axis, because the literature suggests there are important differences in age-related and pathological-related changes between the anterior and posterior areas. However, there are no clear anatomical reasons for the cutoff points used in the present study (i.e., $35 \%$ for the anterior volume; $35 \%$ for the middle volume; and $30 \%$ for the posterior volume). Nevertheless, one of the aims of this study was to explore group differences along the longitudinal axis, which has been made possible by our MRI-based approach. When it comes to investigating the subregions of the medial temporal lobe in more detail, cytoarchitectonic studies are considered more ideal.

In sum, our results suggest that parahippocampal volume discriminates better than hippocampal volume between cases of healthy aging, $\mathrm{aMCl}$, and $\mathrm{AD}$, in particular in the early phase of the disease. Our findings stress the importance of parahippocampal atrophy as an early biomarker of AD. Such predictive biological markers could be of great help for the development of early interventions designed to retard the progression of the disease. A possible implication could be a visual rating scale of the parahippocampal gyrus, similar to the one that exists for the hippocampus (Scheltens et al., 1992), which could help detect the earliest neurodegenerative changes indicative of $A D$ in routine clinical practice.

\section{References}

Braak H, Braak E (1990) Neurofibrillary changes confined to the entorhinal region and an abundance of cortical amyloid in cases of presenile and senile dementia. Acta Neuropathol 80:479-486.

Burgmans S, van Boxtel MP, van den Berg KE, Gronenschild EH, Jacobs HI, Jolles J, Uylings HB (2009) The posterior parahippocampal gyrus is preferentially affected in age-related memory decline. Neurobiol Aging 32 (9): 1572-1578.

Detoledo-Morrell L, Goncharova I, Dickerson B, Wilson RS, Bennett DA (2000) From healthy aging to early Alzheimer's disease: in vivo detection of entorhinal cortex atrophy. Ann N Y Acad Sci 911:240253. 
Detoledo-Morrell L, Sullivan MP, Morrell F, Wilson RS, Bennett DA, Spencer S (1997) Alzheimer's disease: in vivo detection of differential vulnerability of brain regions. Neurobiol Aging 18:463-468.

DeToledo-Morrell L, Stoub TR, Bulgakova M, et al (2004) MRI-derived entorhinal volume is a good predictor of conversion from MCl to AD. Neurobiol Aging 25:1197-1203.

Dickerson BC, Goncharova I, Sullivan MP, et al (2001) MRI-derived entorhinal and hippocampal atrophy in incipient and very mild Alzheimer's disease. Neurobiol Aging 22:747-754.

Du AT, Schuff N, Amend D, et al (2001) Magnetic resonance imaging of the entorhinal cortex and hippocampus in mild cognitive impairment and Alzheimer's disease. J Neurol Neurosurg Psychiatry 71:441-447.

Folstein MF, Folstein SE, McHugh PR (1975) "Mini-mental state". A practical method for grading the cognitive state of patients for the clinician. J Psychiatr Res 12:189-198.

Gronenschild EH, Burgmans S, Smeets F, Vuurman EF, Uylings HBM, Jolles J (2010) A time-saving and facilitating approach for segmentation of anatomically defined cortical regions: MRI volumetry. Psychiatry Res 181:211-218.

Hackert VH, den Heijer T, Oudkerk M, Koudstaal PJ, Hofman A, Breteler MM (2002)

Hippocampal head size associated with verbal memory performance in nondemented elderly. Neuroimage 17:1365-1372.

Insausti R, Amaral DG (2008) Entorhinal cortex of the monkey: IV. Topographical and laminar organization of cortical afferents. J Comp Neurol 509: 608-641.

Insausti R, Insausti AM, Sobreviela MT, Salinas A, Martinez-Penuela JM (1998) Human medial temporal lobe in aging: anatomical basis of memory preservation. Microsc Res Tech 43:8-15.

Jack CR, Jr., Knopman DS, Jagust WJ, et al (2010) Hypothetical model of dynamic biomarkers of the Alzheimer's pathological cascade. Lancet Neurol 9:119-128.

Jack CR, Jr., Petersen RC, Xu YC, et al (1997) Medial temporal atrophy on MRI in normal aging and very mild Alzheimer's disease. Neurology 49:786-794.

Jack CR, Jr., Petersen RC, Xu Y, et al (200) Rates of hippocampal atrophy correlate with change in clinical status in aging and AD. Neurology 55:484-489.

Jauhiainen AM, Pihlajamaki M, Tervo S, et al (2009) Discriminating accuracy of medial temporal lobe volumetry and fMRI in mild cognitive impairment. Hippocampus 19:166-175.

Killiany RJ, Hyman BT, Gomez-Isla T, et al (2002) MRI measures of entorhinal cortex vs hippocampus in preclinical AD. Neurology 58:1188-1196.

Laakso MP, Frisoni GB, Kononen M, et al (2000) Hippocampus and entorhinal cortex in frontotemporal dementia and Alzheimer's disease: a morphometric MRI study. Biol Psychiatry 2000 47:1056-1063.

McKhann G, Drachman D, Folstein M, Katzman R, Price D, Stadlan EM (1984) Clinical diagnosis of Alzheimer's disease: report of the NINCDS-ADRDA Work Group under the auspices of Department of Health and Human Services Task Force on Alzheimer's Disease. Neurology 34:939-944.

Pennanen C, Kivipelto M, Tuomainen S, et al (2004) Hippocampus and entorhinal cortex in mild cognitive impairment and early AD. Neurobiol Aging 25:303-310.

Petersen RC, Smith GE, Waring SC, Ivnik RJ, Tangalos EG, Kokmen E (1999) Mild cognitive impairment: clinical characterization and outcome. Arch Neurol 56:303-308.

Petersen RC, Doody R, Kurz A, et al (2001) Current concepts in mild cognitive impairment. Arch Neurol 58:1985-1992.

Raz N, Lindenberger U, Rodrigue KM, et al (2005) Regional brain changes in aging healthy adults: general trends, individual differences and modifiers. Cereb Cortex 15:1676-1689.

Raji CA, Lopez OL, Kuller LH, Carmichael OT, Becker JT (2009) Age, Alzheimer disease, and brain structure. Neurology 73:1899-1905.

Scheltens P, Leys D, Barkhof F, et al (1992) Atrophy of medial temporal lobes on MRI in "probable" Alzheimer's disease and normal ageing: diagnostic value and neuropsychological correlates. J Neurol Neurosurg Psychiatry 55:967-972. 
Scher Al, Xu Y, Korf ES, et al (2007) Hippocampal shape analysis in Alzheimer's disease: a populationbased study. Neuroimage 36:8-18.

Shrout PE, Fleiss JL (1979) Intraclass correlations: uses in assessing rater reliability. Psychol Bull 86:420428.

Smith SM (2002) Fast robust automated brain extraction. Hum Brain Mapp 17:143-155.

Tapiola T, Pennanen C, Tapiola M, et al (2008) MRI of hippocampus and entorhinal cortex in mild cognitive impairment: a follow-up study. Neurobiol Aging 29:31-38.

Thangavel R, Van Hoesen GW, Zaheer A (2008) Posterior parahippocampal gyrus pathology in Alzheimer's disease. Neuroscience 154:667-676.

Van der Elst W, van Boxtel MP, van Breukelen GJ, Jolles J (2005) Rey's verbal learning test: normative data for 1855 healthy participants aged 24-81 years and the influence of age, sex, education, and mode of presentation. J Int Neuropsychol Soc 11:290-302.

Van de Pol LA, Hensel A, van der Flier WM, et al (2006) Hippocampal atrophy on MRI in frontotemporal lobar degeneration and Alzheimer's disease. J Neurol Neurosurg Psychiatry 77:439-442.

Van Hoesen GW (1982) The parahippocampal gyrus: new observations regarding its cortical connections in the monkey. Trends in neurosciences 5

Visser PJ, Verhey FR, Hofman PA, Scheltens P, Jolles J (2002) Medial temporal lobe atrophy predicts Alzheimer's disease in patients with minor cognitive impairment. J Neurol Neurosurg Psychiatry 72:491-497.

Visser PJ, Scheltens P, Verhey FR, et al (1999) Medial temporal lobe atrophy and memory dysfunction as predictors for dementia in subjects with mild cognitive impairment. J Neurol 246:477-485.

Wang L, Miller JP, Gado MH, et al (2006) Abnormalities of hippocampal surface structure in very mild dementia of the Alzheimer type. Neuroimage 30:52-60.

Weniger G, Irle E (2006) Posterior parahippocampal gyrus lesions in the human impair egocentric learning in a virtual environment. Eur J Neurosci 24:2406-2414.

Xu Y, Jack CR, Jr., O'Brien PC, et al (2000) Usefulness of MRI measures of entorhinal cortex versus hippocampus in AD. Neurology 54:1760-1767. 

CHAPTER 7

Concluding remarks 
In this thesis, the dementia syndrome is described from a multidimensional perspective, including clinical, neuropathological, and neuroimaging features of dementia. The main aim of the research underlying it was to investigate the correlation between clinical and neuropathological features of dementia. The specific research questions are therefore related to the correlations between clinical and neuropathological diagnoses and to clinical features of the dementia syndrome. Most of the research reported in this thesis was based on brain tissue from the Brain Bank of Navarre (Pamplona, Spain) and the Netherlands Brain Bank (Amsterdam). All the participants included in the study of the correlations between clinical and neuropathological diagnoses had been diagnosed with a neurodegenerative disorder (most of them with dementia) during life as well as post-mortem. All types of dementia present were included in order to assess the correlation between ante-mortem and post-mortem diagnoses. Clinical features, such as the prevalences of risk factors and neuropsychiatric symptoms (NPSs), were studied in patients with Alzheimer's disease (AD) and vascular dementia (VaD), which are the most common types of dementia.

\section{Summary of the main findings}

\section{Multiple pathologies in dementia}

Chapter 2 discusses the rate of agreement between clinical and neuropathological diagnoses of dementia. The data showed low rates of agreement for the most common diagnoses, which is mainly due to the fact that several pathological changes often co-occur in the brains of demented patients. Overall, the agreement between clinical and pathological diagnosis was less than half $(44 \%)$, confirming that the underlying biological findings often differ from the neuropathological disease suggested by the clinical diagnosis. Along the same line, Chapter 3 focuses on the relationship between the most prevalent pathological changes co-occurring in the same brain, which are Alzheimer's disease (AD)-related, Lewy body (LB)related, and vascular pathology (VaD or cerebrovascular lesions (CVL)). The analysis found evidence to support a positive association between $A D$ and vascular lesion severity, suggesting that there may be a common pathogenesis underlying $A D$ and vascular lesions. On the other hand, the results did not support a link between $A D$ and LB pathologies, though it appears that LB pathology is a mediating factor which leads to a positive relationship between the severity of CVLS and AD-related pathology.

\section{Cerebrovascular risk factors in dementia}

The study reported on in Chapter 4 explored the role of vascular risk factors in dementia by estimating the prevalence of different risk factors in cases of dementia with neuropathologically confirmed $A D, V a D$ and mixed $A D$ plus vascular pathology. 
Previous in vivo studies have reported various vascular conditions to be risk factors for dementia, and differences in risk factor profile have been found between subtypes of dementia. In order to compare the results of the sample from the Netherlands Brain Bank (NBB) with a more representative sample of the Dutch population, data from several control groups representing the elderly Dutch population were also included. Comparison of the three disease groups did not reveal significant differences in the prevalence of any of the vascular risk factors considered, except for a greater prevalence of a history of stroke in VaD and MD. Compared to controls, the only differences found were that smoking was more common in AD cases and that more $\mathrm{VaD}$ cases had a history of stroke. Our data show that the use of neuropathological confirmation of dementia diagnoses led to the disappearance of most of the previously reported differences in vascular risk factors between $A D$, $\mathrm{MD}, \mathrm{VaD}$, and controls.

\section{Neuropsychiatry in vascular and degenerative pathology}

Chapter 5 discusses the presence of NPSs associated with dementia in patients with neuropathologically confirmed $\mathrm{AD}$ and $\mathrm{VaD}$. The most common symptom in the sample as a whole was agitation (45 cases, 57\%), followed by depression (33, $41.2 \%)$ and anxiety $(28,35.4 \%)$. No significant differences between groups were found regarding the prevalences of NPSs, suggesting that NPSs are related to dementia in a non-specific way, that is, $A D$ and $V a D$ patients do not differ significantly in terms of NPSs. Our results suggest that the prevalence of these NPSs cannot be related to the dementia diagnosis of $A D$ or $\mathrm{VaD}$. We want to stress that previous studies were based on clinical diagnoses, which were probably often not sufficiently accurate, especially those for VaD. Our study is the first one in the literature to provide an assessment of NPSs in types of dementia based on clinical as well as neuropathological diagnoses.

\section{Early stages of dementia}

Chapter 6 discusses magnetic resonance imaging (MRI) markers of early stage AD. Previous neuropathological studies have identified the parahippocampal gyrus as the first structure to be involved in AD (Braak \& Braak, 1991), but neuroimaging studies have been focusing on changes in the hippocampus as a biomarker for early stage AD. The role of changes in the parahippocampal gyrus as a neuroimaging biomarker for early stage AD was explored by measuring the volume of this structure and of the hippocampus in healthy volunteers, and in patients with amnestic mild cognitive impairment $(\mathrm{aMCl})$ and mild $A D$. The results suggest that parahippocampal volume is better able to discriminate between cases of healthy ageing, aMCl, and mild AD than hippocampal volume, especially in the early stages of the disease. These findings underline the importance of parahippocampal atrophy as an early biomarker of $A D$, which had not been demonstrated before. 


\section{Methodological considerations}

There are some methodological issues that need to be addressed as regards the research underlying this thesis, mainly arising from the characteristic limitations of a retrospective neuropathological study not based on a population series but on a series of donors from brain banks.

First, as is inherent in all clinicopathological studies, the data used for our thesis are subject to selection bias. Such selection bias most commonly results from referral bias, which is influenced by the severity of the disorder and the management provided by the caregiver or caregivers of the demented person (Zaccai et al., 2006). In fact, patients with rarer neuropathological conditions are more likely to become brain bank donors (Jicha et al., 2008; Schneider et al., 2009). For instance, there is a particularly high prevalence of FTLD and prion disease cases in the sample from the Brain Bank of Navarre. Besides, donors to brain banks are usually elderly patients in the later stages of their diseases. Since our samples from the brain banks are thus not entirely representative of the European population, our findings may have been affected by selection bias, so they must be interpreted very cautiously, especially when it comes to assessing demographical or epidemiological variables.

Second, the relatively small number of participants in our clinico-neuropathological studies could have resulted in low statistical power and, hence, failure to find significant results. Furthermore, most of the donors to the brain banks were in the later stages of their diseases; for instance, most individuals with AD were at Braak stages of $\mathrm{V}$ or $\mathrm{VI}$. This narrow range of Braak stages may have hampered the process of finding robust correlations, especially when studying the relationship between the severity of AD pathology and CVLs. These results have to be interpreted by taking into account that they apply mostly to the later stages of the dementia syndrome. We have no neuropathological findings for the early stages of the disease, and consequently have no information about the way pathology spreads through the brain until its later stages.

Third, there was a time lag between clinical assessment and pathological data collection in our studies. In addition, clinical data were not collected prospectively, but in a retrospective way from patients' medical and brain bank records. Although clinical studies can be strictly controlled and prospective, clinical information is often lacking at the moment of neuropathological analysis. The research for this thesis found that clinical parameters, such as the presence of vascular risk factors or NPSs, were not always available or had not been compiled consistently. Indeed, no standardized tools were used for assessing the presence and severity of NPSs. On the other hand, the availability of a neuropathological diagnosis is a considerable advantage. In a clinico-pathological study like ours, pure $A D$ and VaD cases can be distinguished. Only 40 pure $\mathrm{VaD}$ cases were diagnosed in the NBB sample, while 660 pure $A D$ cases were diagnosed in the same period of time. As mentioned 
above, there was a high degree of heterogeneity in terms of the vascular lesions in the group. Accordingly, with pure $\mathrm{VaD}$ being such a rare diagnosis in the available sample, it was impossible to establish more homogeneous vascular subgroups that were large enough for robust statistical analyses. Therefore, the conclusions apply to the heterogeneous group which is referred to as $\mathrm{VaD}$, but which is not a pure nosological entity. Note that this approach is similar to that adopted in previous studies (Kalaria et al., 2004; Pantoni et al., 2006; Alafuzoffa et al., 2012 ).

\section{Implications}

What do our findings mean for diagnosis, for doctors who look after people with this syndrome, for pathologists, for researchers, and for patients? This thesis raises several important questions, and an attempt will be made to answer these questions, approaching them from different perspectives, i.e. from both a clinical and a neuropathological point of view, as well as from the perspective of researchers, brain banks, and of course patients and their caregivers.

\section{Nosological implications: multiple pathologies in dementia}

The criteria for differentiating between dementia types are currently based on neuropathological changes, and follow traditional nosological classifications. However, it is known that clinical diagnoses often need to be revised when neuropathological findings are taken into account (Braak \& Braak, 1991; Kovacs et al., 2008; Brunnstrom \& Englund, 2009; Echávarri et al., 2012; Alzheimer's Association, 2012), since the high incidence of comorbid neuropathologies complicates the differentiation between dementia diagnoses in clinical practice. The findings presented in the present thesis show that the co-occurrence of neuropathological changes is likely to increase with advanced age, as the incidence of comorbidity was higher in patients over the age of 80 . This is in line with other results for community-dwelling older persons and autopsy series (Galasko et al., 1994; Echávarri et al., 2011). This thesis supports the idea of a multidimensional approach to diagnosing dementia, in which dementia syndromes are not categorized into diagnostic types, but are seen as one clinical syndrome representing the gradual accumulation of multiple pathologies. This multidimensional approach takes into consideration that categorical diagnoses made in vivo often do not correspond to the multimorbid pathology, and may thus be oversimplified. In agreement with Richard and Brayne (Richards \& Brayne, 2009), we claim that diagnostic classifications made on the basis of assumed clinicopathological correlations should be changed so as to arrive at a global approach. Thus, this thesis underlines that a multidimensional approach would not only increase the accuracy of dementia diagnoses, but also lead to a better understanding of neurodegenerative diseases among clinicians. 


\section{Cerebrovascular risk factors in dementia}

Previous studies of the relationship between vascular risk factors and dementia have produced inconsistent results. Although data from longitudinal epidemiological studies have supported the view that there is a relationship between vascular risk factors and dementia (Pohjasvaara et al., 1998; Knopman et al., 2001; Kivipelto et al., 2001; Kivipelto et al., 2005; Kuller et al., 2005; Reitz et al., 2008; Schneider et al., 2009; Knopman \& Roberts, 2010), this was not confirmed by some other researchers (Launer et al., 2008; Purnell et al., 2009; Richard et al., 2009). In agreement with other studies, this thesis notes that common clinical dementia (like AD, Lewy bodies dementia or $\mathrm{VaD}$ ) cases are often in fact mixed conditions, with Alzheimer's, vascular and Lewy body-related pathologies (Dickerson et al., 2001; Jellinger \& Attems, 2003; Trojanowski et al., 2003; Parkkinen et al., 2008; Knopman \& Roberts, 2010; Echávarri et al., 2012). This would explain the failure to identify vascular risk factor patterns associated with types of dementia ( $A D, V a D$, or MD). In Chapter 4, we argued that vascular risk factors may indeed not be related to the presence of dementia, except for stroke history in VaD. Specifically, no differences were found regarding the distribution of vascular risk factors in $A D, V a D$, and mixed dementia, suggesting that the burdens caused by vascular and AD type lesions are independent of each other. On the other hand, Chapter 3 presents evidence indicating a relationship between degenerative and vascular lesion severity, which is consistent with a synergic effect of the two types of lesions in dementia (Launer et al., 2000). From a clinical perspective, bearing in mind all the aforementioned findings, this thesis suggests that the presence of vascular risk factors should be taken into account in demented patients. That is, it is essential to consider the vascular component of degenerative dementias to provide better treatment options for demented patients; the data reflect how important it is to prevent vascular risk factors throughout the course of dementia, in order to minimize the severity of the disease.

\section{Neuropsychiatry in vascular and degenerative pathology}

In agreement with prior studies, our study of the NBB sample suggests that pure $\mathrm{VaD}$ cases are rather rare, making it difficult to attribute different patterns of symptoms associated with dementia specifically to AD or VaD (Launer et al., 2008). Our results suggest that the prevalence of these NPSs cannot be related to the underlying (and pathologically verified) dementia diagnosis of $A D$ or $\mathrm{VaD}$, which means that NPSs in dementia do not differ with the subtype of dementia. A few previous studies have compared NPSs between dementia subtypes, with conflicting results. Some studies found higher prevalences of NPSs in VaD, including depression, anxiety, or agitation, while others found higher prevalences in $A D$, including anxiety and agitation, and still others found no differences between groups (Ballard et al., 2000; Caputo et al., 2008; Johnson et al., 2011). Again, these contradictory results may be due to a lack of accuracy in diagnosing dementia subtypes. Our study is the only one performed on this topic which provides a sample with neuropathological con- 
firmation of clinical diagnoses. Although no differences regarding NPSs were found between the $A D$ and $V a D$ groups, we stress the high prevalence of NPSs in demented patients. Thus, it is important to investigate these NPSs in each demented patient individually, to be able to improve the therapeutic approach and decrease caregiver burden as much as possible.

\section{Early stage dementia}

Results presented in this thesis suggest that changes in the parahippocampal gyrus are a highly sensitive marker for detecting $A D$ at a very early stage. This is in line with earlier reports on the anterior part of the parahippocampal gyrus, the entorhinal cortex (Reitz et al., 2008; Echávarri et al., 2011). The present thesis adds to the existing body of knowledge in that it shows that this is also true for the posterior part of the parahippocampal gyrus. The findings underline the importance of parahippocampal atrophy as an early biomarker of $A D$, which has never been shown before. In fact, there have been no previous studies focusing on the role of the parahippocampal gyrus as a neuroradiological biomarker of AD. Such predictive biological markers could be very valuable for the development of early interventions designed to delay the progression of the disease. An implication is that it might be useful to develop a visual rating scale of the parahippocampal gyrus, similar to the one that exists for the hippocampus (Scheltens et al., 1992), as this could help detect the earliest neurodegenerative changes indicative of $A D$ in routine clinical practice.

\section{Directions for the future}

The high dependency associated with dementia results in very high costs to society (Alzheimer's Association, 2012), which makes research into the aetiology and pathogenesis of late-life dementia a high priority. Beyond the pathological confirmation of diagnoses, working with neuropathological findings allows a range of other issues to be investigated. These include identification of the brain lesions that best correlate with cognitive decline, and the assessment of links between pathological findings and potential risk factors. This thesis highlights the role of brain banks in research in neurosciences, in particular in dementia; the study of brain tissue is essential since it provides useful feedback to clinical teams and may also lead to further improvements in the diagnostic procedures (Brunnstrom \& Englund, 2009). Further systematic comparisons of clinical and pathological dementia diagnoses are needed.

The potential to establish an early diagnosis, to predict the underlying pathology during life, and to stage disease progression will all be required for trials of disease-specific treatments in the future. This approach highlights the importance of brain lesions as substrates for the decline noted in normal ageing, in comparison to dementia. It is possible to test hypothetical semi-quantitative 
thresholds definable in terms of a staging system to classify clinical dementia and shed light on the critical steps in the neurobiological progression of cognitive decline through states such as $\mathrm{MCl}$. Thus, identifying neuropathological markers relevant to cognitive function is useful for both the diagnostic process and our understanding of the molecular and clinical aetiologies of various types of dementia, and can ultimately be expected to result in the development of better treatments. 


\section{References}

Alafuzoff I, Gelpi E, Al-Sarraj S, Arzberger T, Attems J, Bodi I, Bogdanovic N, Budka H, Bugiani O, Englund E, Ferrer I, Gentleman S, Giaccone G, Graeber MB, Hortobagyi T, Höftberger R, Ironside JW, Jellinger K, Kavantzas N, King A, Korkolopoulou P, Kovács GG, Meyronet D, Monoranu C, Parchi P, Patsouris E, Roggendorf W, Rozemuller A, Seilhean D, Streichenberger N, Thal DR, Wharton SB, Kretzschmar $H$ (2012) The need to unify neuropathological assessments of vascular alterations in the ageing brain: Multicentre survey by the BrainNet Europe consortium. Experimental Gerontology Jun 15. [Epub ahead of print]

Alzheimer's Association. 2012 Alzheimer's disease facts and figures. Alzheimer's and Dementia: The Journal of the Alzheimer's Association. March 2012; 8:131-168

Ballard C, Neill D, O'Brien J, McKeith IG, Ince P, Perry R. Anxiety, depression and psychosis in vascular dementia: prevalence and associations. J Affect Disord 2000; 59:97-106

Braak H and Braak H (1991) Neuropathological stageing of Alzheimer-related changes. Acta Neuropathol. 82(4):239-59

Brunnstrom H, Englund E (2009) Clinicopathological concordance in dementia diagnostics. Am J Geriatr Psychiatry 17:664-670

Caputo M, Monastero R, Mariani E, et al (2008) Neuropsychiatric symptoms in 921 elderly subjects with dementia: a comparison between vascular and neurodegenerative types. Acta Psychiatr Scand 117:455-464

Dickerson BC, Goncharova I, Sullivan MP, Forchetti C, Wilson RS, Bennett DA, Beckett LA, deToledoMorrell L (2001) MRI-derived entorhinal and hippocampal atrophy in incipient and very mild Alzheimer's disease. Neurobiol Aging 22:747-754

Echávarri C, Burgmans S, Caballero MC, García-Bragado F, Verhey FRJ, Uylings HBM (2012) Cooccurrence of different pathologies in dementia: implications for dementia diagnosis. Journal of Alzheimer's disease 30(4): 909-917

Echávarri C CM, Aramendía A, García-Bragado F, Tuñón T (2011) Multi-protein deposits in neurodegenerative disorders. Our experience in the Tissue Brain Bank of Navarra. The Anatomical Record 294:1191-1197

Galasko D, Hansen LA, Katzman R, Wiederholt W, Masliah E, Terry R, Hill LR, Lessin P, Thal L (1994) Clinical-neuropathological correlations in Alzheimer's disease and related dementias. Arch Neurol 51:888-895

Jellinger KA, Attems J (2003) Incidence of cerebrovascular lesions in Alzheimer's disease: a postmortem study. Acta Neuropathol 105:14-17

Jicha GA, Abner E, Schmitt FA, Cooper GE, Stiles N, Hamon R, Carr S, Smith CD, Markesbery WR (2008) Clinical features of mild cognitive impairment differ in the research and tertiary clinic settings. Dement Geriatr Cogn Disord 26:187-192

Johnson DK, Watts AS, Chapin BA, Anderson R, Burns JM. Neuropsychiatric profiles in dementia. Alzheimer Dis Assoc Disord 2011;25:326-332

Kalaria RN, Kenny RA, Ballard CG, Perry R, Ince P, Polvikoski T (2004) Towards defining the neuropathological substrates of vascular dementia. J Neurol Sci 226:75-80

Kivipelto M, Helkala EL, Hanninen T, Laakso MP, Hallikainen M, Alhainen K, Soininen H, Tuomilehto J, Nissinen A (2001) Midlife vascular risk factors and late-life mild cognitive impairment: A populationbased study. Neurology 56:1683-1689

Kivipelto M, Ngandu T, Fratiglioni L, Viitanen M, Kareholt I, Winblad B, Helkala EL, Tuomilehto J, Soininen $\mathrm{H}$, Nissinen A (2005) Obesity and vascular risk factors at midlife and the risk of dementia and Alzheimer disease. Arch Neurol 62:1556-1560

Knopman D, Boland LL, Mosley T, Howard G, Liao D, Szklo M, McGovern P, Folsom AR (2001) Cardiovascular risk factors and cognitive decline in middle-aged adults. Neurology 56:42-48 
Knopman DS, Roberts R (2010) Vascular risk factors: imaging and neuropathologic correlates. J Alzheimers Dis 20:699-709

Kovacs GG, Alafuzoff I, Al-Sarraj S, Arzberger T, Bogdanovic N, Capellari S, Ferrer I, Gelpi E, Kovari V, Kretzschmar H, Nagy Z, Parchi P, Seilhean D, Soininen H, Troakes C, Budka H (2008) Mixed brain pathologies in dementia: the BrainNet Europe consortium experience. Dement Geriatr Cogn Disord 26:343-350

Kuller LH, Lopez OL, Jagust WJ, Becker JT, DeKosky ST, Lyketsos C, Kawas C, Breitner JC, Fitzpatrick A, Dulberg C (2005) Determinants of vascular dementia in the Cardiovascular Health Cognition Study. Neurology 64:1548-1552

Launer LJ, Petrovitch H, Ross GW, Markesbery W, White LR (2008) AD brain pathology: vascular origins? Results from the HAAS autopsy study. Neurobiol Aging 29:1587-1590

Launer LJ, Ross GW, Petrovitch H, Masaki K, Foley D, White LR, Havlik RJ (2000) Midlife blood pressure and dementia: the Honolulu-Asia aging study. Neurobiol Aging 21:49-55

Pantoni L, Sarti C, Alafuzoff I, Jellinger K, Munoz DG, Ogata J, Palumbo V (2006) Postmortem examination of vascular lesions in cognitive impairment: a survey among neuropathological services. Stroke 37:1005-1009

Parkkinen L, Pirttila T, Alafuzoff I (2008) Applicability of current staging/categorization of alpha-synuclein pathology and their clinical relevance. Acta Neuropathol 115:399-407

Pennanen C, Kivipelto M, Tuomainen S, Hartikainen P, Hanninen T, Laakso MP, Hallikainen M, Vanhanen M, Nissinen A, Helkala EL, Vainio P, Vanninen R, Partanen K, Soininen H (2004) Hippocampus and entorhinal cortex in mild cognitive impairment and early AD. Neurobiol Aging 25:303-310

Pohjasvaara T, Erkinjuntti T, Ylikoski R, Hietanen M, Vataja R, Kaste M (1998) Clinical determinants of poststroke dementia. Stroke 29:75-81

Purnell C, Gao S, Callahan CM, Hendrie HC (2009) Cardiovascular risk factors and incident Alzheimer disease: a systematic review of the literature. Alzheimer Dis Assoc Disord 23:1-10

Reitz C, Luchsinger JA, Mayeux R (2008) Vascular disease and cognitive impairment. Expert Rev Neurother 8:1171-1174

Richard E, Kuiper R, Dijkgraaf MG, Van Gool WA (2009) Vascular care in patients with Alzheimer's disease with cerebrovascular lesions-a randomized clinical trial. J Am Geriatr Soc 57:797-805

Richards M, Brayne C (2009) What do we mean by Alzheimer's disease?. BMJ 341:865-867

Scheltens P, Leys D, Barkhof F, Huglo D, Weinstein HC, Vermersch P, Kuiper M, Steinling M, Wolters EC, Valk J (1992) Atrophy of medial temporal lobes on MRI in "probable" Alzheimer's disease and normal ageing: diagnostic value and neuropsychological correlates. J Neurol Neurosurg Psychiatry 55:967-972

Schneider JA, Aggarwal NT, Barnes L, Boyle P, Bennett DA (2009) The neuropathology of older persons with and without dementia from community versus clinic cohorts. J Alzheimers Dis 18:691-701

Skoog I, Lernfelt B, Landahl S, Palmertz B, Andreasson LA, Nilsson L, Persson G, Oden A, Svanborg A (1996) 15-year longitudinal study of blood pressure and dementia. Lancet 347:1141-1145

Trojanowski JQ, Lee VM (2003) Parkinson's disease and related alpha-synucleinopathies are brain amyloidoses. Ann N Y Acad Sci 991:107-110

Zaccai J, Ince P, Brayne C. Population-based neuropathological studies of dementia: design, methods and areas of investigation--a systematic review. BMC Neurol 2006; 6:2. 
SUMMARY 
Dementia is a clinical syndrome characterized by an acquired and persistent impairment in multiple cognitive domains that is severe enough to interfere with everyday functioning. Although standardized clinical and neuropathological criteria for different subtypes of dementia have been proposed in consensus meetings, correlations between clinical and neuropathological symptoms and diagnoses are far from optimal. The research reported on in this thesis investigated this relationship between the clinical and neuropathological approaches to dementia. The general introduction (Chapter 1) provides background information regarding clinical and neuropathological characteristics of dementia subtypes, and outlines the main aim and research questions of this thesis.

In Chapter 2 we investigate the level of agreement between clinical and neuropathological diagnoses in neurodegenerative disorders. We found a mean agreement of $44.0 \%$ between the clinical diagnosis and the purely neuropathological diagnosis. This level of agreement differed between dementia subtypes, e.g. $85 \%$ for prion disease, $49 \%$ for $A D$ and $0 \%$ for Lewy bodies dementia. Our data confirmed that co-occurrence of multiple neuropathological disorders is very common in individuals with dementia, supporting a multidimensional approach to diagnosing dementia, in which dementia syndromes are characterized using a combination of various neuropathological dimensions.

Chapter 3 discusses the associations between the severity of Alzheimer pathology (i.e., Braak stage), cerebrovascular lesions (CVLs) and Lewy bodies in demented patients. Cases of pure AD and AD with comorbidity were analyzed together and also separately, in both groups. For the group as a whole, we found a significant positive relationship between AD Braak stage and CVL severity, which was not found when analyzing pure $A D$ and $A D$ plus comorbidity groups separately. No relationship was found between Braak and LB stages. Our study supports a positive association between $A D$ pathology and CVLs in demented patients with $A D$, suggesting that $A D$ and CVLs may have a common pathogenesis.

Chapter 4 compares the prevalences of vascular risk factors in neuropathologically confirmed cases of $A D$, vascular dementia $(\mathrm{VaD})$, and mixed $A D$ and $\operatorname{VaD}(M D)$. It compares the results with published prevalence data for elderly local Dutch control populations. Comparing the three disease groups did not reveal significant differences in prevalence for any of the risk factors considered, except for a greater prevalence of a history of stroke in $\mathrm{VaD}$ and $\mathrm{MD}$. Compared to controls, the only differences found were that smoking was more common in AD cases and more VaD cases had a history of stroke. We argue that risk factors may not be related to the presence of dementia, except for stroke history in VaD. Although differences in vascular risk factors between $A D, M D$, and $\mathrm{VaD}$ had previously been reported from in vivo studies, we demonstrate that these differences disappear when using neuropathological confirmation of dementia diagnoses.

Chapter 5 discusses the prevalence of NPSs associated with dementia in cases with neuropathologically confirmed $A D$ and $V a D$. Our study failed to find differ- 
ences between groups regarding these symptoms, suggesting that $A D$ and $V a D$ patients do not differ significantly in terms of NPSs. This is the first study on this topic to use neuropathological confirmation of the diagnoses.

Chapter 6 examines the role of the parahippocampal gyrus as an early neuroimaging biomarker of $A D$ by measuring the volume of this structure and the hippocampus in healthy participants and participants with amnestic mild cognitive impairment $(\mathrm{aMCl})$ and mild $\mathrm{AD}$. Our results suggest that parahippocampal volume discriminates better than hippocampal volume between cases of healthy ageing, aMCl, and mild $A D$, especially in the early stages of the disease. Our study is this first one to demonstrate the importance of parahippocampal atrophy as the earliest neuroradiological biomarker of AD.

Chapter 7 presents some concluding remarks and summarizes the main findings of this thesis, comparing them with those previously reported in the literature. It also presents some methodological considerations and discusses implications of our results in relation to clinical practice and further research. 



\section{ACKNOWLEDGEMENTS}

This thesis is the final step in a journey of work and hopes. This whole journey is dedicated to you, mum ("mamica"), who was and continues to be my strongest and sweetest support and who has taught me the most important thing in life: how to live with love.

This journey started some years ago in Spain; something inside me urged me to expand my professional and personal experience abroad. Ana, Pilar and Mari helped me realize that this hope might come true. My first words of thank therefore go to the three of you, for taking such good care of me and guiding me through my first months in The Netherlands.

Thanks are also due to Frans Verhey, Saartje Burgmans and Harry Uylings, my first contacts at Maastricht University, for believing in me without even knowing me; for giving me an opportunity and for opening for me the door to a great, great life experience; the experience of working in a really good team and knowing what efficiency and professionalism mean. Thanks for being always available and for make me enjoy the work. Thanks, Saartje, for being such a nice person, and colleague, for your well-done work, and for your patience!

Thanks Susan, for being a friend, for helping me to believe in myself, for sharing your house and your life with me during those months in Maastricht.

I was so happy in the Netherlands, that I decided to stay on and move from Maastricht to Amsterdam. Thank you Annemieke Rozemuller, thank you Wouter Kamphorst for also believing in me; it was a pleasure to share your work and learn from you and from your enthusiasm Annemieke; you introduced me to the fascinating world of neuropathology and brain banks. Thanks Wout for our Skype sessions and hard work, for teaching me to pay attention to every detail. Thanks Begoña, thanks Rubén for your help and friendship. 
And then I moved to Cambridge... I guess that spending some months at Addenbrooke's Hospital was one of the best professional experiences I will ever have. Dr Xuereb, you made learning seem like an art! My passion for neuropathology increased even further.

I am also grateful to my colleagues in Pamplona, my dear home town. I want to thank the "Teresas": Teresa Tuñón, my main supervisor at the Brain Bank of Navarre, Teresa Cabada for sharing your friendship with me, and Teresa Ayuso for being such a support to me and my family. My thanks also go to the other colleagues from the Neurology department at the Hospital of Navarre, Nuria, Beatriz, María, Elena, Irache, Jaime and others, for helping me in the hardest months of this journey. Thanks from the bottom of my heart.

Thank you Federico, Cristina (!), Isabel J. and all those who shared my interest in and love for neurosciences.

A huge thanks to my three wonderful brothers, to Gabriela, her mum Isabel and Yolanda; and specially to my dad, Josetxo. Dad, your love has been essential for me during this journey.

Thanks to all with whom I share the gift of faith, the deeper reason for this journey; thanks girls!!!

I have learned many things about neurosciences, research, brain banks, and about other countries..., and in fact about life, during this journey. The main benefit I got out of it is to know how pleasant and worthwhile it is to live with hopes and to work hard to realize these hopes!. My wish is that I will be able to continue living like this.

MANY THANKS TO ALL OF YOU 


\section{AGRADECIMIENTOS}

Esta tesis es el paso final de un viaje de trabajo e ilusión. Todo el viaje está dedicado a ti mamá ("mamica"), quien fuiste y continuas siendo mi más fuerte y dulce apoyo, quien me ha enseñado lo más importante de la vida: a vivir con amor.

Este viaje empezó hace unos años en España; algo dentro me llevó a ampliar mi experiencia profesional y personal en el extranjero. Ana, Pilar y Mari me ayudasteis a darme cuenta de que esta ilusión podía hacerse realidad. Mis primeras palabras de agradecimiento son por tanto para vosotras tres, por haberme guiado y cuidado tan bien durante mis primeros meses en Holanda.

Gracias a Frans Verhey, Saartje Burgmans and Harry Uylings, mis primeros contactos en la Universidad de Maastricht, por creer en mí sin ni siquiera conocerme, por darme una oportunidad y por abrirme la puerta a una gran gran experiencia en la vida; la experiencia de trabajar en un buen equipo y conocer qué significa la eficiencia y la profesionalidad. Gracias por estar siempre disponibles y por hacerme disfrutar de mi trabajo. Gracias Saartje, por ser tan buena persona y colega, por tu trabajo bien hecho, y ipor tu paciencia!.

Gracias Susan, por ser una amiga, por ayudarme a creer en mí, por compartir tu casa y tu vida durante esos meses en Maastricht.

Estaba tan contenta en Holanda, que decidí quedarme y me fui de Maastricht a Ámsterdam...Gracias Annemieke Rozemuller, gracias Wouter Kamphorst por creer también en mí; fue un placer muy grande compartir tu trabajo y aprender de ti y de tu entusiasmo, Annemieke; me introdujisteis en el fascinante mundo de la neuropatología y de los bancos de cerebros. Gracias Wout por nuestras sesiones en Skype y por el trabajo duro, por enseñarme a prestar atención a cada detalle. Gracias Begoña, gracias Rubén, por vuestra ayuda y amistad. 
Y después fui a Cambridge..; en el Hospital Addenbrooke pasé la que será probablemente una de mis mejores experiencias profesionales. Dr Xuereb, hiciste que aprender fuera como hacer arte! Mi pasión por la neuropatología creció aún más.

Agradezco también a mis colegas de Pamplona, mi querida ciudad natal. A las "Teresas": Teresa Tuñón, mi principal maestra en el Banco de Cerebros de Navarra, Teresa Cabada, por compartir tu amistad conmigo, Teresa Ayuso, por haber sido tanto apoyo para mi familia y para mí. Mi agradecimiento también a los demás compañeros de Neurología del Hospital de Navarra, a Nuria, Beatriz, María, Elena, Irache, Jaime y otros, por haberme ayudado durante los meses más duros de este viaje. Gracias desde el fondo de mi corazón.

Gracias Federico, Cristina (!), Isabel J, y todos los que compartimos el interés y gusto por las neurociencias.

Un gracias enorme a mis tres hermanos, a Gabriela, a su mamá Isabel, a Yolanda; y un gracias especial a mi padre, Josetxo. Papá, tu cariño ha sido esencial para mí durante este viaje.

Gracias a todos con los que comparto el regalo de la fe, la más profunda razón de este viaje; iigracias chicas!!.

He aprendido mucho sobre neurociencias, investigación, bancos de cerebros, sobre otros países.. y en definitiva sobre la vida en este viaje. La mayor ventaja de todo esto es conocer cuánto merece la pena vivir con ilusiones y trabajar por esas ilusiones. ¡Ojalá sea capaz de seguir viviendo así!

MUCHAS GRACIAS A TODOS 


\section{CURRICULUM VITAE}

Carmen Echávarri Zalba was born 17 April 1976 in Pamplona, Spain. She studied medicine at the University of Navarra, Spain (1994-2000), continuing her training in neurology at the Hospital of Navarra in Pamplona, Spain (2002-2006). She has worked as a general neurologist and as a neurologist specializing in psychogeriatry and dementia in various places: the Department of Neurology at the Hospital of Navarre, the Psychogeriatric Clinic Josefina Arregui in Alsasua (Navarra), the Memory Clinic at the ACE foundation in Barcelona (Spain), and at the hospitals of Harrogate and Scarborough (United Kingdom). She completed a three-year training period in neuropsychology (organized by the Spanish Society of Neurology in Barcelona). She further developed her skills in neuropathology and brain bank management at various hospitals: the Department of Pathology of the Complex of Hospitals of Navarra under Drs Teresa Tuñón and Federico García-Bragado, the Department of Neuropathology at the University Hospital of Belltvitge (Barcelona, Spain) under Professor Isidro Ferrer, the Department of Neuropathology and Brain Bank of Cambridge at Addenbrooke's Hospital (United Kingdom) under Dr John Xuereb and the Department of Neuropathology and Brain Bank of the Netherlands (at the VU Medical Center) under Professor Annemieke Rozemuller and Dr Wouter Kamphorst.

She completed her doctorate courses in neurosciences at the University Clinic of Navarre (2003-3006) under Professor Jose Masdeu, and started her PhD project at the Department of Neuropsychiatry and Psychology at Maastricht University under the supervision of Professor Frans Verhey, Professor Harry Uylings and Dr Saartje Burgmans. 


\section{PUBLICATIONS}

Erro, M.E., Echávarri, C., Tuñón, T.; 2006. Síndrome de la cabeza caída secundario a miopatía nemalínica [Dropped head syndrome secondary to nemalinic myopathy]. Revista de Neurología 21 (7), 376-7 (in Spanish).

Iriarte, J., Ayuso, T., Echávarri, C., Alegre, M., Urrestarazu, E., Lacruz, F., Gállego, J., Artieda, J.; 2007. Agrypnia excitata in fatal familial insomnia. A video-polygraphic study. Neurology 69(6), 607-8.

Echávarri, C., Erro, M.E; 2007. Trastornos del sueño en los ancianos y en demencias [Sleep disorders in the elderly and in dementias]. An Sist Sanit Navar. 30 Suppl 1, 155-61 (in Spanish).

Cabada, T., Caballero, M.C., Echávarri, C., Solchaga, S., Bacaicoa, M.C.; 2009. Puesta al día en radiopatología en demencias: resonancia magnética postmortem [Radiopathologic update on dementias: postmortem magnetic resonante]. Radiología 51(2), 127-39 (in Spanish).

Echávarri, C., Cabada, T., Caballero, C.; 2010. Correlato patológico de leucoaraiosis en estudios de resonancia magnética postmortem en enfermedad de Alzheimer y otras demencias [Pathological correlate of leukoaraiosis in postmortem MRI studies in Alzheimer disease and other dementias. Alzheimer]. Real Invest Demenc 44, 15 23 (in Spanish).

Echávarri, C., Aalten, P., Uylings, H.B.M., Jacobs, H.I.L., Visser, P.J., Gronenschild, E.H.B.M., Verhey, F.R.J., Burgmans, S; 2011. Atrophy in the parahippocampal gyrus as an early biomarker of Alzheimer's disease. Brain Struct Funct 215, 265-271.

Echávarri, C., Caballero, M.C., Aramendía, A., García-Bragado, F.,Tuñón, T; 2011. Multi-protein deposits in neurodegenerative disorders. Our experience in the Tissue Brain Bank of Navarra. The Anatomical Record 294, 1191-1197.

Echávarri, C., Burgmans, S., Caballero, M.C., García-Bragado, F., Verhey, F.R.J., Uylings, H.B.M; 2012. Co-occurrence of different pathologies in dementia: implications for dementia diagnosis. Journal of Alzheimer's Disease 30(4), 909-917.

Echávarri, C., Burgmans, S., Uylings, H.B.M., Kamphorst, W., Cuesta, M.J., Peralta, V., Rozemuller, A.J.M., Verhey, F.R.J; 2012. Neuropsychiatric symptoms in Alzheimer's disease and vascular dementia. Journal of Alzheimer's Disease 33 (3). 


\section{SUBMITTED}

Echávarri, C., Burgmans, S.,Tuñón, T., Jáuregui, I., Verhey, F.R.J., Uylings, H.B.M., in revision. Correlation between Braak stage and comorbidity in Alzheimer's disease. Neurobiology of Aging.

Echávarri, C., Burgmans, B., Verhey, F.R.J., Uylings, H.B.M., Layana, E., Rozemuller, A.J.M., Kamphorst, W., in revision. Vascular risk factors in neuropathologically confirmed Alzheimer's disease and vascular dementia. Journal of Alzheimer's Disease.

Basterra, V., Adán, J., Echávarri, C., Sánchez, A.M., Peralta, V., Manuel J. Cuesta, M.J., in revision. Frontotemporal dementia and myotonic dystrophy type 1 . A case report. The Neurologist.

Echávarri, C., Cabada, T., Caballero, M.C., Aramendia, A., Garcia-Bragado, F., Tuñón, T., in revision. Hippocampal volume and signal intensity in post-mortem magnetic resonance imaging in dementia. The Anatomical Records. 
